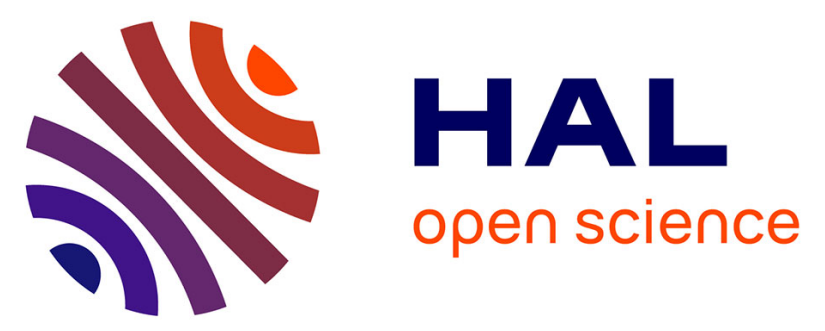

\title{
Synthesis, structural and spectroscopic features, and investigation of bioactive nature of a novel organic-inorganic hybrid material 1H-1,2,4-triazole-4-ium trioxonitrate
}

Sofian Gatfaoui, Noureddine Issaoui, Ali Mezni, Fehmi Bardak, Thierry Roisnel, Ahmet Atac, Houda Marouani

\section{To cite this version:}

Sofian Gatfaoui, Noureddine Issaoui, Ali Mezni, Fehmi Bardak, Thierry Roisnel, et al.. Synthesis, structural and spectroscopic features, and investigation of bioactive nature of a novel organic-inorganic hybrid material 1H-1,2,4-triazole-4-ium trioxonitrate. Journal of Molecular Structure, 2017, 1150, pp.242-257. 10.1016/j.molstruc.2017.08.092 . hal-01619417

HAL Id: hal-01619417

https://hal-univ-rennes1.archives-ouvertes.fr/hal-01619417

Submitted on 24 Oct 2017

HAL is a multi-disciplinary open access archive for the deposit and dissemination of scientific research documents, whether they are published or not. The documents may come from teaching and research institutions in France or abroad, or from public or private research centers.
L'archive ouverte pluridisciplinaire HAL, est destinée au dépôt et à la diffusion de documents scientifiques de niveau recherche, publiés ou non, émanant des établissements d'enseignement et de recherche français ou étrangers, des laboratoires publics ou privés. 
Molecular structure

Elsevier Editorial System(tm) for Journal of Manuscript Draft

Manuscript Number: MOLSTRUC-D-17-01951

Title: Synthesis, structural and spectroscopic features, and investigation of bioactive nature of a novel organic-inorganic hybrid material 1H-1,2,4-triazole-4-ium trioxonitrate

Article Type: Research Paper

Keywords: Hirshfeld surface analysis; X-ray diffraction; DFT; antioxidant properties; molecular docking; topological AIM

Corresponding Author: Dr. Noureddine ISSAOUI, HDR

Corresponding Author's Institution: Faculty of Sciences

First Author: Sofian Gatfaoui

Order of Authors: Sofian Gatfaoui; Noureddine ISSAOUI, HDR; Ali Mezni; Fehmi Bardak; Thierry Roisnel; Ahmet Atac; Houda Marouani 


\section{Synthesis, structural and spectroscopic features, and investigation of bioactive nature of a novel organic-inorganic hybrid material 1H-1,2,4-triazole-4-ium trioxonitrate}

Sofian Gatfaoui ${ }^{a}$, Noureddine Issaoui ${ }^{b}$, Ali Mezni ${ }^{c}$, Fehmi Bardak $^{d}$, Thierry Roisnel ${ }^{e}$, Ahmet Atac $^{d}$, Houda Marouani ${ }^{a} *$

${ }^{a}$ Laboratoire de chimie des matériaux, Faculté des Sciences de Bizerte, Université de Carthage, 7021 Zarzouna,Tunisia ; ${ }^{\mathrm{b}}$ Quantum Physics Laboratory, Faculty of Sciences, University of Monastir, Monastir 5079, Tunisia ; ${ }^{c}$ Département de science de la vie, Faculté des Sciences de Bizerte, Université de Carthage, 7021 Zarzouna,Tunisia ; ${ }^{\mathrm{d}}$ Department of Physics, Celal Bayar University, Manisa, Turkey ; Centre de Diffractométrie X, UMR 6226 CNRS, Unité Sciences Chimiques de Rennes, Université de Rennes I, 263 Avenue du Général Leclerc, 35042 Rennes, France

*Corresponding author: issaoui_noureddine@yahoo.fr, houdamarouani2015@gmail.com

\section{ABSTRACT:}

The novel inorganic-organic hybrid material $1 H$-1,2,4-triazole-4-iumtrioxonitrate (TAN) have been elaborated and crystallized to the monoclinic system with space group $\mathrm{P} 2{ }_{1} / \mathrm{c}$ and the lattice parameters obtained are $\mathrm{a}=8.8517(15) \AA, \mathrm{b}=8.3791(15) \AA, \mathrm{c}=7.1060(11) \AA, \beta=$ $103.776(7)^{\circ}, V=511.89(15) \AA^{3}$ and $Z=4$. The crystal structure exposed substantial hydrogen bonding stuck between the protonated 1,2,4-triazole ring and the nitrate forming thus sheets parallel to the plans $\left(\begin{array}{lll}-1 & 0 & 1\end{array}\right)$. The three-dimensional supramolecular network is formed through the $\pi \ldots \pi$ interactions involving heterocyclic rings in these sheets. Assessment of intermolecular contacts in the crystal arrangement was quantified by Hirshfeld surface analysis and interactions were analyzed by orbital NBO and topological AIM approaches. This compound was also investigated by means of infrared spectroscopy, electrical conductivity, thermal analysis TG-DTA, and DSC. Moreover, the antioxidant properties of TAN were determined via the DPPH radical scavenging, the ABTS radical scavenging, hydroxyl radical scavenging, and ferric reducing power (FRP). Obtained results confirm the functionality of antioxidant potency of TAN. The molecular structure and vibrational spectral analysis of TAN have been reported by using density functional theory calculations at B3LYP/6-311++G(d,p) level of theory. Molecular docking behaviors of TAN along with well-known triazole antifungal agents (fluconazole, itraconazole, posaconazole, and voriconazole) with saccharomyces cerevisiae CYP51 (Lanosterol 14-alpha demethylase) were investigated. The potent of TAN as an inhibitor was discussed on the basis of noncovalent 
interaction profile. Furthermore, protonic conduction of this compound has been intentional in the temperature range of 295-373 K.

Keywords: Hirshfeld surface analysis; X-ray diffraction; DFT; antioxidant properties; molecular docking; topological AIM .

\section{Introduction}

A compound is referred to as a hybrid if it is made up of both an organic and an inorganic matrix mixed on the molecular scale. The synergy of the properties of these two components when they self-assemble in a crystalline state opens up a wide field of application in various domain, namely biology [1-3], optics, electrical conductivity, photochemistry [4-9], medicine [10-12], and photo catalysis [13,14]. Generally, heterocyclic compounds occupy a more interesting place in organic chemistry every day, so they are widely dispersed in nature and participate in important parts of many biochemical processes, especially in the medical field [15]. Particularly, the triazole belongs to a versatile class of five-membered heterocyclic azole compounds having three isomers, including 1,2,3-triazole, 1,2,4-triazole, and 1,3,4-triazole derivatives, depending on the relative positions of the three nitrogen atoms. Among these, the 1,2,4-triazole is a basic aromatic heterocycle with molecular formula $\mathrm{C}_{2} \mathrm{H}_{3} \mathrm{~N}_{3}$. 1,2,4-Triazole can be used as a drug precursor because of possessing antibacterial [16-21], antifungal, [22,23] antitubercular [24], antimycobacterial [25], anticancer [26,27], diuretic [28,29], and hypoglycemic properties [30]. Antifungal behaviors of triazole based ligands have special importance because they have been used as drugs approved by European Medicines Agency and US FDA for a broad spectrum infections (See Table 1 in Ref. [31]). These antifungals inhibit the synthesis of ergosterol from lanosterol in the fungal cell membrane, thus, lead to either inhibition of fungal cell growth or death [31-33]. The target of the triazole antifungals is the cytochrome P450 (CYP)-dependent 14-alpha-demethylase (CYP51). The crystal structures of various mutants of the CYP51 with fluconazole, itraconazole, posaconazole, and voriconazole has been reported in the literature [34]. Depending on the structure of the triazole compound, the binding affinities and interaction profile shows significant variations resulting in different antifungal activities and side effects [35]. Therefore, the exploration of the ligand-enzyme interactions has great importance in understanding the intrinsic mechanism of inhibitor behaviors of the potent antifungals. Regarding these matters, we investigate the molecular docking characteristics of TAN with saccharomyces cerevisiae CYP51 and compare to that of fluconazole, itraconazole, posaconazole, and voriconazole. 
$1 \mathrm{H}-1,2,4$-triazole has a high calculated heat of formation of $+109 \mathrm{~kJ} / \mathrm{mol}$ [36], it is commercially available and selected to make new families of energetic salts by way of example, protonated heterocycle based on nitrate, perchlorate or dinitramide [37]. Notably nitric acid $\left(\mathrm{HNO}_{3}\right)$ an inorganic acid may be associated with functionalized organic molecules (amines or amides) to produce organic-inorganic hybrid systems with potentially forceful hydrogen bond interactions between donor (D) and acceptor (A) components. In this work, we present a collective experimental and theoretical study on the crystal structure of a new organic-inorganic hybrid material $\left(\mathrm{C}_{2} \mathrm{H}_{4} \mathrm{~N}_{3}\right) \mathrm{NO}_{3}$. The compound has been characterized by $\mathrm{X}$ ray diffraction, which is the main technique to determine the crystallographic characteristics and atomic arrangements. To confirm the results observed by X-ray diffraction, the structure was analyzed and evaluated from the point of view of intermolecular interactions and hydrogen bond networking using detailed analyses of Hirshfeld surface and fingerprints plots calculations. In order to enhance our investigations on the synthesized material and detect a possible electrical conduction we have studied the electric transport properties of our crystal. Theoretical and experimental studies have been considered along this work to determine the vibrational (IR) characteristics with DFT calculations using the B3LYP / 6-311++G (d, P) method, to present NBO analysis [38] for determination of the stability of the intermolecular interaction, furthermore an attempt was made to explain the topological property of compound using atoms in molecule (AIM) theory $[39,40]$. To better understand the behavior of the synthesized compound with respect to the temperature we studied it by differential and thermogravimetric thermal analysis (DTA, TG) and differential scanning calorimetric (DSC). Due to the different potential biological activity of the title compound, studies of antioxidant activity and molecular docking are also reported.

\section{Experimental}

\subsection{Materials and physical measurements}

The intensity data were collected at $150 \mathrm{~K}$ using a D8 VENTURE Bruker-AXS diffractometer with MoK $\alpha$ radiation $(\lambda=0.71073 \AA$ ). Absorption corrections were performed using the multi-scan technique using the SADABS program [41]. The total number of measured reflections was 4547 among which 1147 were independent and 994 had intensity $I>2 \sigma(I)$. The structure was solved by direct methods using the SIR97 program [42] and then refined with full-matrix least-square methods based on $F^{2}$ (SHELXL-97) [43] with the aid of the WINGX program [44]. All non-hydrogen atoms were refined with anisotropic atomic displacement parameters. All the hydrogen atoms were placed in calculated positions and 
refined with fixed individual displacement parameters $\left[\mathrm{U}_{\mathrm{iso}}(\mathrm{H})=1.2 U_{\text {eq }}\right]$ according to the riding model $(\mathrm{C}-\mathrm{H}$ and $\mathrm{N}-\mathrm{H}$ bond lengths of $0.95 \AA ̊$ and $0.88 \AA ⿱$, , respectively).

A final refinement on $F^{2}$ converged at $R\left(F^{2}\right)=0.062$ and $w R\left(F^{2}\right)=0.148$. The parameters used for the X-ray data collection as well as the strategy for the crystal structure determination and its final results are reported in Table 1. An ORTEP [44] drawing of the molecular structure is shown in Fig. 1. IR spectrum was recorded in the range $4000-400 \mathrm{~cm}^{-1}$ with a NICOLET IR 200 FT-IR infrared spectrometer. Thermal analysis was performed using a multimodule 92 Setaram analyzer operating from room temperature up to $500{ }^{\circ} \mathrm{C}$ at an average heating rate of $10{ }^{\circ} \mathrm{C} / \mathrm{min}$ and the mass of the simple was $13.18 \mathrm{mg}$ for DTA/TG and $9 \mathrm{mg}$ for DSC. The impedance diagrams were recorded in the $5 \mathrm{~Hz}-13 \mathrm{MHz}$ frequency range using a Hewlett Packard HP 4192A analyzer with $5^{\circ} \mathrm{C}$ steps. Impedance measurements were performed, as a function of temperature (295 - $373 \mathrm{~K})$, using two electrode configurations with signal amplitude of $0.5 \mathrm{~V}$. The fine grain samples were pressed into pellets with $13 \mathrm{~mm}$ diameters and $1.2 \mathrm{~mm}$ thicknesses using a hydraulic press. A layer of silver paint was deposited on the pellets' surfaces to ensure good electrical contact between the sample and the electrical junctions.

\subsection{Chemical preparation of $\left(\mathrm{C}_{2} \mathrm{H}_{4} \mathrm{~N}_{3}\right) \mathrm{NO}_{3}$}

An aqueous solution containing $1 \mathrm{mmol}$ of $\mathrm{HNO}_{3}$ in $10 \mathrm{~mL}$ of water was added to $1 \mathrm{mmol}$ of 1, 2, 4-triazol in $10 \mathrm{~mL}$ of ethanol. The obtained solution was stirred for $30 \mathrm{~min}$ and then left for slow evaporation at room temperature. Colorless prisms of the title compound were crystallized after some days. Schematically the reaction can be written:

$$
\mathrm{C}_{2} \mathrm{H}_{3} \mathrm{~N}_{3}+\mathrm{HNO}_{3} \stackrel{25^{\circ} \mathrm{C}}{\longrightarrow}\left[\mathrm{C}_{2} \mathrm{H}_{4} \mathrm{~N}_{3}\right]\left(\mathrm{NO}_{3}\right)
$$

\subsection{Antioxidant activity $\left(\mathrm{C}_{2} \mathrm{H}_{4} \mathrm{~N}_{3}\right) \mathrm{NO}_{3}$ (TAN)}

\subsubsection{DPPH radical scavenging activity}

The DPPH radical scavenging activity of the compounds with the different concentration (1-0.2 $\mathrm{mg} / \mathrm{mL}$ ) (TAN) was measured in terms of percentage scavenging using the stable radical 2,2-diphenyl-2-picrylhydrazyl hydrate (DPPH) described by Barca et al.(2000) [45]. Briefly, solution of DPPH in methanol was prepared $(0,035 \mathrm{mg} / \mathrm{mL})$ and stock solution of various concentration compounds. $3 \mathrm{~mL}$ of $\mathrm{DPPH}$ solution was mixed with $1 \mathrm{~mL}$ of compounds. The samples were kept in the dark for 30 minutes at room temperature.

The absorbance was measured at $517 \mathrm{~nm}$. All the tests were run in triplicate and expressed as the mean \pm standard deviation (SD). Ascorbic acid was used as standard, parallel to the test 
compound and in the absence of the test compound/standard used as the negative control. The capability to scavenge the DPPH radical was calculated using the following equation.

$\%$ inhibition of DPPH radical $=\left[\left(\mathrm{A}_{\text {cont }}-\mathrm{A}_{\text {test }}\right) / \mathrm{A}_{\text {cont }}\right] \times 100$

Where $\mathrm{A}_{\text {cont }}=$ absorbance of the control (reacting mixture without the test sample) and, $\mathrm{A}_{\text {test }}$ sample $=$ absorbance of reacting mixture with the test sample.

\subsubsection{ABTS radical scavenging activity}

ABTS assay was performed according to the protocol [46]. The stock solution was prepared by mixing equal volumes of $7 \mathrm{mM}$ ABTS solution and $2.45 \mathrm{mM}$ potassium persulfate solution followed by incubation for $12 \mathrm{~h}$ at room temperature in the dark to yield a dark-colored solution containing ABTS •+ radicals. Working solution was prepared freshly before each assay by diluting the stock solution by mixing of stock solution to $50 \%$ methanol. ABTS radical scavenging activity was assessed by mixing $300 \mu \mathrm{L}$ of compound (TAN) with different concentrations $(1-0.2 \mathrm{mg} / \mathrm{mL})$ with $3.0 \mathrm{~mL}$ of ABTS working standard. The absorbance was measured at $734 \mathrm{~nm}$. Data for each assay was recorded in triplicate. Ascorbic acid was used as positive controls. The scavenging activity was estimated based on the percentage of ABTS radicals scavenged by the following formula:

$\%$ scavenging $=\left[\left(\mathrm{A}_{\text {cont }}-\mathrm{A}_{\text {test }}\right) / \mathrm{A}_{\text {cont }}\right] \times 100$, where $\mathrm{A}_{\text {cont }}$ is absorption of control, $\mathrm{A}_{\text {test }}$ is absorption of tested compound.

\subsubsection{Hydroxyl radical scavenging ability}

This assay was determined according to the method of desoxyribose degradation described by Halliwell and Gutteridge (1981) [47]. The ability of the new compound (TAN) with different concentrations $(1-0.2 \mathrm{mg} / \mathrm{ml})$ to prevent the formation of hydroxyl radicals result of decomposition of desoxyribose as the Fenton's reaction. Briefly, reaction mixture containing a methanolic solution of compound, $120 \mu \mathrm{L} 20 \mathrm{mM}$ deoxyribose, $400 \mu \mathrm{L} 0.1 \mathrm{M}$ phosphate buffer, $40 \mu \mathrm{L} 20 \mathrm{mM}$ hydrogen peroxide and $40 \mu \mathrm{L} 500 \mu \mathrm{M} \mathrm{FeSO}_{4}$, and the volume for made to $800 \mu \mathrm{L}$ with distilled water. The reaction mixture was incubated at $37{ }^{\circ} \mathrm{C}$ for $30 \mathrm{~min}$, and the reaction was stop by the addition of $0.5 \mathrm{~mL}$ of $2.8 \%$ TCA (trichloroacetic acid), this was followed by the addition of $0.4 \mathrm{~mL}$ of $0.6 \%$ TBA solution. The tubes were subsequently incubated in boiling water for $20 \mathrm{~min}$. The absorbance was measured at $532 \mathrm{~nm}$ in spectrophotometer.

Percentage $\mathrm{OH}$ radical scavenging ability $(\%)=\left[\left(\mathrm{A}_{\text {cont }}-\mathrm{A}_{\text {test }}\right) / \mathrm{A}_{\text {cont }}\right] \times 100$ 
$\mathrm{A}_{\text {cont }}=$ absorbance of the control (reacting mixture without the test sample) and, $\mathrm{A}_{\text {test }}$ sample $=$ absorbance of reacting mixture with the test sample.

\subsubsection{Reducing propriety}

The reducing power of new compound (TAN) was assayed according to the method of Pulido et al. (2000) [48]. Briefly, a methanolic solution of compound TAN (1 mL) with different concentration (1- $0.2 \mathrm{mg} / \mathrm{mL})$ was mixed with $2.5 \mathrm{ml}$ of phosphate buffer $(0.2 \mathrm{M})$ and $2.5 \mathrm{~mL}$ of $1 \%$ potassium ferricyanide and incubated at $50{ }^{\circ} \mathrm{C}$ for $20 \mathrm{~min}$. To this mixture, $2.5 \mathrm{ml}$ of $10 \%$ trichloroacetic acid was added and the mixture was centrifuged at $3000 \mathrm{rpm}$ for $20 \mathrm{~min}$. The upper layer $(2.5 \mathrm{~mL})$ was mixed with $2.5 \mathrm{~mL}$ of deionized water and $0.5 \mathrm{ml}$ of 0.1\% Ferric chloride and the same treatment was performed to a standard ascorbic acid solution and the absorbance taken at $700 \mathrm{~nm}$. The reducing property was measured using the following equation:

Reducing power $\%=\left[\left(\mathrm{A}_{\text {cont }}-\mathrm{A}_{\text {test }}\right) / \mathrm{A}_{\text {cont }}\right] \times 100$

Where $\mathrm{A}_{\text {cont }}=$ absorbance of the control (reacting mixture without the test sample) and, $A_{\text {test }}$ sample $=$ absorbance of reacting mixture with the test sample.

\subsection{Theoretical studies}

Hirshfeld surface analysis is a study based on a three-dimensional graphics used for the visualization and understanding of intermolecular interactions, this approach represents the region of space where molecules come into contact. And a two-dimensional graph that summarizes complex information in a structure and identifies each type of intermolecular interaction. The three-dimensional Hirshfeld surfaces and two-dimensional fingerprint plots were generated based on the $d_{i}$ and $d_{e}$ distances using Crystal Explorer 3.1 [49], where $d_{e}$ is the distance from the point to the nearest atom outside to the surface, and $d_{i}$ is the distance to the nearest atom inside to the surface.

The molecular geometry optimization and all quantum-chemical calculations have been performed by using the hybrid B3LYP/6-311++G (d,p) method with the Gaussian 09 software package [50] and the GaussView molecular visualization program [51]. Stability of crystal as a result of hyper-conjugative interactions and electron delocalization were analyzed using natural bond orbital (NBO) analysis [52]. Following the geometry optimizations, the vibrational wavenumber, HOMO-LUMO energies and atomic charge distribution were calculated by using DFT method. The wave function obtained from the optimization was used to calculate the topological parameters at the BCPs using the Bader's theory of 'Atoms in Molecules, implemented in AIM 2000 software [53]. 
Before performing the docking calculations, protein structure of CYP51 taken from the Research Collaboratory for Structural Bioinformatics (RCSB) Protein Data Bank (PDB ID: 5HS1) is cleared from water molecules and preexisting ligand. The polar hydrogens and Kollman partial charges corresponding electrostatic potential using quantum mechanics are added in AutoDockTools [54] to assign appropriate ionization states for the amino acid residues. Docking calculations and post screening analysis of ligand-enzyme interactions are performed using iGEMDOCK [55] on the basis of GEMDOCK (Generic Evolutionary Method for DOCKing Molecules) scoring function [56]. The visual representations of ligands in docked state are obtained via PyMol (Schrödinger, LLC, Cambridge, MA, USA) interface [57]. The hydrogen bonding and ionization surfaces are created in Discovery Studio 4.1 developed by Accelrys (Dassault Systemes, BIOVIA Corp., San Diego, CA, USA).

\section{Results and discussion}

\subsection{X-ray diffraction and geometry optimization}

The asymmetric unit of the title salt, $\mathrm{C}_{2} \mathrm{H}_{4} \mathrm{~N}_{3}{ }^{+} . \mathrm{NO}_{3}{ }^{-}$contains one $1 \mathrm{H}-1,2,4$-triazole-4-ium cation and one nitrate anion (Fig. 1a). The crystal structure exposed substantial hydrogen bonding (Fig. 2a) stuck between the protonated 1,2,4-triazole ring and the nitrate forming thus sheets parallel to the plans $\left(\begin{array}{lll}-1 & 0 & 1\end{array}\right)$ (Fig. 2c). These sheets are interconnected via $\pi \ldots \pi$ interactions (Fig. 2b) involving heterocyclic rings. The three-dimensional supramolecular network is subsequently shaped.

Together nitrate and aromatic cation are in a good guess planar with r.m.s. deviations of $0.0019 \AA$ and $0.0022 \AA$, respectively, and form a dihedral angle of $3.64^{\circ}$. Selected bond lengths and angles are given in Table 2. Examination of the nitrate anion shows that the interatomic bond lengths and angles spread respectively within the ranges 1.235(3) - 1.268(3) $\AA$ and 119.24(19) - 120.42(19) ${ }^{\circ}$. These geometrical features have been observed in further related crystal structures as well [58-60]. We can notice that the $\mathrm{N} 1-\mathrm{O} 1$ is the shortest distance in the trigonal nitrate anion, and this may be due to the weak hydrogen bond in which $\mathrm{O} 1$ is applied by comparing it to the connections made by $\mathrm{O} 2$ and $\mathrm{O} 3$ (Table 2).

Concerning the organic cation, the $\mathrm{N} 3-\mathrm{C} 2$ distance is lower than $\mathrm{N} 4-\mathrm{C} 1$ and $\mathrm{N} 4-\mathrm{C} 2$ distances proving that $\mathrm{N} 3-\mathrm{C} 2$ has a double bond character and the other two bonds are intermediate among the single and double. This circumstances justifies the most stable mesomeric forms of 1,2,4-tiazolium cation [61]. Geometrical parameters of the organic cation are found to be in agreement with those of other similar structures containing the same ring cation [62]. 
All $\mathrm{H}$ atoms are applied in hydrogen bonding hence the protonated amine groups are donors and the nitrate oxygen atoms are completely acceptors. Furthermore, this structure reveals two types of hydrogen bonds, the primary type, $\mathrm{N}-\mathrm{H}$... $\mathrm{O}$, with $\mathrm{D}$...A distance ranging from 2.735(3) to 2.980(3) $\AA$. Even as the next one, C-H...O, with D...A distance spreading from $3.015(3)$ to $3.022(3) \AA$. Each organic entity is bounded to three different nitrate anions through three $\mathrm{N}-\mathrm{H} \cdots \mathrm{O}$ and two $\mathrm{C}-\mathrm{H} \cdots \mathrm{O}$ hydrogen bonds forming $R_{4}^{3}(13), R_{2}^{1}$ (5) and $R_{1}^{2}$ (4) motifs (Fig. 2d) and (Table 3) [63]. A two-dimensional layer is then created. These layers are interconnected thanks to $\pi . . . \pi$ staking interactions. As a result, the three-dimensional network is enhanced which could elucidate the high density of $1.71 \mathrm{~g} . \mathrm{cm}^{-3}$.

The optimized molecular structure of TAN compound is given in Fig. 1b. Comparison between selected optimized geometrical parameters obtained using HF, M06-2X and B3LYP methods with 6-311++G(d,p) basis set, with experimental X-ray crystallographic parameters are given in Table 2. The comparison of the global minimum energy, given by the three methods, and the dipole moment values shows clearly the utility of the use of the DFT method using the $6-311++\mathrm{G}(\mathrm{d}, \mathrm{p})$ basis set. The stable form of our material possesses an overall energy equal to -523.321 Hartree and a dipole moment of order 5.56 Debye. Our calculation shows also that the binding energy between of the organic cation and the inorganic-anion is equal to $-121.77 \mathrm{kcal} / \mathrm{mol}$. This interaction takes place through two hydrogen-bonded contacts $(\mathrm{N}-\mathrm{H} \cdots \mathrm{O}$ and $\mathrm{C}-\mathrm{H} \cdots \mathrm{O})$, which result in increased stabilization of our compound. Examination of the organic cation reveals that the calculated values of binding lengths of aromatic ring $(\mathrm{N}-\mathrm{N}$ and $\mathrm{C}-\mathrm{N})$ according to the three methods (HF, B3LYP and M06-2X) are slightly different from those observed experimentally by X-ray diffraction. The average value of the optimized bond length of aromatic $\mathrm{C}-\mathrm{H}$ and $\mathrm{N}-\mathrm{H}$ is $1.03 \AA$ and elongate around $0.12 \AA$ from observed XRD average value $0.90 \AA$. This difference is due to that the theoretical calculations belong to isolated molecule in gaseous phase and experimental results belongs to molecules in solid state, where the crystal structure is related to inter and intramolecular interactions, such as hydrogen bonding and van der Waals interactions. The binding angles forming the triazolium ring are almost identical except for C2-N4-C1 and N4C1-N2 which are almost $3^{\circ}$. The optimized binding angles C2-N4-C1 (103.6377º, N3-N2-C1 $\left(102.5700^{\circ}\right)$ and N4-C1-N2 $\left(114.0970^{\circ}\right)$ are not in good agreement with the inside angle of a regular pentagon which is the order of $108^{\circ}$. This allows us to conclude that our triazolium ring is slightly deformed from a perfect pentagonal shape.

Now examining the nitrate anion, the deprotonation of latter is confirmed by the optimized bond lengths N-O is mainly N1-O3 which is widely extended (1.268(3) $\AA$ (X-ray), 
$1.313 \AA$ (HF), $1.370 \AA$ (DFT) and $1.343 \AA$ (M06-2X)). The elongation of the bond length N4$\mathrm{H} 4$ of the TAN compound is due to the hydrogen bonding between the two moieties (organicinorganic).The $\mathrm{H} 4$ atom captured by the organic cation connected this last by nitrate anion through a hydrogen bond N4-H4 ... O3, the angle formed by this intermolecular hydrogen bond is observed to be linear, according to both theoretical and experimental methods, which leads to the maintenance and stability of crystalline edifice.

\subsection{Hirshfeld surface analysis}

The molecular Hirshfeld surface; $d_{n o r m}$, shape index and curvedness for the title compound is represented in Figure 3, and mapped over $d_{\text {norm }}$ ranges -0.680 (red) to 0.966 (blue), shape index ranges -1 to 1 , and curvedness ranges -4 to 4 , respectively. The representation in $d_{\text {norm }}$ shows a surface with a color scheme: red, blue and white (Fig. 3a) or red spots show the shortest intermolecular contacts that are assigned to interactions $\mathrm{N}-\mathrm{H} \ldots \mathrm{O}$ and $\mathrm{C}-\mathrm{H} \ldots \mathrm{O}$ (Fig. 4 ), while other visible areas on the surface are related to the inter-contact $\mathrm{H} \ldots \mathrm{H}$ and C...H. ${ }^{[64]}$ The estimated intermolecular contacts for our salt are shown in Fig. 5.

The $\mathrm{O} \ldots \mathrm{H} / \mathrm{H} \ldots \mathrm{O}$ contacts have the largest contribution on the Hirshfeld surface (57.4\%), they are attributed to the N-H ... O and C-H ... O hydrogen-bonding interactions, and appear as two sharp symmetric spikes in two-dimensional fingerprint maps around a sum of $d_{e}+d_{i} \sim 1.8 \AA$ (Fig. 5a). Pairs of somewhat blunted spikes corresponding to N...H/H...N (18.8\%) contacts at $d_{e}+d_{i} \sim 2.6 \AA$ result from $\mathrm{N}-\mathrm{H}$... O interactions between the nitrate anion and $1 H$-1,2,4-triazol-4-ium cation are evident in the overall FP, Fig. 5b. The contacts $\mathrm{O}$ $\ldots \mathrm{O}(7 \%)$ and $\mathrm{H} \ldots \mathrm{H}(6.9 \%)$ comprise $13.9 \%$ of the total surface area of Hirshfeld and appear in the middle of the scattered points in the two-dimensional fingerprint maps with a single broad peak respectively at $d_{e}=d_{i}=1.4 \AA$ and $d_{e}=d_{i}=1.5 \AA$ (Fig. 5c, 5d). The fingerprint plots corresponding to the contacts C...C (Fig. 5i) shows the presence of a triangle centered at $d_{e}=d_{i}=1.7 \AA$, this allows us to think about the $\pi-\pi$ interactions in our crystalline stacking [65]. Two colored properties namely, Shape-index and Curvedness surfaces can be specified based on the local curvature of the Hirshfeld surface [66]. Thus, it is clear that our crystal structure exhibits $\pi-\pi$ interactions; this is confirmed by the presence of the adjacent red and blue triangles on the Shape index cartography identified with arrows in the images of Fig.3b, and in the plane regions delimited by a blue outline on the Hirshfeld surfaces mapped with Curvedness in Fig. 3c.

The various intermolecular interactions existing in the packaging of the crystal building of our compound were evaluated by using the enrichment ratio (ER). The enrichment ratio (ER) 
of a pair of elements is then defined as the ratio between the proportion of actual contacts in the crystal and the theoretical proportion of random contacts [67]. The set of enrichment ratios of the various intermolecular contacts occurring in the $1 H$-1,2,4-triazol-4-ium nitrate compound are recorded in Table 4. The list of enrichment ratios shows the $\mathrm{O} \ldots \mathrm{H} / \mathrm{H} \ldots \mathrm{O}$ contacts $\left(\mathrm{ER}_{\mathrm{OH}}=1.68\right)$ which prove to be favored in the crystal package with the formation of the $\mathrm{N}-\mathrm{H} \ldots \mathrm{O}$ and $\mathrm{C}-\mathrm{H}$... O type hydrogen bonds. The very high value enrichment ratio of the contact $\mathrm{C} \ldots \mathrm{C}\left(\mathrm{ER}_{\mathrm{CC}}=13.33\right)$ due to the $\pi-\pi$ interactions in the structure. The absence of $\mathrm{C}-$ $\mathrm{H} \ldots \pi$ and related interactions is reflected in low $\mathrm{ER}_{\mathrm{CH}}=0.74$. The heterocyclic group $1 H-1$, 2, 4-triazol-4-ium displays high $\mathrm{E}_{\mathrm{CN}}$ and $\mathrm{E}_{\mathrm{NN}}$ values (Table 4). This is explained by the nitrogen $\left(S_{N}=14.2\right)$ element which becomes more abundant on the Hirshfeld surface. This allows us to think of the polarized atoms $\left(\delta^{+}\right.$and $\left.\delta^{-}\right)$which can be of interacting partners [68]. A quantitative study of the Hirshfeld surface carried out on the compound $1 \mathrm{H}-1,2$, 4-triazol4-ium nitrate gives the following measurements, namely the molecular volume $\left(124.17 \AA^{3}\right)$, surface area (142.65 $\left.\AA^{2}\right)$, globularity (0.844) as well as asphericity (0.055).

\subsection{Electrical properties}

Based on the nature of the material responsible for conduction $\left(\mathrm{H}^{+}, \mathrm{Li}^{+}, \mathrm{Na}^{+}, \mathrm{Ag}^{+} \ldots\right)$ the conductivity differs from one material to another, either by the temperature domain used or by the dimensionality of the conductive phase (three-dimensional, lamellar, tunnel...). The research carried out on crystalline structures in the domain of conductivity undergoes a very rapid evolution due to the discovery of many materials with high ionic conductivity $\left(\sigma>10^{-2}\right.$ $\Omega^{-1} \mathrm{~cm}^{-1}$ ), which is very interesting both in the energy and electronics fields. Even if the materials with low conductivity are interesting to specify certain transport mechanisms. The dielectric study of our hybrid material at different temperatures (295 to $373 \mathrm{~K}$ ) in a wide frequency range $(0.01-13000 \mathrm{kHz})$ is a necessary condition for a possible exploitation of their properties. The polycrystalline $\left(\mathrm{C}_{2} \mathrm{H}_{4} \mathrm{~N}_{3}\right) \mathrm{NO}_{3}$ was pressed into pellet with a diameter of $13 \mathrm{~mm}$ and a thickness of $1.2 \mathrm{~mm}$ using a hydraulic press of 7 tons. In order to obtain uniform electrical contact, a deposit of silver lacquer is deposited on both sides of the pellet.

\subsubsection{Impedance spectroscopy}

Figure 6 illustrates the complex impedance diagrams for the compound 1H-1, 2, 4-triazole4-ium trioxonitrate over a temperature range from 295 to $373 \mathrm{~K}$. These spectra are constituted by semicircles centered below the real axis and passing close to the origin suggesting the departure from ideal Debye behavior [69]. This departure is result to the presence of a model consisting of a resistance (R) and a constant phase element (CPE) used to compensate for the 
non-homogeneity in the system. So, the complex impedance spectrum shows that the title compound follows the Cole-Cole rule [70].

The figures $\mathbf{7 a}$ and $\mathbf{7 b}$ show respectively the evolution of the real part of the impedance (Z') and imaginary (Z') with the frequency at different temperatures. It is observed that (Z') decreases as the frequency and temperature increases, thus indicating the possibility of increasing the conductivity in alternating current $\left(\sigma_{\mathrm{ac}}\right)$ of the material [71]. For the curve $\mathrm{Z} "=$ $\mathrm{f}(\log )$ one notices that it is characterized by the appearance of the peaks $\left(\omega_{\max }, Z{ }^{\prime}{ }_{\max }\right)$ whose intensity decreases with the increase of the temperature. These peaks translate the presence of the relaxation phenomenon. Each peak centered at a characteristic frequency $f_{\max }$ decreases in intensity and shifts towards high frequencies for increasing temperatures. This shows that the relaxation phenomenon depends on the temperature and its position corresponds to the condition $\omega_{\mathrm{m}} \cdot \tau_{\mathrm{m}}=1[72-74]$.

\subsubsection{Conductivity analysis}

The conductivity value is determined from the expression $\sigma=\frac{\mathrm{e}}{\mathrm{SR}}$, where e, $\mathrm{S}$ and $\mathrm{R}$ respectively represent the thickness, surface area and resistance of the sample used. The values of resistance $\mathrm{R}$ at different temperatures are determined from the intersection of the Nyquist diagram with the abscissa axis as shown in Figure8. The curve representing Ln ( $\sigma . T)$ $=\mathrm{f}(1000 / \mathrm{T})($ Fig. 8) is constituted by a linear branch which exhibits no rupture, in good agreement with the Arrhenius law $\sigma \mathrm{T}=\mathrm{A} \exp \left(-\mathrm{E}_{\mathrm{a}} / \mathrm{KT}\right)$, where $\mathrm{A}$ is the pre-exponential factor, $\mathrm{K}$ the Boltzman constant and $\mathrm{E}_{\mathrm{a}}$ activation energy. The activation energy Ea expressed in electrons volts is determined from the slope of the line equation given by the following relation $\operatorname{Ln}(\sigma \mathrm{T})=\left(\frac{-\mathrm{E}_{\mathrm{a}}}{\mathrm{KT}}\right)+\operatorname{Ln} \mathrm{A} \quad\left(\mathrm{E}_{\mathrm{a}}=0.11 \mathrm{eV}\right)$. The study of this curve shows a single mode of conduction in the interval of temperature studied. It should be noted that in this same temperature range, no phase shift was detected during its thermal study. The comparison of the value of activation energy $\left(E_{a}=0.11 \mathrm{eV}\right)$ and conductivity $(\sigma)\left[1.97 .10^{-6} \Omega^{-1} \mathrm{~cm}^{-1}(295 \mathrm{~K})\right.$ to $\left.6.13 .10^{-6} \Omega^{-1} \mathrm{~cm}^{-1}(373 \mathrm{~K})\right]$ with those of other materials in the bibliography [75] shows that our material is classified among semiconductors.

\subsubsection{Study of the electrical modulus}

The formalism of the complex modulus $M^{*}=j \omega c_{0} Z^{*}=M^{\prime}+j M^{\prime \prime}$ was used for the first time by Macedo and Coll. [76,77]. They were the first to use modulus to analyze the relaxation of conductivity in glasses as well as highly concentrated aqueous solutions. The 
real and imaginary parts of the electrical modulus were calculated from the following relations: $M^{\prime}=-\omega C_{0} Z$ ' $; M^{\prime}{ }^{\prime}=\omega C_{0} Z^{\prime}$ with $C_{0}=\varepsilon_{0}$ S/e $\left(\varepsilon_{0}\right.$ is the permittivity of free space). The variation of the real part M' as a function of the frequency given in Fig. 9a shows that M' follows very low values close to zero in the low-frequency region. This indicates that polarization phenomena due to interfacial effects and electrodes have a negligible contribution $[78,79]$. On the other hand, in the region of very high frequencies, $M^{\prime}$ increases progressively and tends to saturate at a limit value for the different temperatures.

Figure $9 b$ shows the frequency spectra of imaginary part of electric modulus M'. We note from this curve that at very low frequencies $M$ "' remains constant up to a certain critical frequency where it changes slope in our compound, which indicates that the electrode polarization does not contribute to the modulus data. These spectra relating to $M$ '" have a maximum at a frequency noted $\left(\omega_{\max }\right)$ highlighting the relaxation phenomenon of the system.

\subsubsection{Study of electrical permittivity}

The complex permittivity $\left(\varepsilon^{*}\right)$ is defined by the following expression: $\varepsilon^{*}=\varepsilon^{\prime}-\mathrm{i} \varepsilon^{\prime \prime}$ where $\left(\varepsilon^{\prime}\right)$ is the real part which represents the absorption phenomenon, and ( $\left.\varepsilon^{\prime \prime}\right)$ is the imaginary partrelating to dissipation of energy phenomenon [80]. $\varepsilon^{\prime}$ and $\varepsilon^{\prime \prime}$ are determined from the following relations: $\quad \varepsilon^{\prime}=-\frac{Z^{\prime \prime}}{\omega C_{0}\left(Z^{\prime 2}+Z^{\prime 2}\right)} ; \varepsilon^{\prime \prime}=\frac{Z^{\prime}}{\omega C_{0}\left(Z^{\prime 2}+Z^{\prime 2}\right)}$

Where $\omega=2 \pi \mathrm{f}$ is the angular frequency, $\mathrm{C}_{0}$ is the geometrical capacitance.

Fig. 10a and Fig. 10b respectively show the variation of the real and imaginary part of the permittivity $\varepsilon^{\prime}$ and $\varepsilon^{\prime \prime}$ as a function of the frequency at different temperatures. When the frequency increases these two dielectric characteristics $\left(\varepsilon^{\prime}, \varepsilon\right.$ ') of the permittivity decreases, this can be explained by the difficulty of the dipoles present in the system to reorient rather quickly and to follow the frequency of the applied electric field Where the orientation polarization stops $[81,82]$. On the other hand, the high values of $\varepsilon$ ' and $\varepsilon "$ at low frequencies suggest the existence of an electrode polarization [74,83]. The increase of these constants with the temperature is due to the total polarization which results from the dipole orientation and the trapped charge carriers [84].

\subsubsection{Correlation between electrical and structural properties}

The increase of the temperature can favor the vibration of the layers formed by the nitrate anions and the organic groups and can lead to the reorientation of the $\mathrm{NO}_{3}{ }^{-}$ions and the rapid mobility of the $\mathrm{H}^{+}$proton in the network of the hydrogen bonds. Moreover, it is very important to note that the X-ray diffraction study shows that the hydrogen bonding network in 
the title compound is two-dimensional, this indicates the mean conduction with respect to the three-dimensional structures which possess a strong conductivity where the motion of the protons $\mathrm{H}^{+}$takes place in the three directions $[85,86]$.

\subsection{Thermal behavior}

The differential and thermogravimetric thermal analysis of 1H-1, 2, 4-triazol-4-iumnitrate is carried out using a SETRAM TG-DTA thermoanalyzer in air, from ambient temperature up to $850 \mathrm{~K}$ with a heating rate of $10 \mathrm{~K} / \mathrm{min}$ in an alumina crucible. The DTA curve of this compound indicates in Fig. 11 the presence of two endothermic peaks in a wide temperature range. The first peak at $413 \mathrm{~K}$ corresponds to a melting during which our compound loses its crystalline state and passes to the liquid state. This phenomenon is further confirmed by the heating of our compound on a Kofler bench which makes it possible to estimate the melting temperature of a material, this temperature $(410 \mathrm{~K})$ is near to that observed on the DTA curve. The second peak at $502 \mathrm{~K}$ which is accompanied by a large weight loss on the TG curve relates to the decomposition of the organic molecules and to the transformation of the remainder into $\mathrm{NO}_{2}$ and $\mathrm{NO}$.

A thermal calorimetric analysis is carried under argon on a $9 \mathrm{mg}$ mass sample in a temperature range of 298 to $573 \mathrm{~K}$, with a heating rate of $5 \mathrm{~K} / \mathrm{min}$. The DSC diagram illustrated in Figure12 shows the same phenomena already observed by DTA. The peak at 441 $\mathrm{K}$ attributed to the melting of the material, is accompanied respectively by a heat transformation: $\Delta \mathrm{H}_{\text {melting }}=25.79 \mathrm{~kJ} \cdot \mathrm{mol}^{-1}$ and a molar fusion entropy: $\Delta \mathrm{S}_{\text {melting }}=62.45 \mathrm{~J} \cdot \mathrm{mol}^{-1} \cdot \mathrm{K}^{-1}$.

\subsection{Quantum theory of atoms in molecules (QTAIMs) analysis}

Atoms-In-Molecule (AIM) method provides an effective means of mapping topological properties of the electron density to Lewis structure representation of molecules. According to AIM theory each chemical bond possesses a critical point of binding denoted BCP. This point is defined as being a minimum of electronic density along the connecting path and a maximum in the other two perpendicular directions. After the location of the BCP several energetic and topological parameters can be calculated at their position in space. The topological parameters which calculated are the following: the electron density $\rho(\mathrm{r})$, the ellipticity $(\varepsilon)$, Hessian own values $\lambda_{\mathrm{i}}(\mathrm{i}=1.2 .3)$ and the Laplacian values $\nabla^{2} \rho(\mathrm{r})$. These parameters were used to evaluate the properties of the bonds in compounds and more particularly the hydrogen bonds [87]. Laplacian of total electronic density is related to 
energetic topological parameters by a local expression of the virial theorem at critical points $^{[88]}$ :

$$
1 / 4 \nabla^{2} \rho(r)=2 G(r)+V(r)
$$

Where $G(r)$ and $V(r)$ represent respectively the kinetic and potential electron energy densities at critical points. Either the total electron energy density:

$$
\mathrm{H}\left(\mathrm{r}_{\mathrm{BCP}}\right)=\mathrm{G}\left(\mathrm{r}_{\mathrm{BCP}}\right)+\mathrm{V}\left(\mathrm{r}_{\mathrm{BCP}}\right)
$$

In this context Rozas et al. ${ }^{[89]}$ proposed three criteria for classifying hydrogen bonds: Weak hydrogen bonds $\nabla^{2} \rho\left(\mathrm{r}_{\mathrm{BCP}}\right)>0$ and $\mathrm{H}\left(\mathrm{r}_{\mathrm{BCP}}\right)>0$. Medium hydrogen bonds $\nabla^{2} \rho\left(\mathrm{r}_{\mathrm{BCP}}\right)>0$ and $\mathrm{H}\left(\mathrm{r}_{\mathrm{BCP}}\right)<0$ and Strong hydrogen bonds $\nabla^{2} \rho\left(\mathrm{r}_{\mathrm{BCP}}\right)<0$ and $\mathrm{H}\left(\mathrm{r}_{\mathrm{BCP}}\right)<0$. In addition AIM analysis allows us to detect the presence of cycles in a molecular system. The presence of a critical point in the "RCP" cycle confirms the cyclic nature of certain molecules and an atomic chain. The graphical representation of AIM analysis of the 1H-1,2,4-triazol-4-ium nitrate compound is shown in Figure 13. The topological and energetic parameters obtained are tabulated in Table 5.

The AIM analysis shows that our material is stabilized by two O...H hydrogen bonds. In this study, the BCPs located along the O... H bonds, the Laplacian of total electronic density $\nabla^{2} \rho\left(\mathrm{r}_{\mathrm{BCP}}\right)$ are 0.04566 and 0.64603 a.u with electron energy density $\mathrm{H}\left(\mathrm{r}_{\mathrm{BCP}}\right)$ values 1.038 and $1.2408 \mathrm{kcal} / \mathrm{mol}$ respectively for the two hydrogen bonds $\mathrm{O} 1 \ldots \mathrm{H} 2$ and $\mathrm{O} 3 \ldots \mathrm{H} 4$. For better representation we show in figure 14 the map for electron density in the XY plane. The hydrogen binding energy is calculated using the relationship of Espinosa et al. [90]: $\mathrm{E}_{\mathrm{H} . . . \mathrm{O}}=$ $(1 / 2) \mathrm{V}_{\mathrm{BCP}}$. In our case, the hydrogen bonding energy for $\mathrm{O} 1 \ldots \mathrm{H} 2$ and $\mathrm{O} 3 \ldots \mathrm{H} 4$ are respectively of the order 2.5435 and $-49.4327 \mathrm{kcal} / \mathrm{mol}$. So from these topological parameters we can conclude that hydrogen bond N4-H4 ... O3 is a very strong bond. While C2-H2 ... O1 is considered to be a weak hydrogen bond. The AIM analysis shows, also, that the values of the electronic density and its Laplacian at the RCP of triazolium ring (0.0531, 0.4145 a.u $)$ are greater than those at the RCP level of the closed cycle by hydrogen bonds that connect the nitrate anion to the organic group $(0.0085,0.0426 \mathrm{a}$.u). These results clearly show the high cycle stability of the organic cation. Besides of the above cited parameters, the ellipticity $\varepsilon=$ $\left(\lambda_{1} / \lambda_{2}\right)-1$ also provides an idea of the accumulation of loads in a given plane. Recall that, the $\varepsilon$ at BCP is a sensitive index to monitor the $\pi$-character of bond. In our study, the ellipticity values at the BCP points of the bonds forming the triazolium ring are in a range of 0.01260.4054. These low values advise that these bonds extend delocalization of electrons in triazolium ring [91]. Consequently, the overall ellipticity values suggest that there is strong delocalization in the TNA molecule. 


\subsection{NBO analysis and Mulliken charges}

Natural bond orbital (NBO) analysis is a very effective method for studying intra- and intermolecular interactions in a molecular system. It provides information on charge transfer and possible interaction donor-acceptor between orbital in hydrogen bonded systems [92]. A second order perturbation analysis of the "donor-acceptor" interactions is performed between occupied and vacant NBO. Indeed, the most stable interaction can be estimated by calculation of the interaction energy by using second order perturbation theory, for each donor (i) and acceptor (j) group, the second-order stabilization energy $E^{(2)}$ associated with delocalization of electrons between donor and acceptor [93] is written as follows:

$$
E^{(2)}=q_{i} \frac{F^{2}(i, j)}{\varepsilon_{i}-\varepsilon_{j}}
$$

Where $\mathrm{q}_{\mathrm{i}}$ is the donor orbital occupancy, $\varepsilon_{\mathrm{i}}$ and $\varepsilon_{\mathrm{j}}$ are diagonal elements orbital energies and $F(i, j)$ is the off diagonal NBO Fock matrix element [94]. More than the $E^{(2)}$ energy is greater, more than interaction between the electron donor and electron acceptor is intense.

This analysis is an efficient tool for the chemical interpretation of hyperconjugate exchanges and the electrons transfers from LP (A) free electron pairs to the $\sigma(\mathrm{D}-\mathrm{H})$ antibinding orbit in a hydrogen bond $\mathrm{D}-\mathrm{H} \cdot \mathrm{A}$ [92]. The results of the NBO analysis correspond to the second-order perturbation theory calculated for TAN compound are summarized in Table 6.

The orbital analysis of our crystal structure clearly shows the existence of an important interaction between the lone pair LP $(\mathrm{O} 3)$ orbital and the $\sigma^{*}(\mathrm{~N} 4-\mathrm{H} 4)$ antibonding orbital with stabilization energy equal to $97.33 \mathrm{Kcal}_{\mathrm{mol}}{ }^{-1}$, this is reflected by the strong interaction between the anionic and cationic groups which is manifested by the formation of a hydrogen bond $\mathrm{N} 4-\mathrm{H} 4$... O3.The stabilization energy $\mathrm{E}^{(2)}$ of the hyperconjugant interactions of triazolium ring associated to $\pi(\mathrm{N} 2-\mathrm{C} 1) \rightarrow \pi^{*}(\mathrm{~N} 3-\mathrm{C} 2)$ and $\pi(\mathrm{N} 3-\mathrm{C} 2) \rightarrow \pi^{*}$ interactions the order of $12 \mathrm{kcal}^{\mathrm{mol}}{ }^{-1}$. Apart from this we notice very strong intramolecular interactions existing in the nitrate anion due to the delocalization of a single pair of oxygen electrons on the $\sigma^{*}$ and $\pi^{*}$ orbital with stabilizing energies very interesting, namely: LP (2) O1 $\rightarrow \sigma^{*}(\mathrm{O} 3$ N1) $\left(21.51 \mathrm{kcal}^{\mathrm{mol}}{ }^{-1}\right), \mathrm{LP}(2) \mathrm{O} 2 \rightarrow \sigma^{*}(\mathrm{O} 3-\mathrm{N} 1)\left(25.35 \mathrm{kcal}^{\mathrm{mol}}{ }^{-1}\right), \mathrm{LP}(3) \mathrm{O} 3 \rightarrow \pi^{*}(\mathrm{O} 2-\mathrm{N} 1)$ $\left(55.45 \mathrm{kcal}_{\mathrm{mol}}{ }^{-1}\right), \mathrm{LP}(3) \mathrm{O} 1 \rightarrow \pi^{*}\left(\mathrm{O} 2\right.$ - N1) $\left(129.69 \mathrm{kcal}^{\mathrm{mol}}{ }^{-1}\right)$.Interactions between the $\pi^{*}$ $(\mathrm{N} 3-\mathrm{C} 2)$ and $\pi^{*}(\mathrm{~N} 2-\mathrm{C} 1), \sigma^{*}(\mathrm{~N} 4-\mathrm{H} 4)$ and $\sigma^{*}(\mathrm{~N} 2-\mathrm{C} 1)$ anti-binding orbitals lead to stabilization energies of $20.06 \mathrm{kcal} . \mathrm{mol}^{-1}$ and $10.01 \mathrm{kcal}^{\mathrm{mol}}{ }^{-1}$, respectively.

In addition to the NBO analysis, load distribution analysis of molecule plays a very interesting and significant role in the application of calculations in quantum mechanics for 
molecular systems [95]. The latter affects dipole moment, polarizability, electronic structure and more properties of molecular system [96]. For this reason, the Mulliken population analysis (MPA) and the natural population analysis (NPA) of the title compound are calculated using the DFT / B3LYP method at the base 6-311 ++ G (d, p) and are listed in Table 7. For better representation, the different results obtained have been illustrated in the graph form, as shown in Figure 15. It should be noted that both analyzes (MPA and NPA) predict the same tendencies, as is reported by the results that all hydrogen atoms $(\mathrm{H} 1, \mathrm{H} 2, \mathrm{H} 3$ and H4) have a net positive charge. The stretching electron of the nitrogen atom makes the carbon atom ( $\mathrm{C} 1$ and $\mathrm{C} 2)$ negative. Note that $\mathrm{H} 4$ has very high load values $0.50450 \mathrm{e}(\mathrm{PA})$, 0.558855 e (MPA), N4 exhibits the most negative loads -0.57875e (NPA), -0.472341e (MPA), this suggests the formation of a strong intermolecular hydrogen bond $\mathrm{N} 4-\mathrm{H} 4 \ldots \mathrm{O} 3$, as it is supported by NBO analysis. Finally, we can conclude that the NBO, NPA and MPA analysis confirm that the hydrogen bonding in the TAN compound leads to his crystal structure.

\subsection{Frontier molecular orbital analysis}

The highest Occupied Molecular Orbital (HOMO), Lowest Unoccupied Molecular Orbital (LUMO) and the gap energy between them are very effective quantities in quantum chemistry and more specifically in the theory of molecular orbitals (MO). These orbitals are excellent indicators of transfer of electrons in molecular systems; they play an important role in chemical stability of the molecular edifice. Indeed, the chemical reactivity and kinetic stability of the molecule are characterized by the gap. A high gap indicates a high stability of the molecule. A low gap is criterion of high reactivity. The pictorial representations of the (HOMO, HOMO-1 and LUMO, LUMO+1) and the contribution of the organic and the inorganic units to these orbitals (PDOS) for the title compound are mapped respectively in Figs. 16and 17.The red and green colors of the MO plot show the positive and negative phase, respectively. The calculated energy values of HOMO and LUMO are around $-7.08 \mathrm{eV}$ and $1.62 \mathrm{eV}$ respectively, in the gas phase and in the other solutions. The energy gap between the HOMO and LUMO is in the vicinity of $5.46 \mathrm{eV}$, this high value implies a high kinetic stability and a low chemical reactivity toward chemical reactions in some sense. The big gap HOMO-LUMO means that our crystal is hard. Stereographs of the frontier molecular orbital of the TAN compound show that HOMO components are concentrated on the anionic part, while the LUMO components are mainly located on the organic cation. These findings manifest that the electrons are delocalized in the inorganic part $\left(\mathrm{NO}_{3}{ }^{-}\right)$. 
The energies, electron affinity, global electrophilicity index, ionization potential (IP), electronegativity, global chemical potential, global hardness and global softness of the most important orbital such as the HOMO (HOMO-1) and LUMO (LUMO+1) orbitals are calculated by TD-B3LYP method using the 6-311 ++ G (d, p) basis and are listed in Table 8 .

Using the HOMO and LUMO orbital energies, the ionization potential and the electron affinity are respectively expressed as follows: $\mathrm{IP}=-\mathrm{E}_{\mathrm{HOMO}}$ and $\mathrm{A}=-\mathrm{E}_{\mathrm{LUMO}}$. The electronegativity $\chi$ is defined by Mulliken [97] as follows: $\chi=\frac{(I+A)}{2}$. The chemical hardness and global softness are determined by the following relationships: $\eta=\frac{(I-A)}{2}, \mathrm{~S}=\frac{1}{2 \eta}$

Parr et al. [98], proposed the global electrophilicity power of a ligand as $\Psi=\frac{\mu^{2}}{\eta}$, where $\mu$ is the chemical potential defined by $\mu=-\frac{(I+A)}{2}$. The electrophilicity index measures the stabilization in energy when the system acquires an additional electronic charge from the environment. Thus the high value of the electrophilicity index (see table 8.) for the TAN compound favors its powerful electrophilic behavior. Also it is seen that the chemical potential is negative it means that our crystal is stable and does not decompose spontaneously into its elements [99], which is well known property of biologically active molecules.

\subsection{In vitro antioxidant activity}

The harmful effect of free radicals attracts the attention of the scientist in last few years. The dangerous affect of free radicals reactive oxygen species (ROS) that generated by our body driving scientists to focus their studies on understanding its generation mechanisms, combined diseases and final the best methods to control it [100]. Currently, several pathophysiological events such as ischemia, diabetes, cancer, reperfusion-related injuries (e.g., heart attack, stroke, and organ dysfunction), as well as neurodegenerative disorders such as Alzheimer's, Parkinson's, and Huntington's diseases, have been associated with an increase in ROS generation and concomitant oxidative stress [101]. Therefore, there is a growing interest in the synthesis of new molecules that possess biological activity.

The objective of this study was to evaluate the antioxidant capacity of the new compound (TAN). This capacity was determined, in vitro, by 1,1-diphenyl-2-picrylhydrazyl (DPPH) method, ABTS test, reducing power and hydroxyl scavenging ability using ascorbic acid as control. 


\subsubsection{DPPH radical scavenging activity}

The result was presented in figure 18 showed that the derive TAN has the highest capacity of scavenging DPPH radicals at the concentration $1 \mathrm{mg} / \mathrm{mL}$ with percentage of inhibition respectively $69.51 \pm 3.59 \%($ IC50 $=0.66)$ compared with ascorbic acid at the same concentration $91.35 \pm 1.048 \%$ (IC50=0.476). The consequence of antioxidant on DPP radical was investigated to be owed to their hydrogen donating skill for the free radicals and reducing it to nonreactive species.

\subsubsection{ABTS radical scavenging activity}

Our results presented in figure 19 demonstrate that the compound (TAN) has the highest capacity of scavenging at concentration $1 \mathrm{mg} / \mathrm{mL}$ with value $55.39 \pm 2.96 \%$ (IC50=0.841), ascorbic acid at the same concentration $66.79 \pm 3.91 \%$ (IC50=0.733).

\subsubsection{Hydroxyl radical scavenging ability}

The results were summarized in the figure 20 demonstrated that the compounds TAN has a highest percentage of inhibition of hydroxyl radicals at the high concentration $1 \mathrm{mg} / \mathrm{mL} 58.82$ $\pm 3.98 \%(\mathrm{IC} 50=0.805)$ and compared with ascorbic acid at the same concentration $(1 \mathrm{mg} / \mathrm{ml})$ the percentage of inhibition was $72.706 \pm 1.86 \%$ (IC50=0.68).

\subsubsection{Reducing propriety}

The results was presented in figure 21 reported that TAN presented a high reducing property at the high concentration $(1 \mathrm{mg} / \mathrm{mL})$ with percentage comparable to that of ascorbic acid and the percentage is AA $78.77 \pm 0.94 \%$ (IC50=0.545), TAN $68.58 \pm 0.621 \%$ (IC50=0.627).

In conclusion, our results show that free radical scavenging activity of TAN was increased via amination process. Promotion of antioxidant activity may be attributed to replacing hydroxyl groups with free amine groups. Obtained results confirm functionality of antioxidant potency of TAN.

\subsection{Molecular docking behaviors}

Molecular docking studies were carried out in iGEMDOCK with the accurate docking settings suggested by the program with the following setting; population size is 800 , number of generations is 80 , and number of solutions is 10 . During the calculations, the ligand intramolecular energies are excluded from total energy calculation. The energetic related results of the molecular docking calculations are given in Table 9 and corresponding docking positions are presented in Figure 22. 
Total energy scores for the ligands are at comparable level. Although the docking energy of the TAN is lower than that of the other ligands, considering the size of the molecules, its binding affinity quite remarkable. TAN molecule has much lower molecular weight, therefore when the same dose given, it is expected that it would result in higher effectiveness. TAN molecule has much stronger binding to the protein with tighter hydrogen bonds and even electronic interactions. The hydrogen bonding surface for the ligands are presented in Figure 23 for TAN and Figures S1-S4 for fluconazole, voriconazole, itraconazole, and posaconazole respectively. Hydrogen bonding energies with the H-M-SER, H-S-SER, H-M-THR, H-STHR amino acids are high ( $>5 \mathrm{kcal} / \mathrm{mol})$ whereas the interactions with the H-M-MET, H-MAS, H-M-MET, H-S-ASP amino acids are at moderate level. Hydrogen bonds in the case of the other ligands are only at moderate level. The electronic interaction of TAN occurs only with the E-S-LYS residue. Relatively strong van der Waals interactions ( $>2 \mathrm{kcal} / \mathrm{mol}$ ) exist between TAN and V-M-LEU, V-M-LYS, V-M-ASN, V-S-SER, V-S-LYS, V-M-MET, V-SILE residues. $\pi$-alkyl interactions between surrounding amino acids and triazole moiety are common for all ligands studied. In the case of TAN and fluconazole, multiple $\pi$-alkyl interactions are observed from the same ring. Ionizability surfaces of the ligands at binding sites presented in Figures S5-S10 show that TAN is mostly basic, fluconazole is acidic, and itraconazole, voriconazole, and posaconazole have partially acidic-basic regions. This can be considered as a sign for different inhibitor characteristics of TAN than the other ligands.

\subsection{Vibrational analysis}

To determine the vibrational characteristics of our crystal structure we undertook a vibratory study using infrared spectroscopy at room temperature. The experimental infrared wavenumber compared to the calculated from DFT method assigned by VEDA program [102] and Gauss View software [44] were listed in Table 10 along with a tentative assignment of the observed bands. In this table, we have presented the scaled calculated harmonic vibrational frequencies, observed vibrational frequencies, and detailed PED assignment. In this study, wavenumbers in the ranges from 4000 to $1700 \mathrm{~cm}^{-1}$ and lower than $1700 \mathrm{~cm}^{-1}$ are scaled using scale factors of 0.958 and 0.983 , respectively [103], and with Specsa program [104]. The experimental IR spectrum according the calculated is illustrated in Fig. 24. By reference to the results of the assignment and to the bibliographic study [105-108] we have ascribed the different vibration modes of the nitrate anion $\left(\mathrm{NO}_{3}{ }^{-}\right)$and the organic cation to the set of bands that appeared in IR spectrum. 


\subsubsection{Vibrations of nitrate anion}

Previous work on nitrates [109-111] allowed us to identify the different normal modes of vibration of the $\mathrm{NO}_{3}{ }^{-}$anion in its ideal symmetry $\mathrm{D}_{3 \mathrm{~h}}$, as well their IR and Raman activities. According to the relation $3 \mathrm{~N}-6$ characteristic of non-linear molecules, $\mathrm{NO}_{3}{ }^{-}$contains six vibrations modes which decompose into a symmetric elongation mode $A_{1}{ }^{\prime}\left(v_{1}\right)$ is Raman active, a symmetrical deformation mode $\mathrm{A}_{2}{ }^{\prime}\left(\mathrm{U}_{2}\right)$ is IR active and two asymmetric modes doubly degenerate one of elongation and the other of deformation E' $\left(v_{3}\right.$ and $\left.v_{4}\right)$ are both IR and Raman active. The stretching mode $v_{1}\left(\mathrm{NO}_{3}{ }^{-}\right)$appears as two bands around 1205 and 1165 $\mathrm{cm}^{-1}$. The same stretching vibration is predicted at $1271 \mathrm{~cm}^{-1}$ in DFT method. A very intense band observed at $1394 \mathrm{~cm}^{-1}$ relative to the asymmetric stretching vibration $\mathrm{v}_{3}\left(\mathrm{NO}_{3}{ }^{-}\right)$, whereas it was calculated to be found at $1441 \mathrm{~cm}^{-1}$. Mode $v_{4}\left(\mathrm{NO}_{3}{ }^{-}\right)$appears in the spectral range between 719 and $634 \mathrm{~cm}^{-1}$. These values are in good agreement with calculated value in region $754-623 \mathrm{~cm}^{-1}$. Finally the band situated at $896 \mathrm{~cm}^{-1}$ corresponds to the deformation mode out-of-plan $\mathrm{v}_{2}\left(\mathrm{NO}_{3}{ }^{-}\right)$. This mode it is theoretically calculated at $916 \mathrm{~cm}^{-1}$ by DFT method.

\subsubsection{Triazole vibration}

Concerning the organic entity belonging to the heterocyclic family, the high- frequency region between $3600-2700 \mathrm{~cm}^{-1}$ is assigned to the valence vibration modes of the $\mathrm{N}-\mathrm{H}$ and $\mathrm{C}$ $\mathrm{H}$ groups. The DFT computations give the frequency of these bands at $3588 \mathrm{~cm}^{-1}$ for $\mathrm{N}-\mathrm{H}$ and 3217 and $3210 \mathrm{~cm}^{-1}$ for the $\mathrm{C}-\mathrm{H}$ groups. The spectral domain between 1394 and $949 \mathrm{~cm}^{-1}$ is ascribed to the elongation vibration modes of the $\mathrm{C}-\mathrm{N}$ group. This was calculated to be found in region $1497-1028 \mathrm{~cm}^{-1}$. The bands at 1643,1584 and $1532 \mathrm{~cm}^{-1}$ in experimental spectrum correspond to the $\mathrm{C}=\mathrm{N}$ aromatic stretching and the $\mathrm{N}-\mathrm{H}$ deformation modes. The same vibrations are calculated between 1497 and $1419 \mathrm{~cm}^{-1}$ by DFT level. Finally the absorptions located in the low- frequency region of the spectrum between 896 and $634 \mathrm{~cm}^{-1}$ relate to the deformation vibration modes of the $\mathrm{C}-\mathrm{N}$ and $\mathrm{C}-\mathrm{H}$ groups. The corresponding bands are calculated in range 942 and $649 \mathrm{~cm}^{-1}$.

\subsubsection{N-H ... O hydrogen bond vibrations}

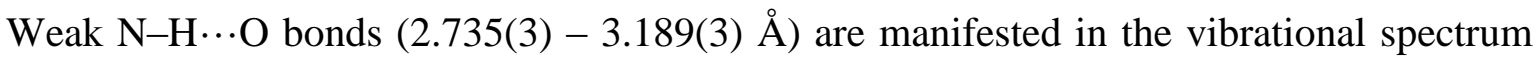
as perturbed $\mathrm{NH}^{+}$group vibration of the protonated $1 \mathrm{H}-1,2,4$ triazol-4-ium cation. The broad band estimated at $2775 \mathrm{~cm}^{-1}$ in calculated IR spectrum is attributed to the N-H...O stretching vibration. 


\section{CONCLUSIONS}

A novel organic-inorganic hybrid material 1H-1,2,4-triazole-4-ium trioxonitrate (TAN) has been successfully synthesized at room temperature by slow evaporation. The crystal structure of this compound show a 3D-supramolecular network supported by means electrostatic, H-bonds type $\mathrm{N}-\mathrm{H} \ldots \mathrm{O}$ and $\mathrm{C}-\mathrm{H} \ldots \mathrm{O}$ and van der Waals interactions. The Hirshfeld surface analysis show that the structure is stabilized by $\mathrm{H} \cdots \mathrm{H}, \mathrm{H} \cdots \mathrm{O} / \mathrm{O} \cdots \mathrm{H}$, $\mathrm{N} \cdots \mathrm{H} / \mathrm{N} \cdots \mathrm{H}, \mathrm{O} \ldots \mathrm{O}, \mathrm{N} \ldots \mathrm{O} / \mathrm{O} \ldots \mathrm{N}, \mathrm{N} \ldots \mathrm{N}, \mathrm{C} \ldots \mathrm{N} / \mathrm{N} \ldots \mathrm{C}, \mathrm{C} \ldots \mathrm{C}, \mathrm{C} \ldots \mathrm{O} / \mathrm{O} \ldots \mathrm{C}$ and $\mathrm{H} \cdots \mathrm{C} / \mathrm{C} \ldots \mathrm{H}$ intermolecular interactions. The dielectric measurements show the appearance of relaxation phenomena. The results of the dielectric study are confirmed by the thermal study which shows no thermal accident in the temperature range studied for this compound. The vibrational wavenumbers of the fundamental modes of (TAN) have been precisely assigned, analyzed, and the theoretical results were compared with the experimental values. NBO analysis and AIM approach explained the stability of title compound. HOMO-LUMO energy gap, molecular hardness, ionization energy, electron affinity, total energy and dipole moment are very interesting physical parameters for chemical reactivity and biological activities of the studied compound. Furthermore this compound was found to be the applicant exhibiting antioxidant property; this is demonstrated by scavenging DPPH radicals, ABTS radicals, reducing property and slight hydroxyl radical scavenging to that of ascorbic acid.

\section{ACKNOWLEDGEMENTS}

This work was supported by the Ministry of Higher Education and Scientific Research of Tunisia.

\section{REFERENCES}

[1] L. M. Novena, S. S. Kumar, S. Athimoolam, Improved solubility and bioactivity of theophylline (a bronchodilator drug) through its new nitrate salt analysed by experimental and theoretical approaches, J. Mol. Struct. 1116 (2016) 45-55.

[2] A. Müller, F. Peters, M. T. Pope, D. Gatteschi, Polyoxometalates: Very Large Clusters-Nanoscale Magnets, Chem. Rev. 98 (1998) 239-272. 
[3] C. Y. Sun, S. X. Liu, D. D. Liang, K. Z. Shao, Y. H. Ren, Z. M. Su, Highly stable crystalline catalysts based on a microporous metal-organic framework and polyoxometalates, J. Am. Chem. Soc. 131 (2009) 1883-1888.

[4] P. Englebienne, A. V. Hoonacker, Gold-conductive polymer nanoparticles: A hybrid material with enhanced photonic reactivity to environmental stimuli, J. Colloid Interface Sci. 292 (2) (2005) 445-454.

[5] H. Zeng, G. R. Newkome, C. L. Hill, Poly(polyoxometalate) Dendrimers: Molecular Prototypes of New Catalytic Materials, Angew. Chem. Int. Ed. Engl. 2000, 39, 17711774.

[6] A. Müller, H. Reuter, S. Dillinger, Supramolecular Inorganic Chemistry: Small Guests in Small and Large Hosts, Angew. Chem. Int. Ed. Engl. 34 (1995) 2328-2361.

[7] D. Hagrman, R. C. Haushalter, J. Zubieta, Three-Dimensional Organic/Inorganic Hybrid Materials Constructed from One-Dimensional Copper Diamine Coordination Polymers Linked by Bridging Oxoanion Tetrahedra: $\left[\mathrm{Cu}(\mathrm{dpe})\left(\mathrm{MoO}_{4}\right)\right]$ and $\left[\mathrm{Cu}(\mathrm{dpe})\left(\mathrm{SO}_{4}\right)\left(\mathrm{H}_{2} \mathrm{O}\right)\right]$ (dpe = 1,2-trans-(4-pyridyl)ethene), Chem. Mater. 10 (1998) 361-365.

[8] X. L. Wang, C. Qin, E-B. Wang, L. Xu, Z-M. Su, C-W. Hu, Interlocked and Interdigitated Architectures from Self-Assembly of Long Flexible Ligands and Cadmium Salts, Angew. Chem. Int. Ed. Engl. 43 (2004) 5036-5040.

[9] C. M. Liu, D. Q. Zhang, M. Xiong, D. B. Zhu, Chem. Commun. (2002) 1416-1417.

[10] A. K. Cheetham, G. Férey, T. Loiseau, Open Framework inorganic materials, Angew. Chem. Intl. Ed. 38 (1999) 3268-3292.

[11] P.V. Braun, P. Osenar, V. Tohver, S. B. Kennedy, S. I. Stupp, Nanostructure templating in inorganic solids with organic lyotropic liquid crystals, J. Am. Chem. Soc. 121 (1999) 7302-7309.

[12] M-C. Daniel, D. Astruc, Gold nanoparticles: assembly, supramolecular chemistry, quantum-size-related properties, and applications toward biology, catalysis, and nanotechnology, Chem. Rev. 104 (2004) 293-346.

[13] Y. Li, Y. Yu, L. Wu, J. Zhi, Processable polyaniline/titania nanocomposites with good photocatalytic and conductivity properties prepared via peroxo-titanium complex catalyzed emulsion polymerization approach, Appl. Surf. Sci. 273 (2013) 135-143. 
[14] F. Wang, S. Min, Y. Han, L. Feng, Visible-light-induced photocatalytic degradation of methylene blue with polyaniline-sensitized $\mathrm{TiO}_{2}$ composite photocatalysts, Superlattices Microstruct. 48 (2010) 170-180.

[15] G. K. Gribble, M. G. Saulnier, M. P. Sibi, J. A. Obaza-Nutaitis, Synthesis and DielsAlder reactions of 1,3-dimethyl-4-(phenylsulfonyl)-4H-furo[3,4-b]indole. A new annulation strategy for the construction of ellipticine and isoellipticine, J. Org. Chem. 49 (1984) 4518-4523.

[16] P. Kumar, B. Narasimhan, D. Sharma, V. Judge, R. Narang, Hansch analysis of substituted benzoic acid benzylidene/furan-2-yl-methylene hydrazides as antimicrobial agents, Eur. J. Med. Chem. 44 (2009) 1853-1863.

[17] A. Foroumadi, S. Mansouri, Z. Kiani, A. Rahmani, Synthesis and in vitro antibacterial evaluation of $\mathrm{N}$-[5-(5-nitro-2-thienyl)-1,3,4-thiadiazole-2-yl] piperazinyl quinolones, Eur. J. Med. Chem. 38 (2003) 851-854.

[18] V. J. Ram, L. Mishra, N.H. Pandey, D.S. Kushwaha, L.A.C. Pieters, A.J. Vlietinck, Bis heterocycles as potential chemotherapeutic agents. X. Synthesis of bis(4arylthiosemicarbazido)-, bis(2-arylamino-1,3,4-thiadiazol-5-yl) and bis(4-aryl-1,2,4triazolin-3-thione-5-yl)pentanes and related compounds, J. Heterocycl. Chem. 27 (1990) 351-355.

[19] C. Kirilmis, M. Ahmedzade, S. Servi, M. Koca, A. Kizirgil, C. Kazaz, Synthesis and antimicrobial activity of some novel derivatives of benzofuran: Part 2. The synthesis and antimicrobial activity of some novel 1-(1-benzofuran-2-yl)-2-mesitylethanone derivatives, Eur. J. Med. Chem. 43 (2008) 300-308.

[20] B.S. Holla, C.S. Prasanna, B. Poojary, K.S. Rao, K. Shridhara, Synthesis, characterization and biological studies of some triazolothiadiazines and triazolothiadiazoles containing 6-chloropyridin-3-yl methyl moiety, Indian J. Chem. 45B (2006) 2071-276.

[21] B. M. Ashok, J. S. Holla, Convenient synthesis of some triazolothiadiazoles and triazolothiadiazines carrying 4-methylthiobenzyl moiety as possible antimicrobial agents, J. Pharmacol. Toxicol. 2 (2007) 256-263.

[22] R.V. Chambhare, B. G. Khadse, A. S. Bobde, R. H. Bahekar, Synthesis and preliminary evaluation of some $\mathrm{N}$-[5-(2-furanyl)-2-methyl-4-oxo-4H-thieno[2,3d]pyrimidin-3-yl]-carboxamide and 3-substituted-5-(2-furanyl)-2-methyl-3Hthieno[2,3-d]pyrimidin-4-ones as antimicrobial agents, Eur. J. Med. Chem. 38 (2003) 89-100. 
[23] S. Rollas, N. Kalyoncuoðlu, D. Sur-Altiner, Y. Yegenoðlu, 5-(4-aminophenyl)-4substituted-2,4-dihydro-3H-1,2,4-triazole-3-thiones: synthesis and antibacterial and antifungal activities, Pharmazie 48 (1993) 308-309.

[24] I. Mir, M.T. Siddiqui, A. Comrie, Antituberculosis agents -I: $\alpha$ - [5-(2-Furyl)-1,2,4triazol-3-ylthio] acethydrazide and related compounds, Tetrahedron 26 (1970) 52355238 .

[25] W. Rudnicka, H. Foks, M. Janowiec, Z. Zwolska-Kwiek, Studies of pyrazinederivatives. XXI. Synthesis and tuberculostatic activity of 4-aryl-1pyrazinoylthiosemicarbazides and the products of their cyclization to 1,2,4-triazole-3thione derivatives, Acta Pol. Pharm. 43 (1986) 523-528.

[26] B. S. Holla, B. Veerendra, M.K. Shivananda, B. Poojary, Synthesis characterization and anticancer activity studies on some Mannich bases derived from 1,2,4-triazoles, Eur. J. Med. Chem. 38 (2003) 759-767.

[27] A. Duran, H. N. Dogan, S. Rollas, Synthesis and preliminary anticancer activity of new 1,4-dihydro-3-(3-hydroxy-2-naphthyl)-4-substituted-5H-1,2,4-triazoline-5thiones, Farmaco 57 (2002) 559-564.

[28] H. L. Yale, J. J. Piala, Substituted s-triazoles and related compounds, J. Med. Chem. 9 (1966) 42-46.

[29] M. H. Shah, M.Y. Mhasalkar, M.V. Palki, C.V. Deliwala, U.K. Sheth, New 1,2,4(H)triazole derivatives as diuretic agents, J. Pharm. Sci. 58 (1969) 1398-1401.

[30] M.Y. Mhasalkar, M.H. Shah, S.T. Nikam, K.G. Anantanarayanan, C. V. Deliwala, 4Alkyl-5-aryl-4H-1, 2, 4-triazole-3-thiols as hypoglycemic agents, J. Med. Chem. 13 (1970) 672-674.

[31] C. Lass-Flörl, Triazole antifungal agents in invasive fungal infections: a comparative review, Drugs 71 (2011) 2405-2419.

[32] J. Mohr, M. Johnson, T. Cooper, J. S. Lewis, L. Ostrosky-Zeichner, Current Options in Antifungal Pharmacotherapy, Pharmacother. J. Hum. Pharmacol. Drug Ther. 28 (2008) 614-645.

[33] A. H. Groll, J. C. Gea-Banacloche, A. Glasmacher, G. Just-Nuebling, G. Maschmeyer, T. J. Walsh, Clinical pharmacology of antifungal compounds, Infect. Dis. Clin. North Am. 17 (2003) 159-191.

[34] A. A. Sagatova, M. V. Keniya, R. K. Wilson, M. Sabherwal, J. D. A. Tyndall, B.C. Monk, Triazole resistance mediated by mutations of a conserved active site tyrosine in 
fungal lanosterol 14 $\alpha$-demethylase, Sci. Rep 6:26213 (2016) 1-11.

[35] A. G. S. Warrilow, C. M. Martel, J. E. Parker, N. Melo, D. C. Lamb, W. D. Nes, D. E. Kelly, S.L. Kelly, Antimicrob. Agents Chemother. 54 (2010) 4235-4245.

[36] P. Jiminez, M. V. Roux,, C. Turrion, Thermochemical Properties of M-heterocyclic Compounds II. Enthalpies of Combustion, Vapour Pressures, Enthalpies of Sublimation, and Enthalpies of Formation of 1,2,4-Triazole and Benzotriazole, J. Chem. Thermodyn. 21 (1989) 759.

[37] V. I. Slovetskii, V. M. Brusnikina, L. I. Khmel'nitskii, O. V. Lebedev, Special Features of the Structure of Some Salts of Triazole Bases, Khim. Geterotsikl. Soedin. 2 (1966) 448.

[38] E. D. Glendening, J. K. Badenhoop, A. D. Reed, J. E. Carpenter, F. Weinhold, NBO 3.1, Theoretical Chemistry Institute, University of Wisconsin, Madison, WI, 1996.

[39] R. F. W. Bader, Atoms in Molecules, a Quantum Theory, Oxford University Press, Oxford, 1990, ISBN 0198558651.

[40] F. Biegler-Koning, J. Schonbohm, D. Bayles, AIM2000; A Program to Analyze and Visualize Atoms in Molecules, J. Comput. Chem. 22 (2001) 545.

[41] Bruker (2006). APEX2, SAINT and SADABS. Bruker AXS Inc., Madison,Wisconsin, USA.

[42] A. Altomare, M. C. Burla, M. Camalli, G. L. Cascarano, C. Giacovazzo, A. Guagliardi, A. G. G. Moliterni, G. Polidori, R. Spagna, J. Appl. Cryst. 32 (1999) 115.

[43] G. M. Sheldrick, Crystal structure refinement with SHELXL, Acta Cryst. C71 (2015) 3-8.

[44] L. J. Farrugia, WinGX and ORTEP for Windows: an update, J. Appl. Cryst. 45 (2012) 849-854.

[45] A. Braca, N. D.Tommasi, L. D. Bari, C. Pizza, M. Politi, I. Morelli, Antioxidant principles from Bauhinia terapotensis. J. Nat. Prod. 64 (2001) 892-895.

[46] R. Re, N. Pellegrini, A. Proteggente, A. Pannala, M. Yong, C. Rice-Evas, Antioxidant activity applying an improved ABTS radical cation decoloursation assay. Free Rad. Biol. Med. 26 (1999) 1231-1237.

[47] B. Halliwell, J. M. C. Gutteridge, O. I. Aruoma, The deoxyribose method: a simple test tube assay for determination of rate constants for reactions of hydroxyl radicals. Anal. Biochem. 165 (1987) 215-219. 
[48] R. Pulido, L. Bravo, F. Saura-Calixto. Antioxidant activity of dietary polyphenols as determined by a modified ferric reducing/antioxidant power assay, J. Agric. Food Chem. 48 (2000) 396-402.

[49] S. K. Wolff, D. J. Grimwood, J. J. McKinnon, M. J. Turner, D. Jayatilaka, M.A. Spackman, CrystalExplorer 3.1 (2013), University of Western Australia, Crawley, Western Australia, 2005-2013, http://hirshfeldsurface.net/CrystalExplorer.

[50] M. J. Frisch, et al., GAUSSIAN 09, Revision A.02, Gaussian, Inc., Wallingford, CT, 2009.

[51] R. I. Dennington, T. Keith, J. Millam, GaussView, Version 5.0.8, Semichem. Inc, Shawnee Mission, KS, 2008.

[52] E. D. Glendening, J. K. Badenhoop, A. D. Reed, J. E. Carpenter, F. Weinhold, NBO 3.1; Theoretical Chemistry Institute, University of Wisconsin, Madison, WI, 1996.

[53] F. Biegler-Köning, J. Schönbohm, D. Bayles, AIM2000; a program to analyze and visualize atoms in molecules, J. Comput. Chem. 22 (5) (2001) 545-559.

[54] G.M. Morris, R. Huey, W. Lindstrom, M.F. Sanner, R. K. Belew, D.S. Goodsell, A. J. Olson, AutoDock4 and AutoDockTools4: Automated docking with selective receptor flexibility, J. Comput. Chem. 30 (2009) 2785-2791.

[55] K. C. Hsu, Y. F. Chen, S. R. Lin, J. M. Yang, iGEMDOCK: a graphical environment of enhancing GEMDOCK using pharmacological interactions and post-screening analysis, BMC Bioinformatics 12 Suppl 1 (2011) S33.

[56] J. M. Yang, C. C. Chen, GEMDOCK: a generic evolutionary method for molecular docking, Proteins 55 (2004) 288-304.

[57] L.L.C. Schrödinger, The PyMOL Molecular Graphics System, Version 1.8, 2015.

[58] S. Gatfaoui, H. Marouani, M. Rzaigui, 4-Methylbenzylammonium nitrate, Acta Cryst. E69 (2013) 01453.

[59] S. Gatfaoui, H. Marouani, T. Roisnel, H. Dhaouadi, Dopaminium nitrate, Acta Cryst. E70 (2014) 0571-0572.

[60] S. Gatfaoui, T. Roisnel, H. Dhaouadi, H. Marouani, trans-2,5-Dimethylpiperazine-1,4diium dinitrate, Acta Cryst. E70 (2014) 0725.

[61] K. T. Potts, The Chemistry of 1,2,4-Triazoles, Chem. Rev. 61 (1961) 87-127.

[62] M. Bujak, J. Zaleski, Crystal and Molecular Structure of 1,2,4-Triazolium Chloride and its Salt with Antimony Trichloride - Bis(1,2,4-triazolium) pentachloroantimonate(III)-1,2,4-triazolium Chloride, Z. Naturforsch. 57 b (2002) 157-164. 
[63] J. Bernstein, R. E. Davis, L. Shimoni, N. L. Chang, Patterns in Hydrogen Bonding: Functionality and Graph Set Analysis in Crystals. Angew. Chem. Int. Ed. Engl. 34 (1995) 1555-1573.

[64] S. K. Seth, G. C. Maity, T. Kar, Structural elucidation, Hirshfeld surface analysis and quantum mechanical study of para-nitro benzylidene methyl arjunolate, J. Mol. Struct. 1000 (2011) 120-126.

[65] J. L. Wardell, M. M. Jotani, E. R. T. Tieking, Two dialkylammonium salts of 2-amino4-nitrobenzoic acid: crystal structures and Hirshfeld surface analysis, Acta Cryst. E72 (2016) 1691-1699.

[66] J. J. Koenderink, A. J. van Doorn, Surface shape and curvature scales, Image Vis. Comput. 10 (1992) 557-564.

[67] C. Jelsch, K. Ejsmont, L. Huder, The enrichment ratio of atomic contacts in crystals, an indicator derived from the Hirshfeld surface analysis, IUCrJ. 1 (2014) 119-128.

[68] L. M. Salonen, M. Ellermann, F. Diederich, Aromatic rings in chemical and biological recognition: energetics and structures, Angew. Chem. Int. Ed. 50 (2011) 4808-4842.

[69] J. R. Macdonald, Impedance spectroscopy, Ann. Biomed. Eng. 20 (1992) 289-305.

[70] K. Karoui, A. Ben Rhaiem, F. Hlel, M. Arous, K. Guidara, Dielectric and electric studies of the $\left[\mathrm{N}\left(\mathrm{CH}_{3}\right)_{4}\right]\left[\mathrm{N}\left(\mathrm{C}_{2} \mathrm{H}_{5}\right)_{4}\right] \mathrm{ZnCl}_{4}$ compound at low temperature, Mater. Chem. Phys. 133 (2012) 1-7.

[71] S. Selvasekarapandian, M. Vijaykumar, The ac impedance spectroscopy studies on $\mathrm{LiDyO}_{2}$, Mater. Chem. Phys. 80 (2003) 29-33.

[72] M.F. Mostafa, S.S. El-khiyami, Crystal structure and electric properties of the organicinorganic hybrid: $\left[\left(\mathrm{CH}_{2}\right)_{6}\left(\mathrm{NH}_{3}\right)_{2}\right] \mathrm{ZnCl}_{4}$, J. Solid State Chem. 209 (2014) 82-88.

[73] H. Chouaib, S. Kamoun, AC conductivity and dielectric relaxation of tris(N,Ndimethylanilinium) hexabromidostannate(IV) bromide: $\left(\mathrm{C}_{8} \mathrm{H}_{12} \mathrm{~N}\right)_{3} \mathrm{SnBr}_{6} \cdot \mathrm{Br}$, J. Phys. Chem. Solids 85 (2015) 218-225.

[74] R. Elwej, M. Hamdi, N. Hannachi, F. Hlel, Temperature- and frequency-dependent dielectric properties of organic-inorganic hybrid compound: $\left(\mathrm{C}_{6} \mathrm{H}_{9} \mathrm{~N}_{2}\right)_{2}\left(\mathrm{Hg}_{0.75} \mathrm{Cd}_{0.25}\right) \mathrm{Cl}_{4}$, Mater. Res. Bull. 62 (2015) 42-51.

[75] A. Fadhalaoui, H. Dhaouadi, H. Marouani, A. Kouki, A. Madani, M. Rzaigui, Crsubstitution effect on structural, optical and electrical properties of $\mathrm{Cr}_{\mathrm{x}} \mathrm{Ce}_{1-\mathrm{x}} \mathrm{PO}_{4}(\mathrm{x}=$ 0.00, 0.08, 0.10 and 0.20) nanorods, Mater. Res. Bull. 73 (2016) 153-163.

[76] P. B. Macedo, R. Bose, V. Provenzano, T. A. Litovitz, Amphorous Materials, Mat. Interscience, London (1972) 251. 
[77] P. B. Macedo, C. T. Moynihan, R. Rose, The long time aspects of this correlation function, which are obtainable by bridge techniques at temperatures approaching the glass transition, Phys. Chem. Glasses 13 (1972) 171-176.

[78] F. S. Howell, R. A. Bose, P. B. Macedo, C. T. Moynihan, Electrical relaxation in a glass-forming molten salt, J. Phys. Chem. 78 (1974) 639-648.

[79] I. M. Hodge, M. D. Ingram, A. R. West, A new method for analysing the a.c. behaviour of polycrystalline solid electrolytes, J. Electroanal. Chem. 58 (1975) 429432.

[80] A. M. M. Farea, S. Kumar, K. M. Batoo, A. Yousef, C. G. Lee, Alimuddin, Structure and electrical properties of $\mathrm{Co}_{0.5} \mathrm{Cd}_{\mathrm{x}} \mathrm{Fe}_{2.5-\mathrm{x}} \mathrm{O}_{4}$ ferrites, J. Alloys Compd. 464 (2008) 361-369.

[81] S. Bhadra, N. K. Singha, D. Khastgir, Dielectric properties and EMI shielding efficiency of polyaniline and ethylene 1-octene based semi-conducting composites, Cur. Appl. Phys. (2009) 396-403.

[82] M. M. El-Nahass , A. A. Atta , E. F. M. El-Zaidia , A. A. M. Farag, A. H. Ammar, Electrical conductivity and dielectric measurements of CoMTPP, Mater. Chem. Phys. 143 (2014) 490-494.

[83] M. Ben Gzaiel, A. Oueslati, M. Gargouri, Ac Conductivity and Transport Properties of $\left[\mathrm{N}\left(\mathrm{C}_{3} \mathrm{H}_{7}\right)_{4}\right]_{2} \mathrm{Zn}_{2} \mathrm{Cl}_{6}$ Compound, J. Clust. Sci. 26 (2015) 1577-1594.

[84] S. Hajlaoui, I. Chaabane, A. Oueslati, K. Guidara, Electrical transport properties and modulus behavior of the organic-inorganic $\left[\mathrm{N}\left(\mathrm{C}_{3} \mathrm{H}_{7}\right)_{4}\right]_{2} \mathrm{SnCl}_{6}$ compound, Phys. B 474 (2015) 90-96.

[85] H. Barbes, G. Mascherpa, R. Fourcade, B. Ducourant, Corrélations conductivité protonique-Structures dans le difluorure et le pentafluoroantimonate III d'hydrazinium: Structure cristalline de $\mathrm{N}_{2} \mathrm{H}_{6} \mathrm{SbF}_{5}$, J. Solid State Chem. 60 (1985) 95100.

[86] P. Hagenmuller, W. Van Gool, Solid Electrolytes, Academic Press (1978) 195-213.

[87] U. Koch, P. Popelier, Characterization of C-H-O Hydrogen Bonds on the Basis of the Charge Density, J. Phys. Chem. 99 (1995) 9747-9754.

[88] R. F. W. Bader Atoms in molecules A quantum theory (Oxford: Oxford University Press) 1990. 
[89] I. Rozas. I. Alkorta, J. Elguero, Behavior of Ylides Containing N, O, and C Atoms as Hydrogen Bond Acceptors, J. Am. Chem. Soc. 122 (2000) 11154-11161.

[90] E. Espinosa. E. Molins, C. Lecomte, Hydrogen bond strengths revealed by topological analyses of experimentally observed electron densities, Chem. Phys. Lett. 285 (1998) 170.

[91] L. F. Matta, R. J. Boyd. An Introduction of the Quantum theory of Atom in Molecule. Wiley-VCH Verlag Gmbh. 2007.

[92] F. Weinhold, C.R. Landis, Valency and Bonding: A Natural Bond Orbital DonorAcceptor Perspective, Cambridge University Press, Cambridge, 2005.

[93] A. E. Reed, L.A. Curtiss, F. Weinhold, Intermolecular interactions from a natural bond orbital, donor-acceptor viewpoint, Chem. Rev. 88 (1988) 899-926.

[94] R. Z. Zhang, X. H. Li, X. Z. Zhang, Molecular structure, vibrational spectra and NBO analysis on 1N-acetyl-3-(2, 4dichloro-5-Fluoro-phenyl)-5-(p-methyl-phenyl)-2pyrazoline using DFT method, Indian J. Pure Appl. Phys. 49 (2011) 731-739.

[95] S. Gunasekaran, S. Kumaresan, R. Arunbalaji, G. Anand, S. Srinivasan, Density functional theory study of vibrational spectra, and assignment of fundamental modes of dacarbazine, J. Chem. Sci. 120 (2008) 315-324.

[96] I. Sidir, Y.G. Sidir, M. Kumalar, E. Tasal, Ab initio Hartree-Fock and density functional theory investigations on the conformational stability, molecular structure and vibrational spectra of 7-acetoxy-6-(2,3-dibromopropyl)-4,8-dimethyl -coumarin molecule, J. Mol. Struct. 964 (2010) 134-151.

[97] R. S. Mulliken, A New Electroaffinity Scale; Together with Data on Valence States and on Valence Ionization Potentials and Electron Affinities, J. Chem. Phys. 2 (1934) 782.

[98] R.G. Parr, L. von Szentpály, S. Liu, Electrophilicity Index, J. Am. Chem. Soc. 121 (1999) 1922-1924.

[99] M. Salihovic, S. Huseinovic, S. Spirtovic-Halilovic, A. Osmanovic, A. Dedic, Z. Asimovic, D. Zavrsnik, DFT study and biological activity of some methylxanthines, Bull. Chem. Technol of Bos and Herzeg. 42 (2014) 31-36.

[100] D. Baek, Y. Jin, J. C. Jeong, H. J. Lee, H. Moon, J. Lee, Suppression of reactive oxygen species by glyceraldehyde-3-phosphate dehydrogenase, Phytochem. 69 (2008) 333-338. 
[101] T. P. Ribeiro, C. Fernandes. K. V. Melo, S. S. Ferreira, J. A. Lessa, R. W. Franco, A. Horn, Iron, copper, and manganese complexes with in vitro superoxide dismutase and/or catalase activities that keep Saccharomyces cerevisiae cells alive under severe oxidative stress. Fr. Radi. Biol. and Medic. 80 (2015) 67-76.

[102] M.H. Jamroz, Vibrational Energy Distribution Analysis, VEDA 4, Computer Program, Poland, 2004.

[103] N. Sundaraganesan, S. Illakiamani, H. Saleem, P. M. Wojciechowski, D. Michalska, FT-Raman and FT-IR spectra, vibrational assignments and density functional studies of 5-bromo-2-nitropyridine, Spectrochim. Acta A Mol. Biomol. Spectrosc. 61 (2005) 2995-3001.

[104] M. H. Jamroz, Spesca Program, ICRI, Warsaw, 2002.

[105] L. M. Novena, S. S. Kumar, S. Athimoolam, Improved solubility and bioactivity of Theophylline (a Bronchodilator drug) through its new nitrate salt analysed by experimental and theoretical approaches, J. Mol. Struct. 1116 (2016) 45-55.

[106] P. Barczynski, M. R. Sitarz, L. Nowaczyk, Katrusiak, Z. D. Szafran, M. Szafran, Structure and spectroscopic studies of 2,3-diethoxycarbonyl-1-methylpyridinium nitrate, J. Mol. Struct. 1035 (2013) 348-357.

[107] S. Pandiarajan, M. Umadevi, M. B. Mary, R. K. Rajaram, V. Ramakrishnan, Infrared and Raman spectroscopic studies of L-methioninium nitrate, J. Raman Spectrosc. 35 (2004) 907-913.

[108] A. A. El-Emam, A. S. Al-Tamimi, K. A. Al-Rashood, H. N. Misra, V. Narayan, O. Prasad, L. Sinha, Structural and spectroscopic characterization of a novel potential chemotherapeutic agent 3-(1-adamantyl)-1-\{[4-(2-methoxyphenyl) piperazin-1-yl] methyl -4-methyl-1H-1, 2, 4-triazole-5 (4H)-thione by first principle calculations, J. Mol. Struct. 1022 (2012) 49.

[109] L. Sobczyk, A. Pawlukojć, E. Grech, A. Huczyński, B. Brzezinski, Extremely different structures and vibrational spectra of tetramethylpyrazine nitrate dihydrate in solid and solutions, J. Mol. Struct. 1037 (2013) 264.

[110] R. L. Frost, K. L. Erickson, T. J. Kloprogge, Vibrational spectroscopic study of the nitrate containing hydrotalcite mbobomkulite, Spectrochim. Acta Part A 61 (2005) 2919.

[111] D. J. Goebbert, E. Garand, T. Wende, R. Bergmann, G. Meijer, K. R. Asmis, D. M. Neumark, Infrared Spectroscopy of the Microhydrated Nitrate Ions $\mathrm{NO}_{3}-\left(\mathrm{H}_{2} \mathrm{O}\right) 1-6, \mathrm{~J}$. Phys. Chem. A 113 (2009) 7584. 


\section{Table captions}

Table 1. Crystal data and experimental parameters used for the intensity data collection strategy and final results of the structure determination.

Table 2. Bond length $\left(\mathrm{A}^{\circ}\right)$, bond angles $\left(^{\circ}\right)$ and torsional angles $\left(^{\circ}\right)$ by X-ray data (with estimated standard deviation in parentheses) and by theoretical calculations at different levels of theory.

Table 3. Hydrogen-bond geometry $\left(\AA,^{\circ}\right)$ of TAN.

Table 4. Enrichment ratio of different inter-contact and percentage of each atom on the surface Hirshfeld in $\left(\mathrm{C}_{2} \mathrm{H}_{4} \mathrm{~N}_{3}\right) \mathrm{NO}_{3}$.

Table 5. Topological parameters for interactions: electron density $(\rho)$, Laplacian of electron density $\left(\nabla^{2} \rho(\mathbf{r})\right)$, electron kinetic energy density $(G)$. electron potential energy density $(V)$, total electron energy density $(H)$, estimated interaction energy $\left(E_{\text {int }}\right)$, eigen values of Hessian and ellipticities $(\varepsilon)$ at ring and bond critical point (BCP).

Table 6. Second-order perturbation energies $\mathrm{E}(2)(\mathrm{kCal} / \mathrm{mol})$ corresponding to the most important charge transfer interaction (donor-acceptor) in TAN by DFT/B3LYP/6$311++\mathrm{G}(\mathrm{d}, \mathrm{p})$ method.

Table 7. Natural and Mulliken population analysis of the atoms in hydrogen bondings for the TAN.

Table 8. Global reactivity descriptors and calculated frontier molecular orbital parameters in gas and in solution phase for TAN.

Table 9. Docking energy scores in $\mathrm{kcal} / \mathrm{mol}$ for the ligand molecules (TAN, fluconazole, voriconazole, itraconazole, and posaconazole) with CPY51 receptor and their molecular weights in $\mathrm{g} / \mathrm{mol}$.

Table 10. Observed and calculated wavenumbers $\left(\mathrm{cm}^{-1}\right)$ and assignments of TAN molecule. 


\section{Figure captions}

Fig. 1. ORTEP drawing of $\left(\mathbf{C}_{2} \mathbf{H}_{4} \mathbf{N}_{2}\right) \mathbf{N O}_{3}$ with the atom-labeling scheme. Displacement ellipsoids are drawn at the $30 \%$ probability level. $\mathrm{H}$ atoms are represented as small spheres of arbitrary radii (a) and the optimized molecular structure (b).

Fig. 2. The packaging scheme of TAN, showing the interactions between the two ions $\left(\mathrm{C}_{2} \mathrm{H}_{4} \mathrm{~N}_{3}{ }^{+}\right.$and $\left.\mathrm{NO}_{3}{ }^{-}\right)$. Hydrogen bonds are shown as dashed lines (a) Interactions between organic cations $\pi \ldots \pi$ stacking (b) Projection along the $\vec{b}$ axis of atomic arrangement of TAN (c) Projection of a layer in the plane ( $\mathrm{a} b$ ) showing the patterns of hydrogen bonding in the title compound (d).

Fig. 3. Hirshfeld surfaces mapped with $d_{\text {norm }}(\mathrm{a})$, shape index (b) and curvedness (c) for the $\left(\mathrm{C}_{2} \mathrm{H}_{4} \mathrm{~N}_{3}\right) \mathrm{NO}_{3}$.

Fig. 4. $d_{\text {norm }}$ mapped on the Hirshfeld surface for visualizing the intermolecular interactions of the title $\left(\mathrm{C}_{2} \mathrm{H}_{4} \mathrm{~N}_{3}\right) \mathrm{NO}_{3}$ compound. Color between -0.680 a.u (blue) to 0.966 a.u (red). Dotted lines (red) represent hydrogen bonds.

Fig. 5. Fingerprint plots of the different intercontacts and percentage of various intermolecular contacts contributed to the Hirshfeld surface in the $\left(\mathrm{C}_{2} \mathrm{H}_{4} \mathrm{~N}_{3}\right) \mathrm{NO}_{3}$ compound.

Fig. 6. Cole-Cole plots of the $\left(\mathrm{C}_{2} \mathrm{H}_{4} \mathrm{~N}_{3}\right) \mathrm{NO}_{3}$ at various temperatures.

Fig. 7. Plots of the real and imaginary parts of impedance $Z^{\prime}(a)$ and $Z^{\prime \prime}(b)$ vs $\log (f)$ of $\left(\mathrm{C}_{2} \mathrm{H}_{4} \mathrm{~N}_{3}\right) \mathrm{NO}_{3}$ at various temperatures.

Fig. 8. Arrhenius plots ionic conductivity of $\operatorname{Ln}(\sigma . \mathrm{T})$ versus $1000 / \mathrm{T}$ of $\left(\mathrm{C}_{2} \mathrm{H}_{4} \mathrm{~N}_{3}\right) \mathrm{NO}_{3}$.

Fig. 9. Variation of real and imaginary part of electric modulus M'(a) and M'(b) with frequency at different temperature.

Fig. 10. Variation of dielectric loss with frequency of $\left(\mathrm{C}_{2} \mathrm{H}_{4} \mathrm{~N}_{3}\right) \mathrm{NO}_{3}$ at various temperatures.

Fig. 11. DTA and TGA curves of $\left(\mathrm{C}_{2} \mathrm{H}_{4} \mathrm{~N}_{3}\right) \mathrm{NO}_{3}$ at rising temperature.

Fig. 12. DSC curve of $\left(\mathrm{C}_{2} \mathrm{H}_{4} \mathrm{~N}_{3}\right) \mathrm{NO}_{3}$.

Fig. 13. Graphical representation of the AIM analysis of the $\left(\mathrm{C}_{2} \mathrm{H}_{4} \mathrm{~N}_{3}\right) \mathrm{NO}_{3}$ : bond critical points (small red spheres), ring critical points (small yellow sphere), bond paths (pink lines)using AIM program.

Fig. 14. The map for electron density in the XY plane of TAN.

Fig. 15. Atomic charge distribution of TAN.

Fig. 16. The frontier molecular orbitals of TAN computed with TD-DFT(B3LYP)/6$311++\mathrm{G}(\mathrm{d}, \mathrm{p})$ in gas phase.

Fig. 17. Partial electronic density of states (PDOS). 
Fig. 18. DPPH Radical Scavenging Activity: tested compound (TAN), AA: ascorbic acid).

Fig. 19. ABTS radical scavenging ability: tested compound (TAN), AA: ascorbic acid).

Fig. 20. Reducing power assay: tested compound (TAN), AA: ascorbic acid).

Fig. 21. OH radical scavenging ability: tested compound (TAN), AA: ascorbic acid).

Fig. 22. Localization of the best docked poses for TAN, fluconazole, voriconazole, itraconazole, and posaconazole estimated via accurate docking by iGEMDOCK.

Fig. 23. Non-covalent interactions and hydrogen bonding surface map between TAN at best docked pose and CYP51. Color coding for interactions; Green: H-Bond, Purple: Pi-alkyl interactions, Red: Donor-Donor repulsion, and Brown: Charge-Charge repulsion

Fig. 24. Theoretical and experimental FT-IR spectrum of TAN.

Fig. S 1. Non-covalent interactions and hydrogen bonding surface map between fluconazole at best docked pose and CYP51

Fig. S 2. Non-covalent interactions and hydrogen bonding surface map between voriconazole at best docked pose and CYP51

Fig. S 3. Non-covalent interactions and hydrogen bonding surface map between itraconazole at best docked pose and CYP51

Fig. S 4. Non-covalent interactions and hydrogen bonding surface map between posaconazole at best docked pose and CYP51

Fig. S 5. Ionizability surface map for TAN at binding site of CYP51.

Fig. S 6. Ionizability surface map for fluconazole at binding site of CYP51.

Fig. S 7. Ionizability surface map for voriconazole at binding site of CYP51.

Fig. S 8. Ionizability surface map for itraconazole at binding site of CYP51.

Fig. S 9. Ionizability surface map for posaconazole at binding site of CYP51. 
Figure(s)

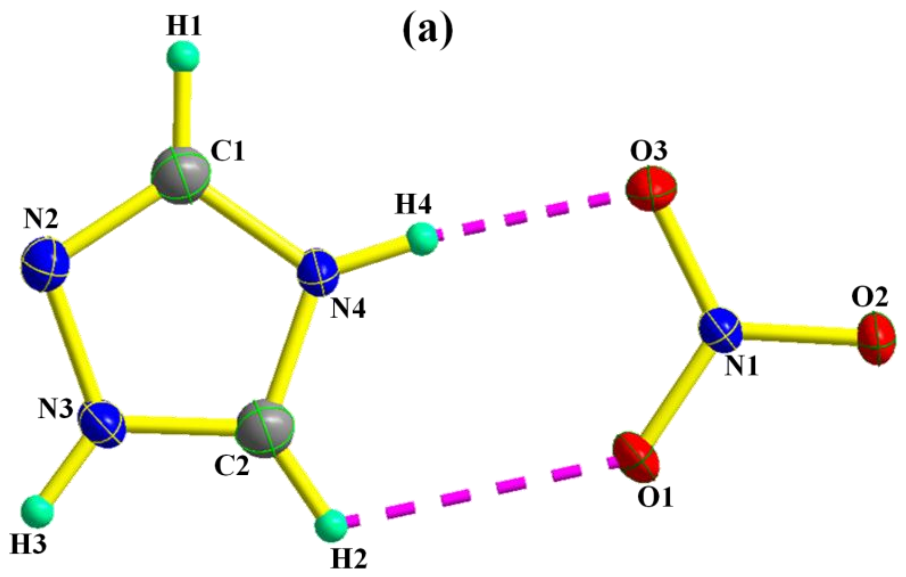

(b)

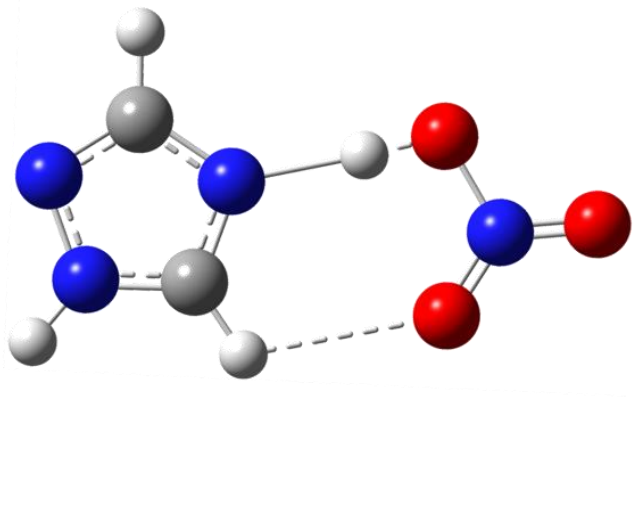

Fig. 1 


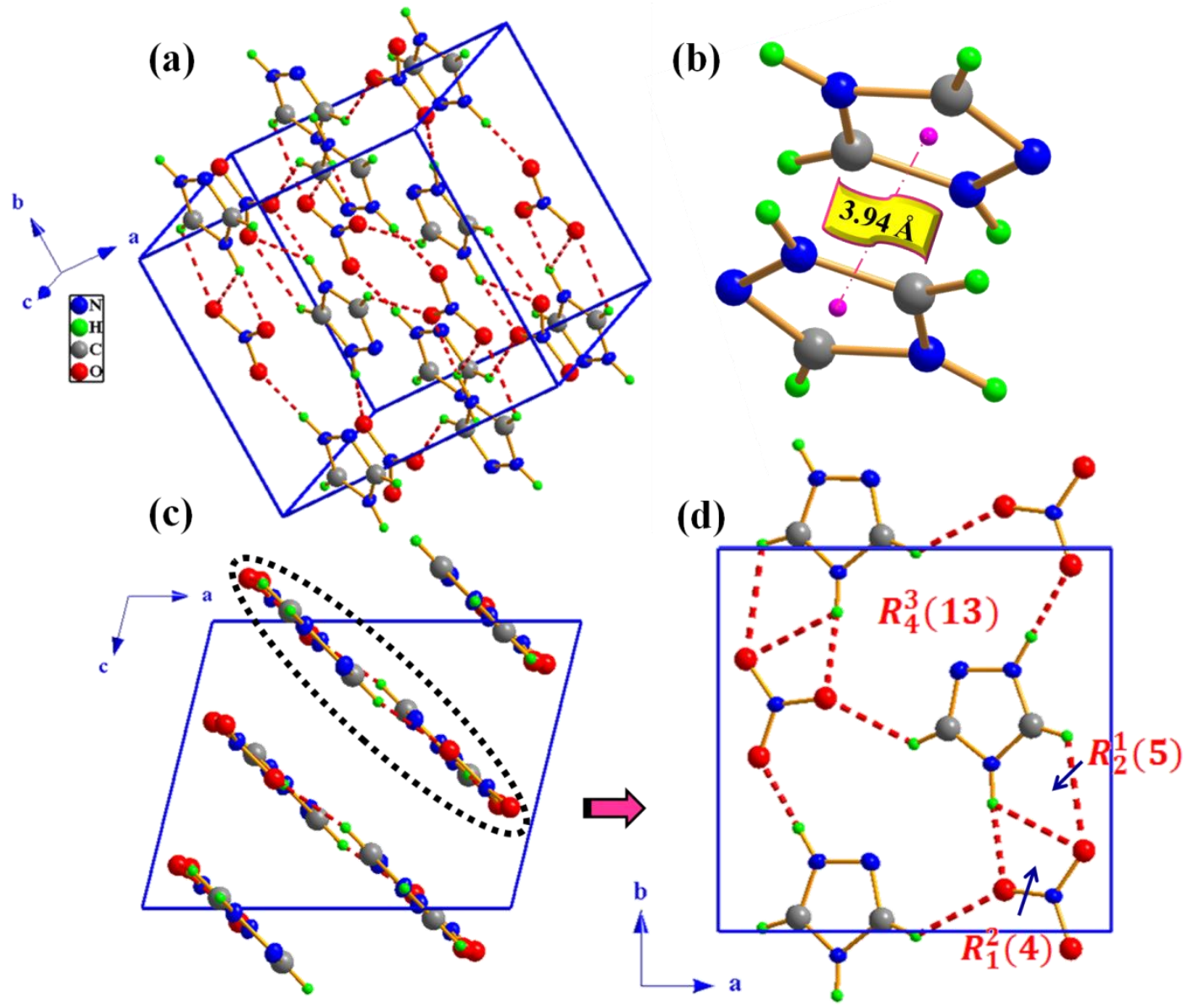

Fig. 2 
(a)

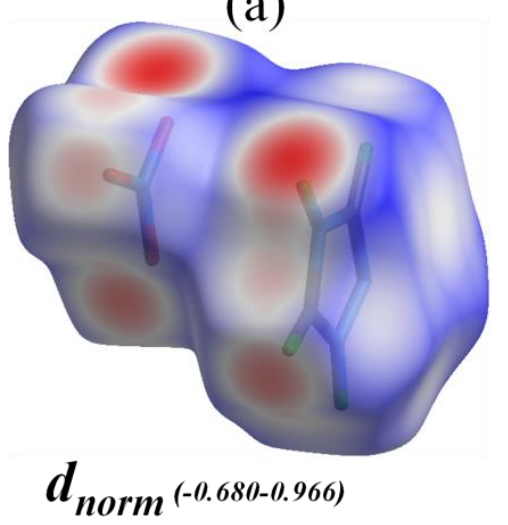

(b)

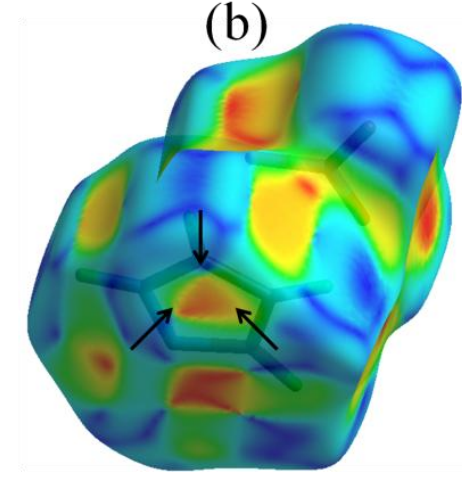

Shape index $(-1-1)$ (c)

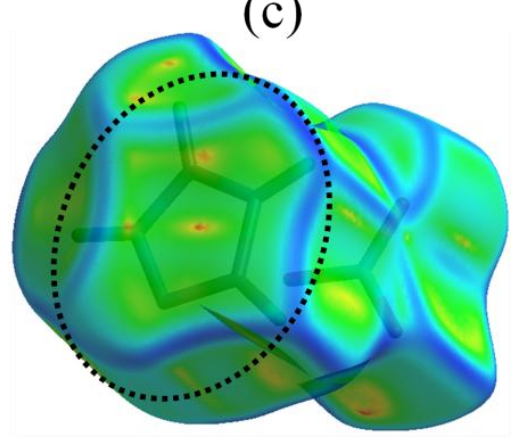

Curvedness(-4-4)

Fig. 3 


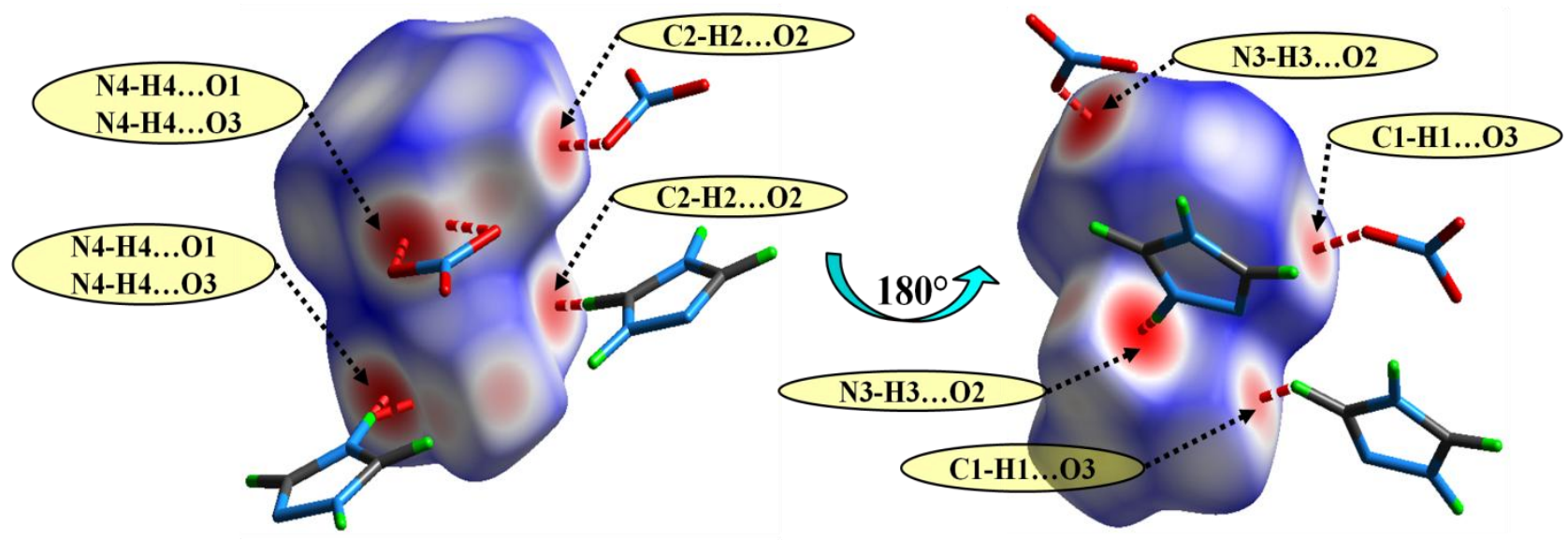

Fig. 4
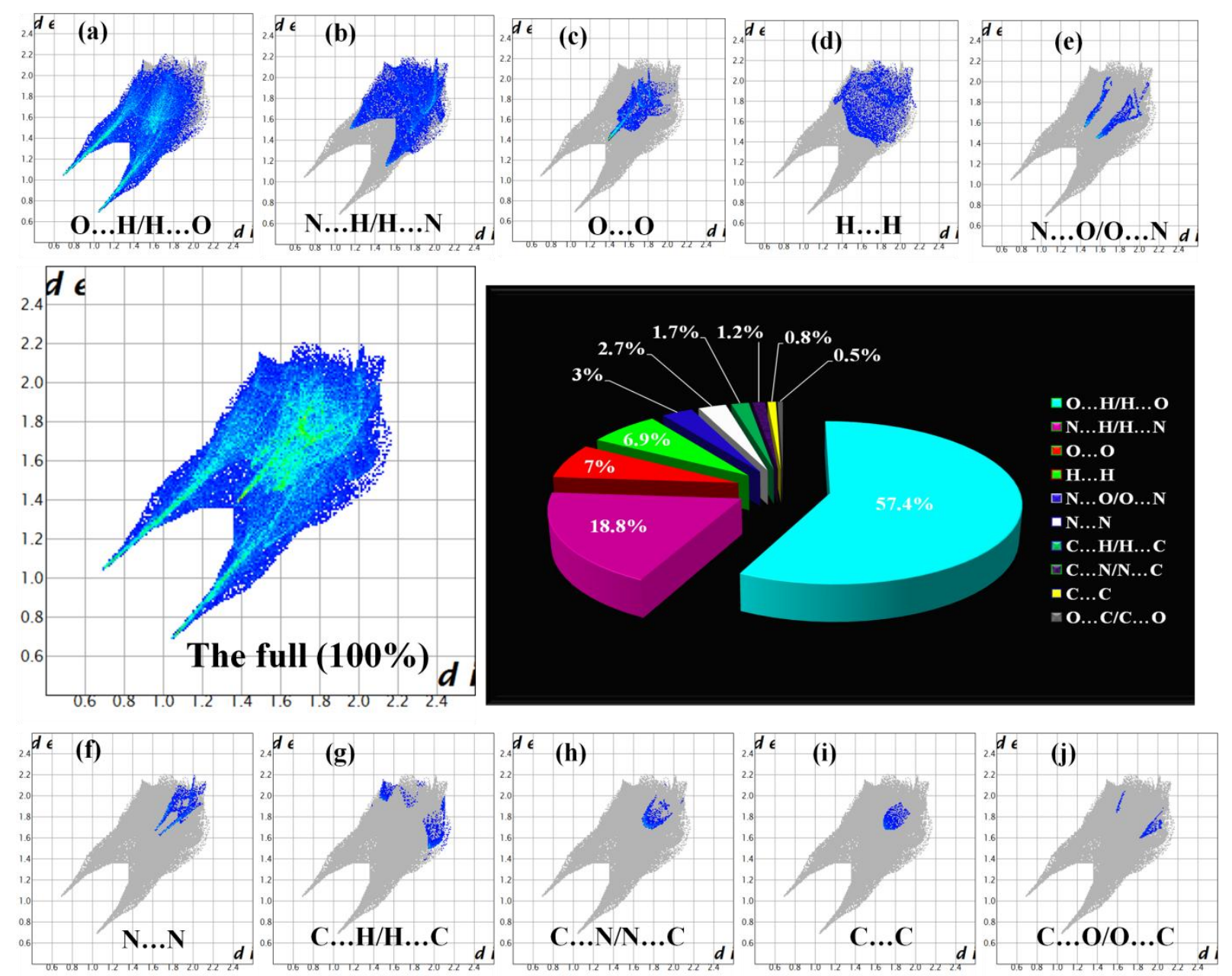

Fig. 5 


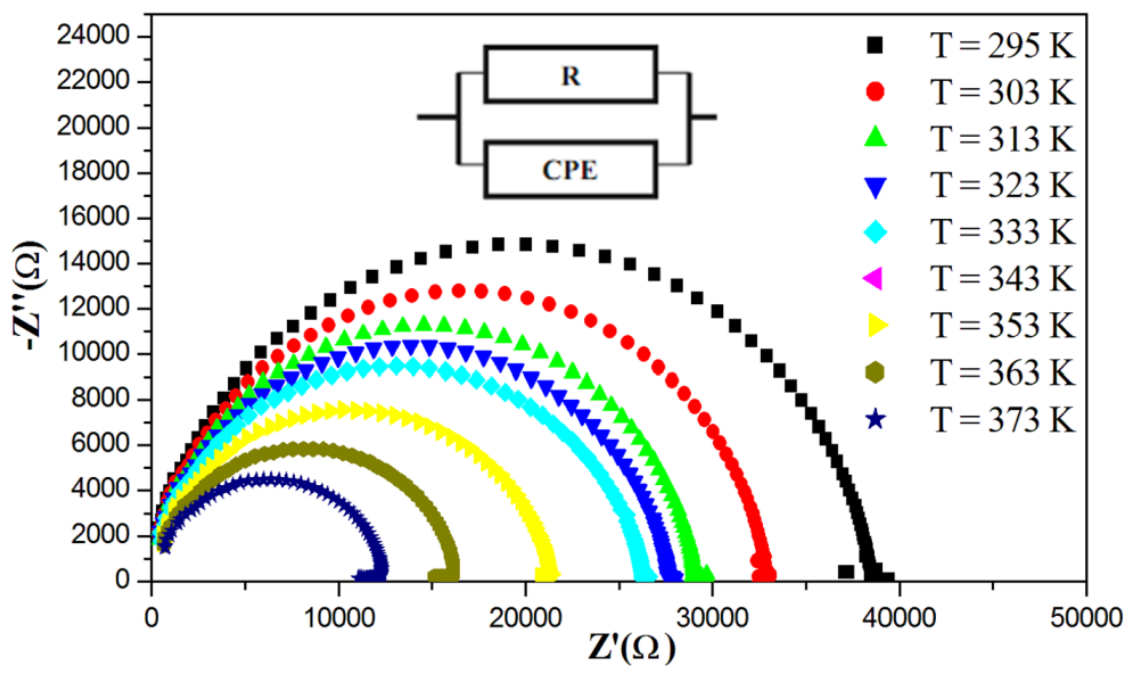

Fig. 6
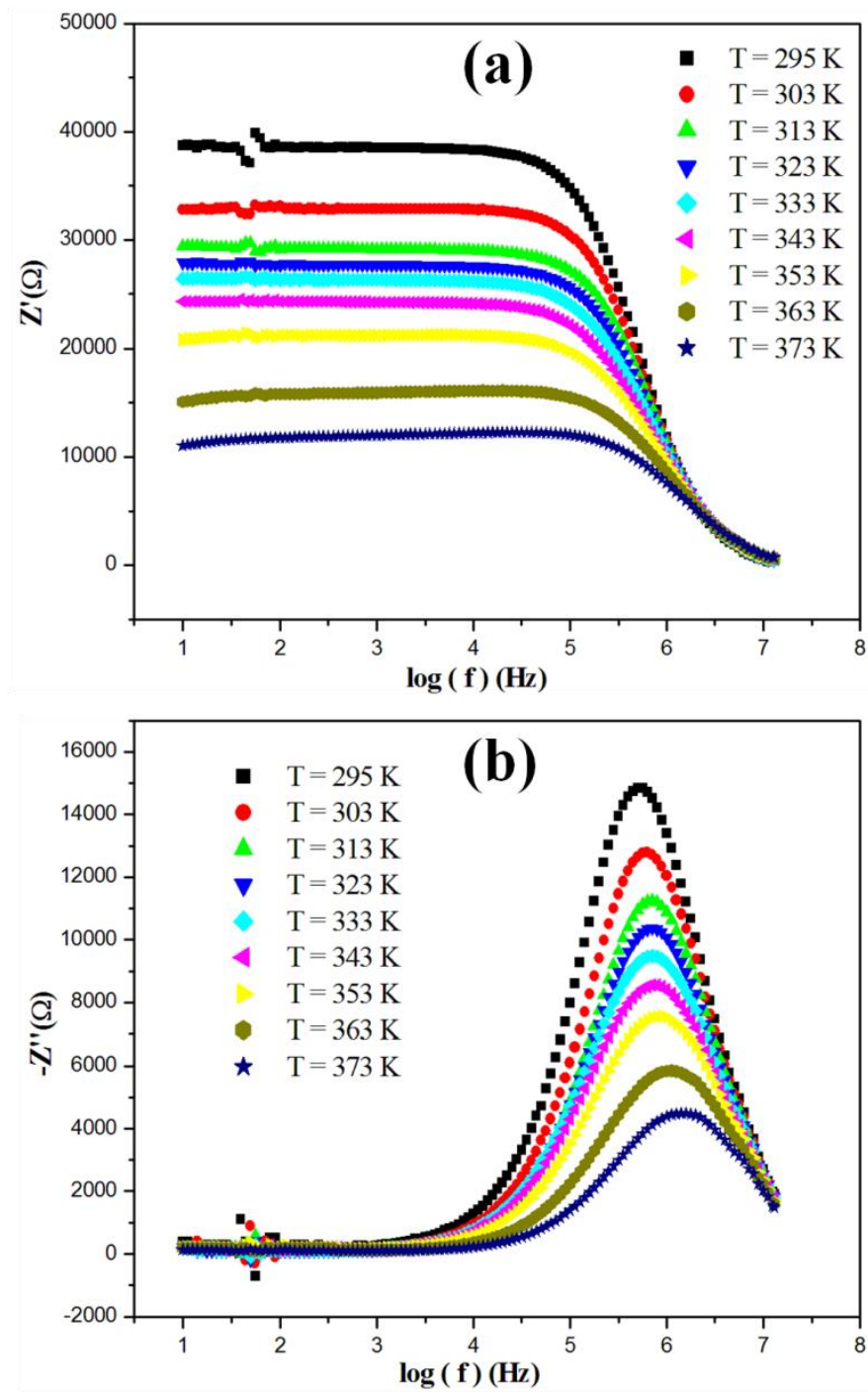

Fig. 7 


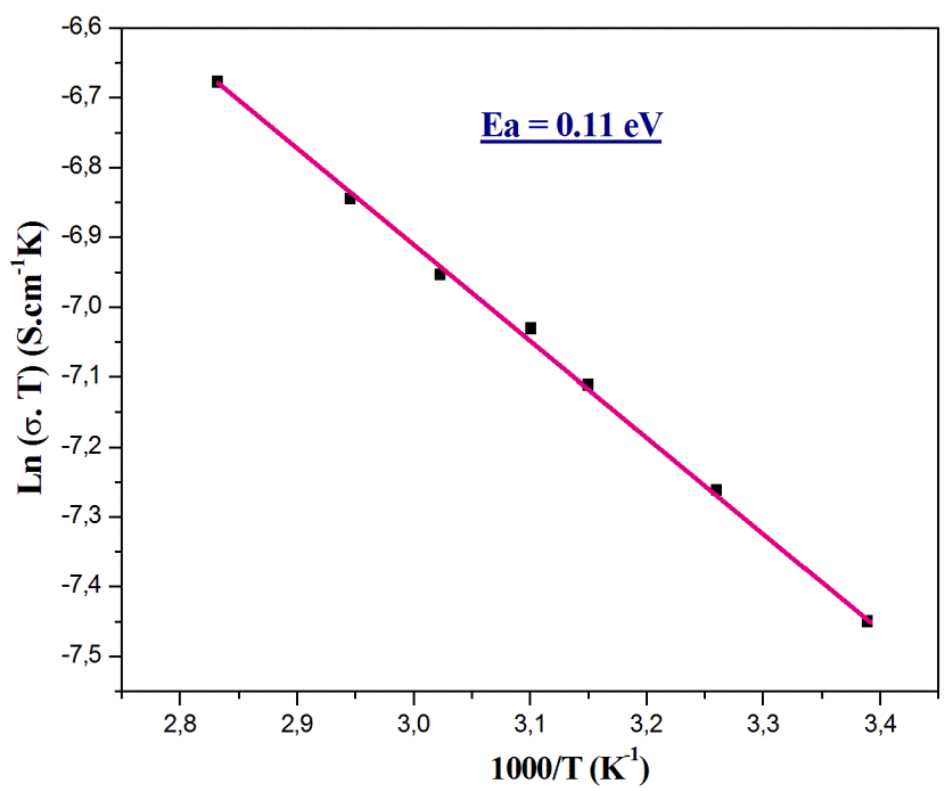

Fig. 8
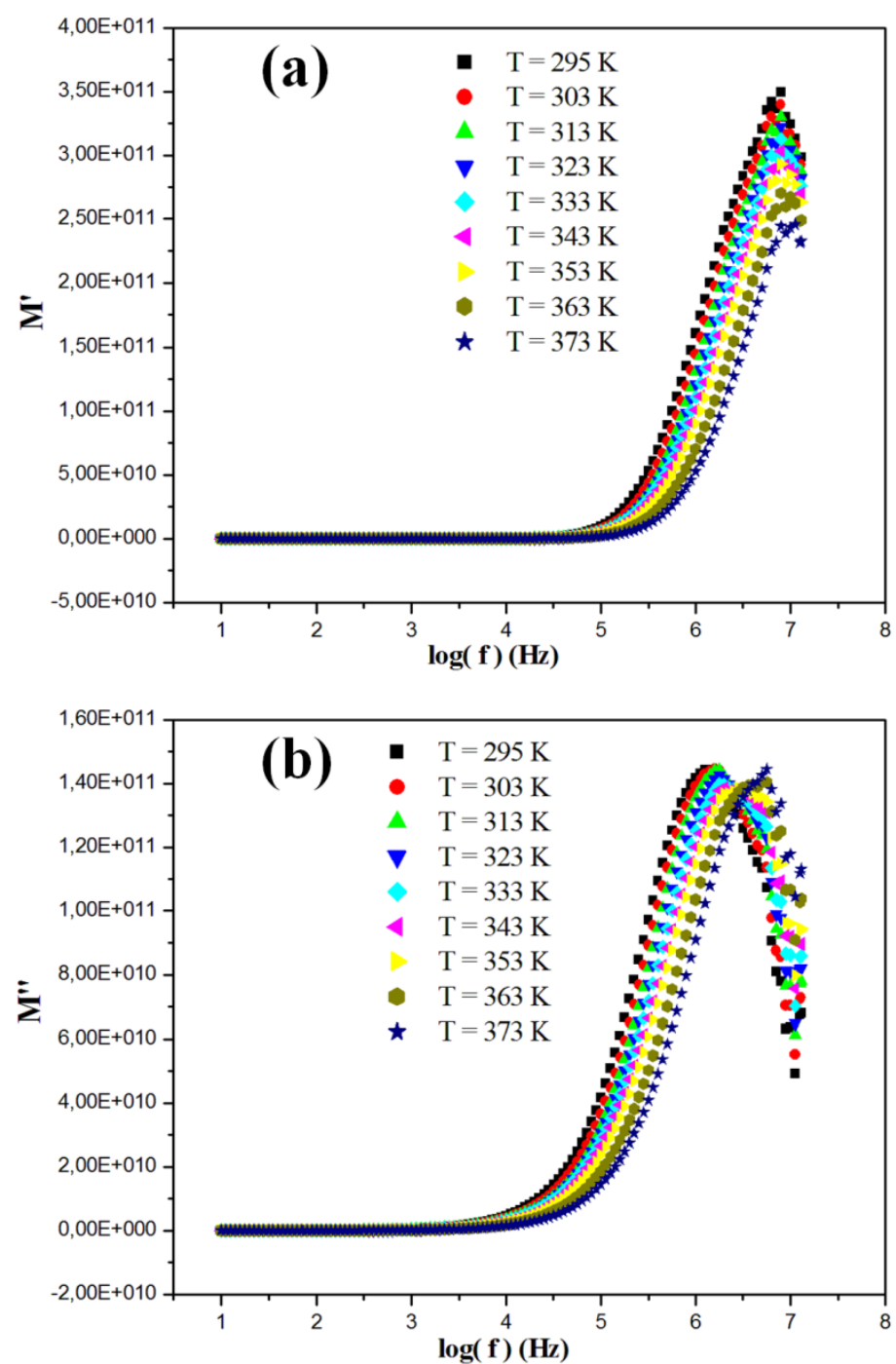

Fig. 9 

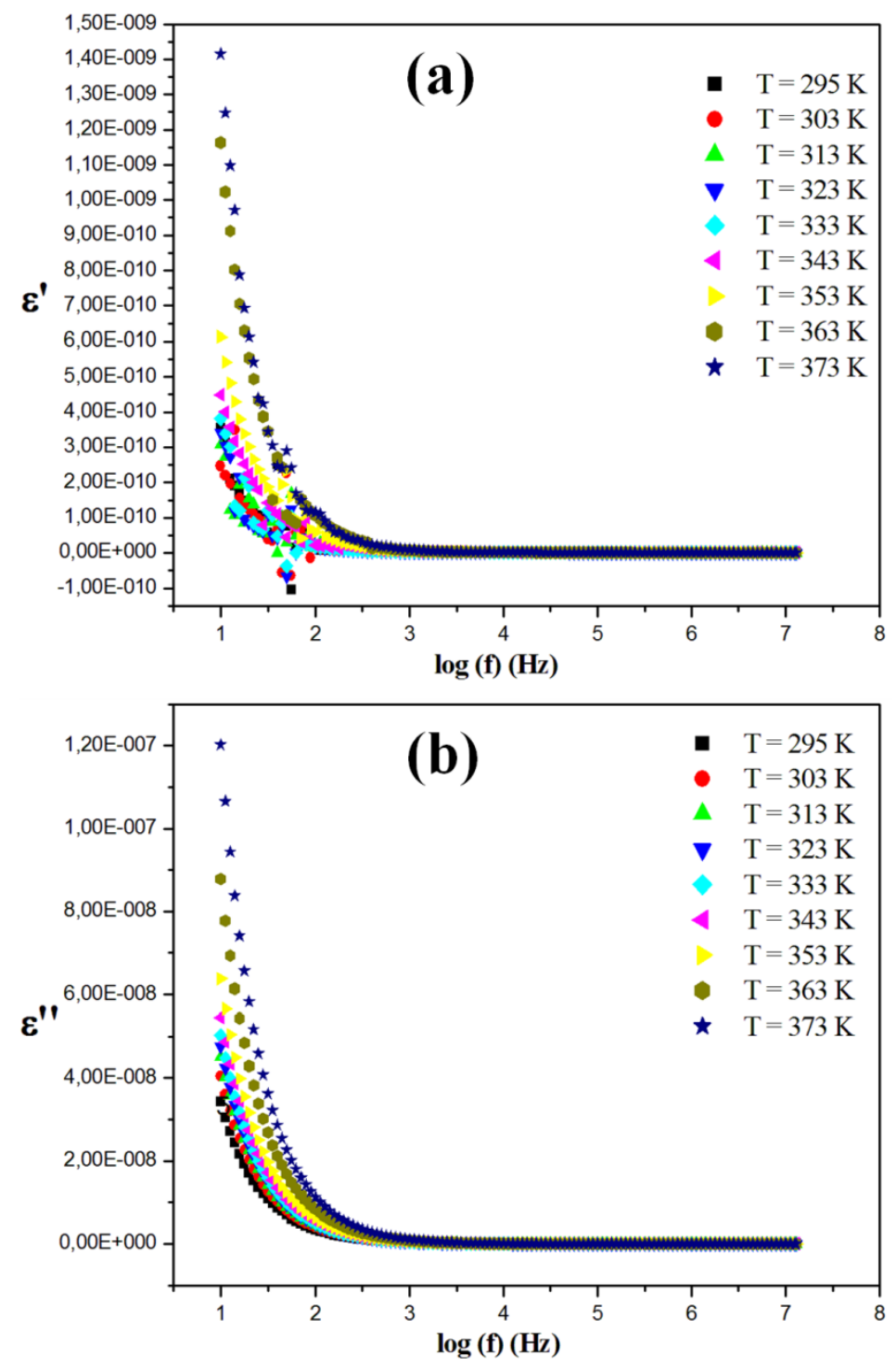

Fig. 10 


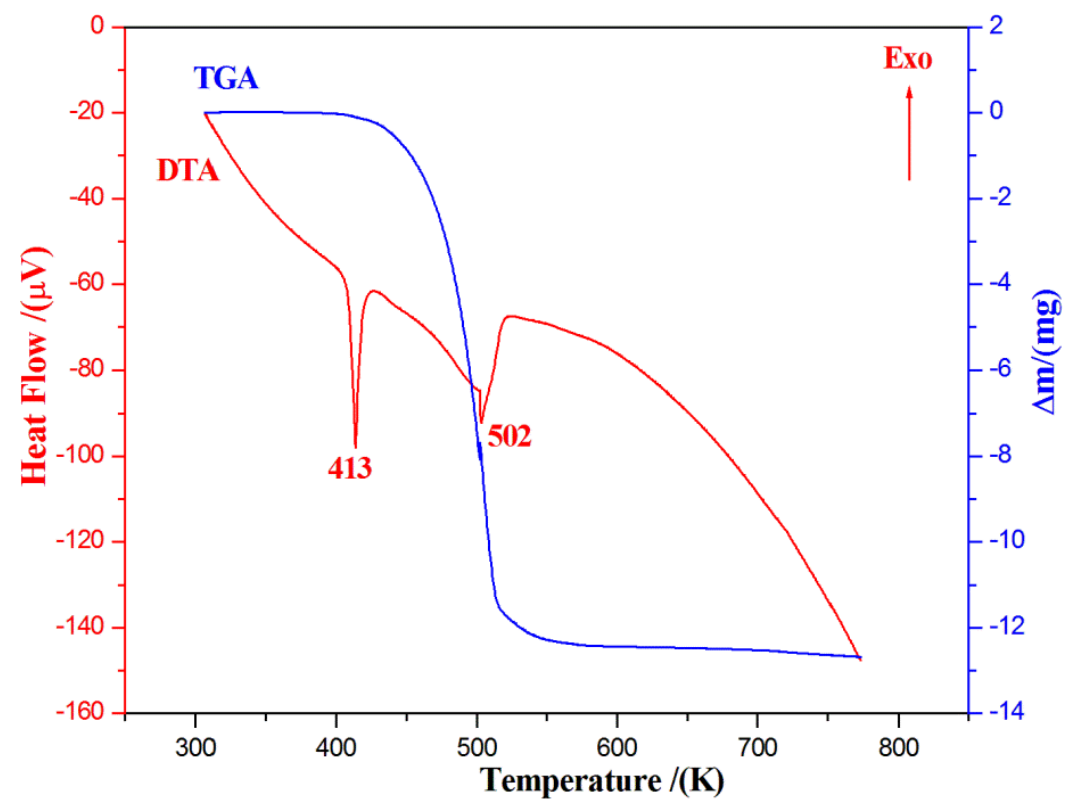

Fig. 11

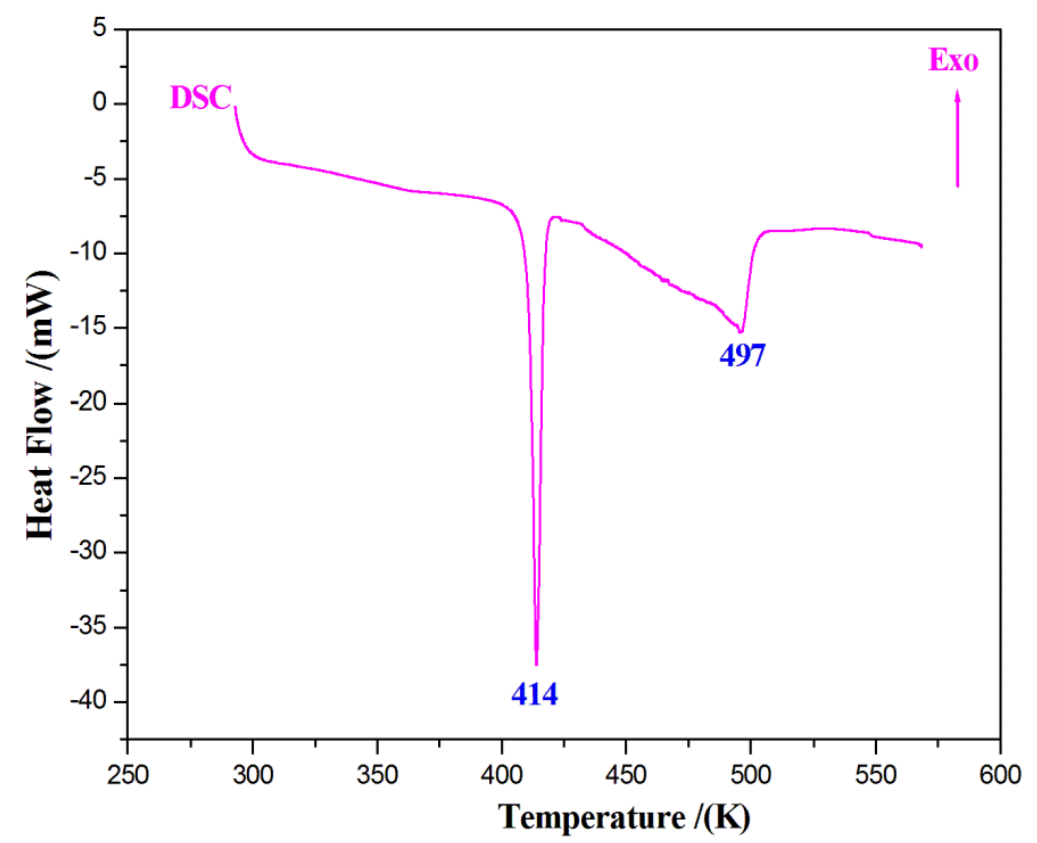

Fig. 12 


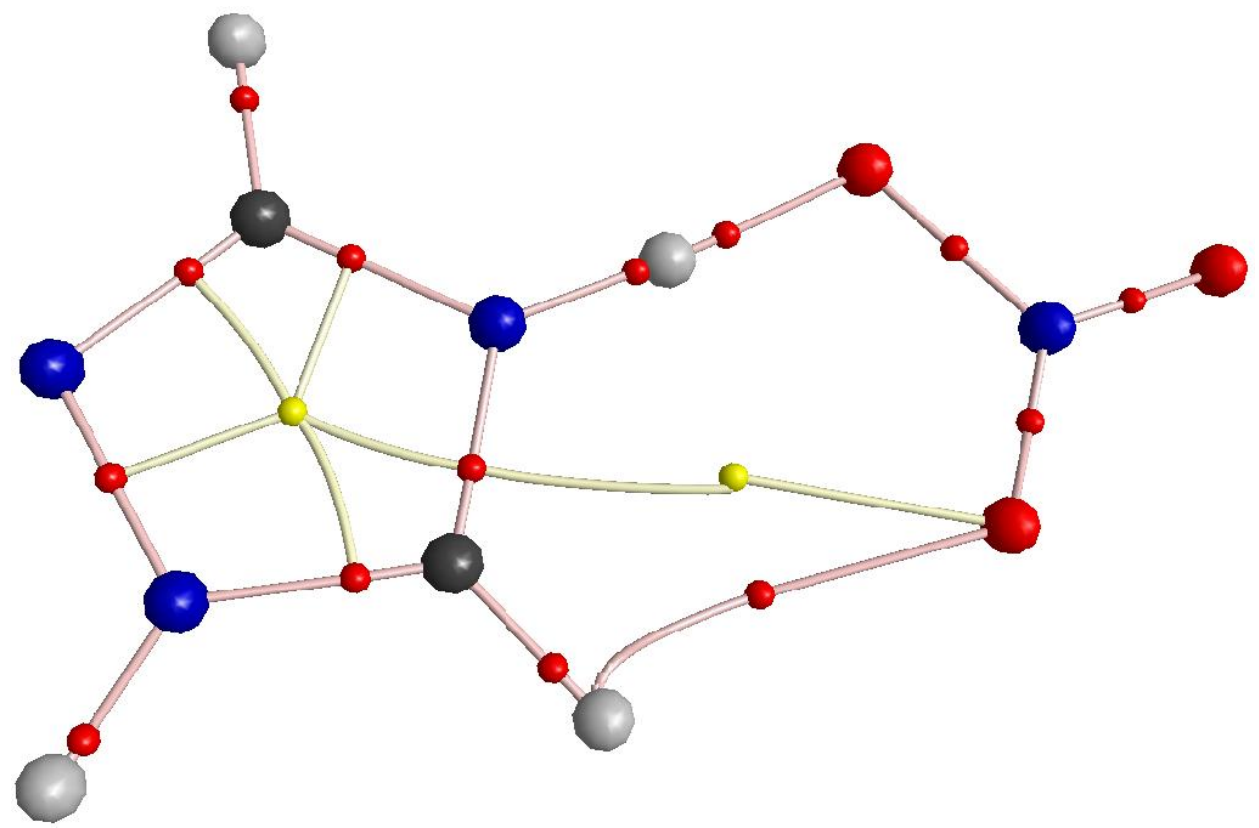

Fig. 13

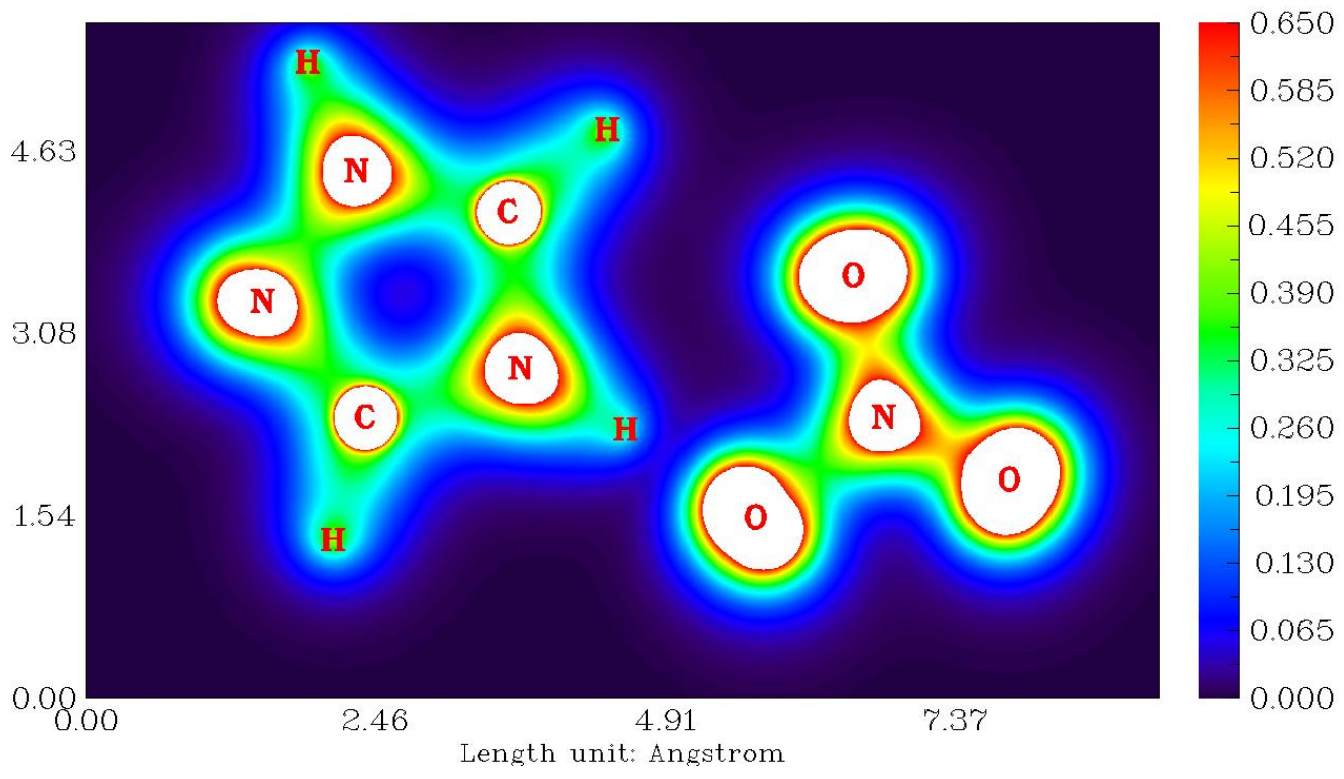

Fig. 14 


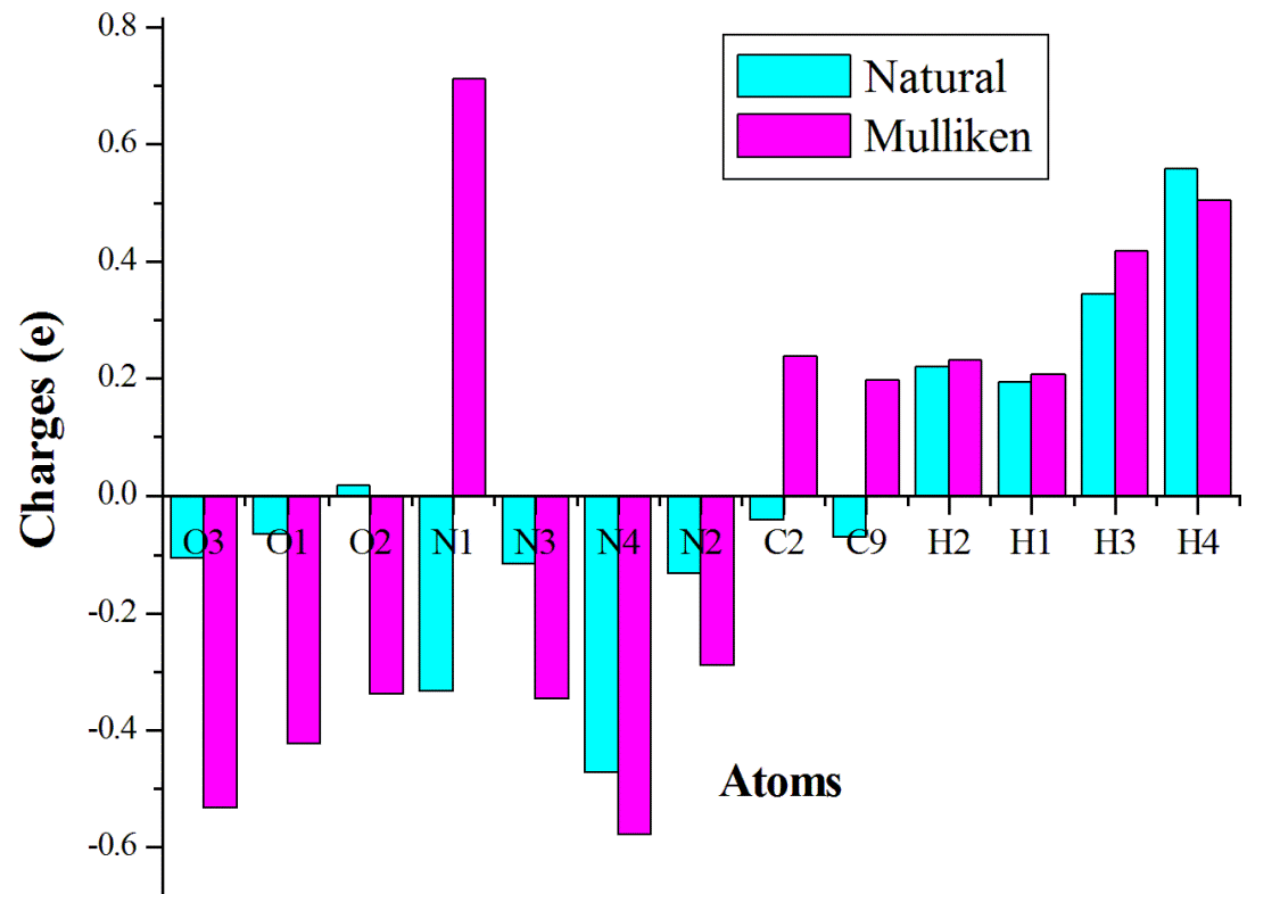

Fig. 15 
HOMO-1

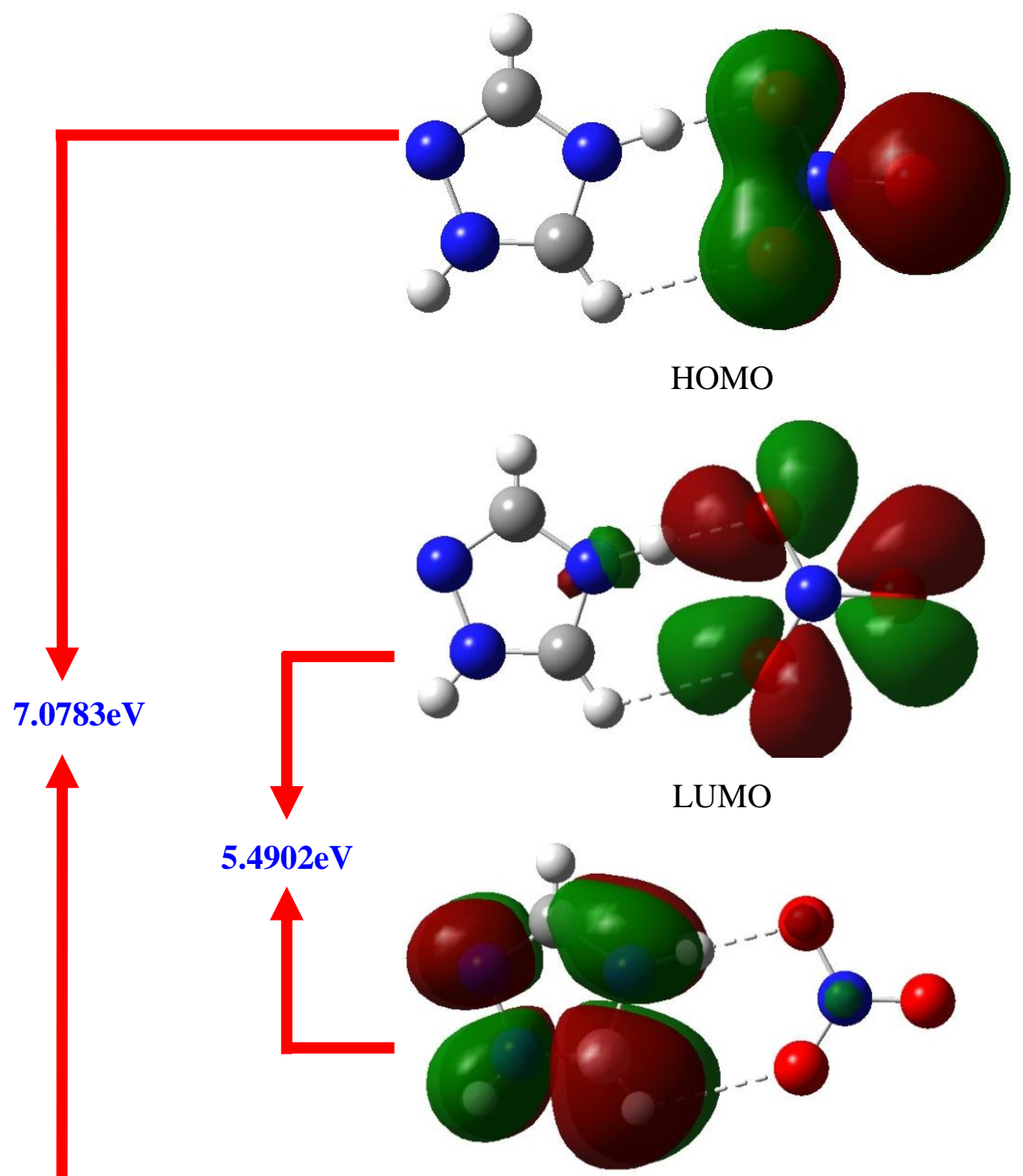

\section{LUMO+1}

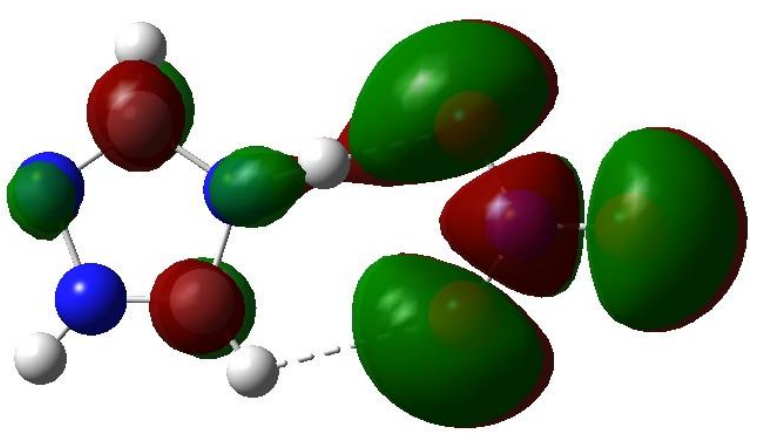

Fig. 16 


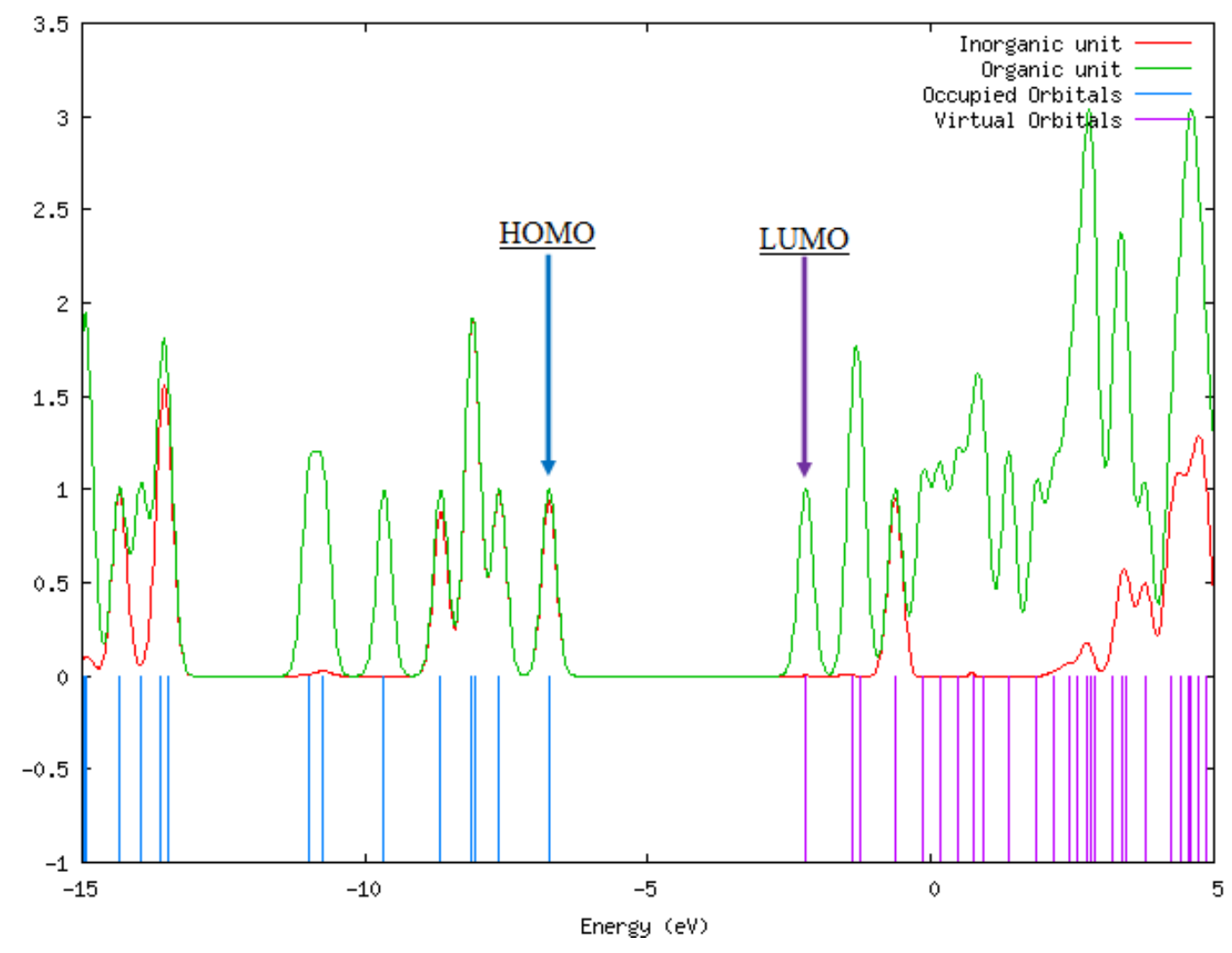

Fig. 17

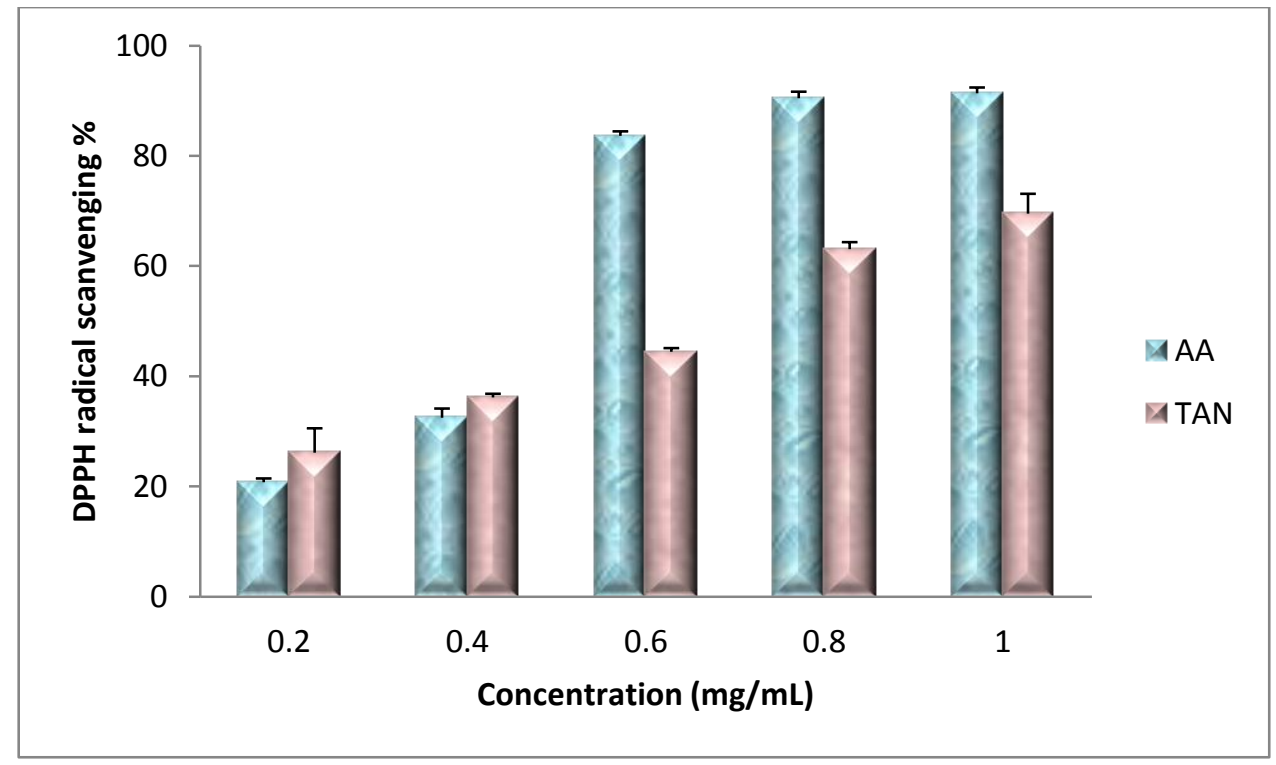

Fig. 18 


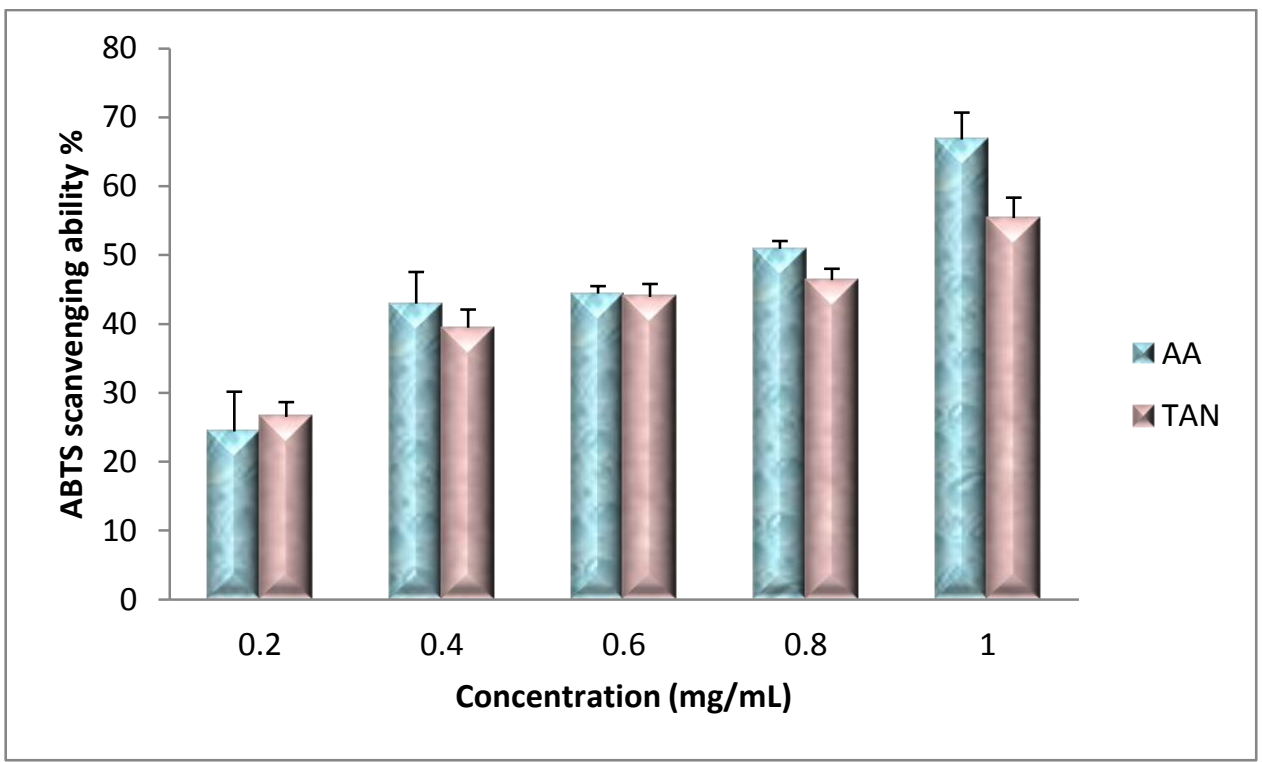

Fig. 19

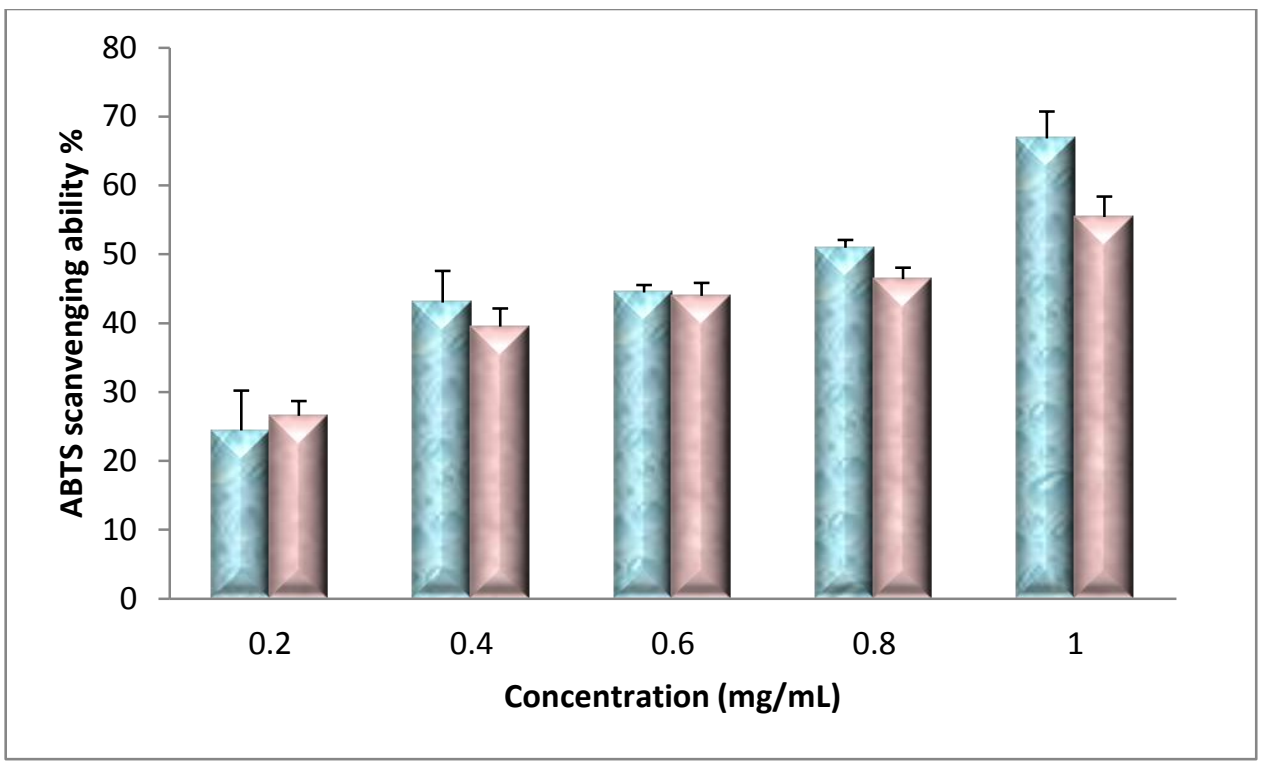

Fig. 20 


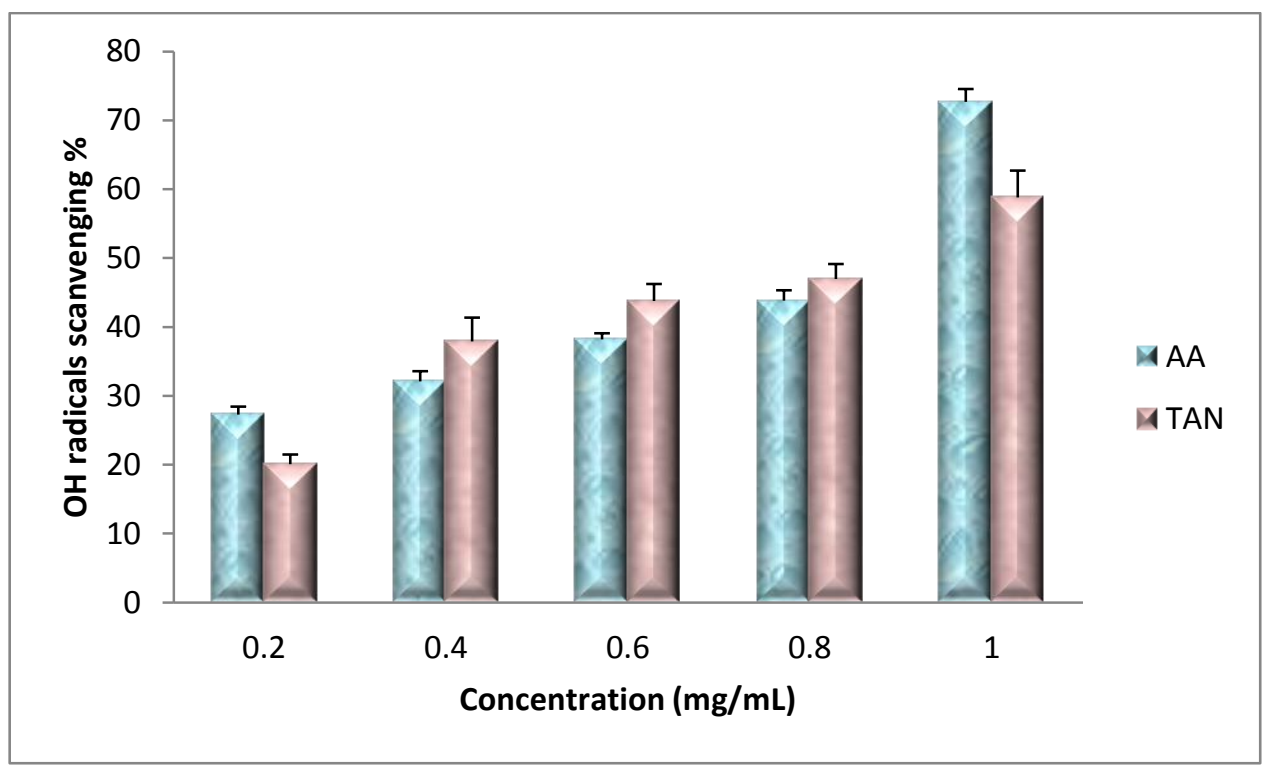

Fig. 21

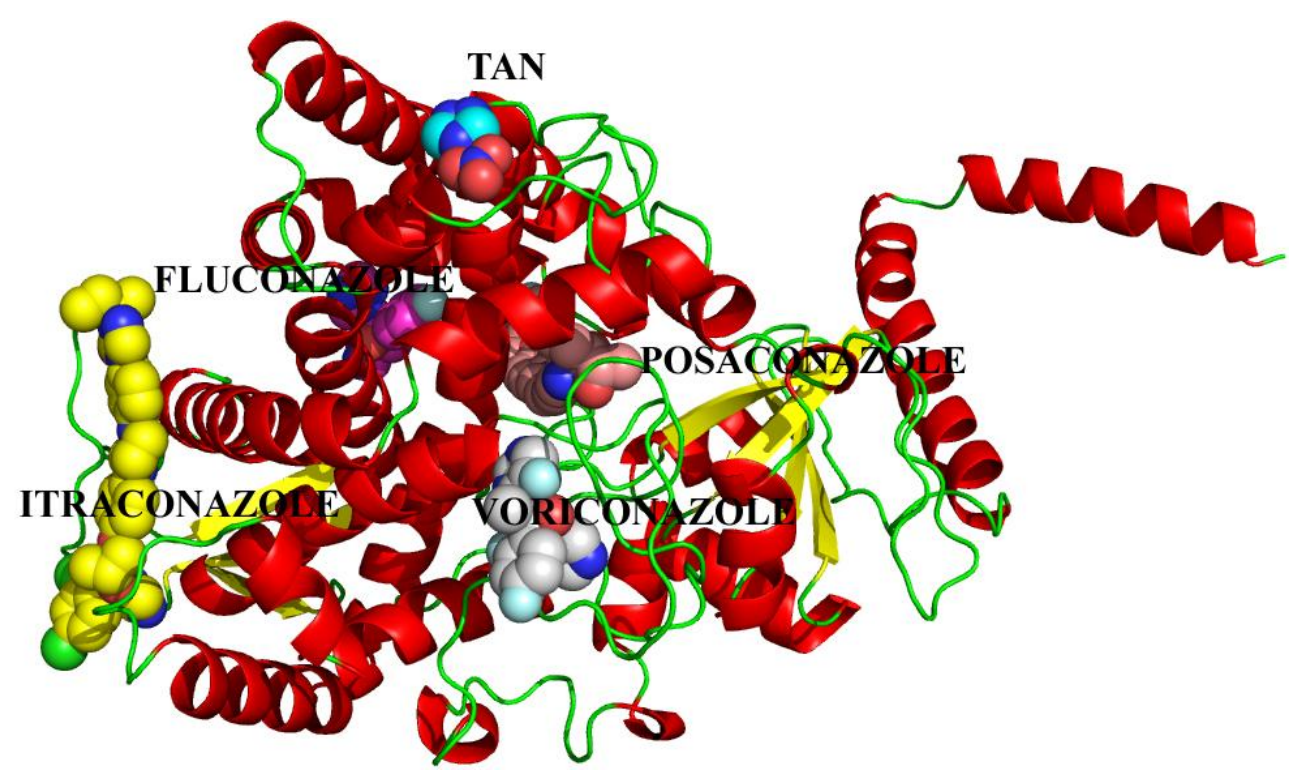

Fig. 22 


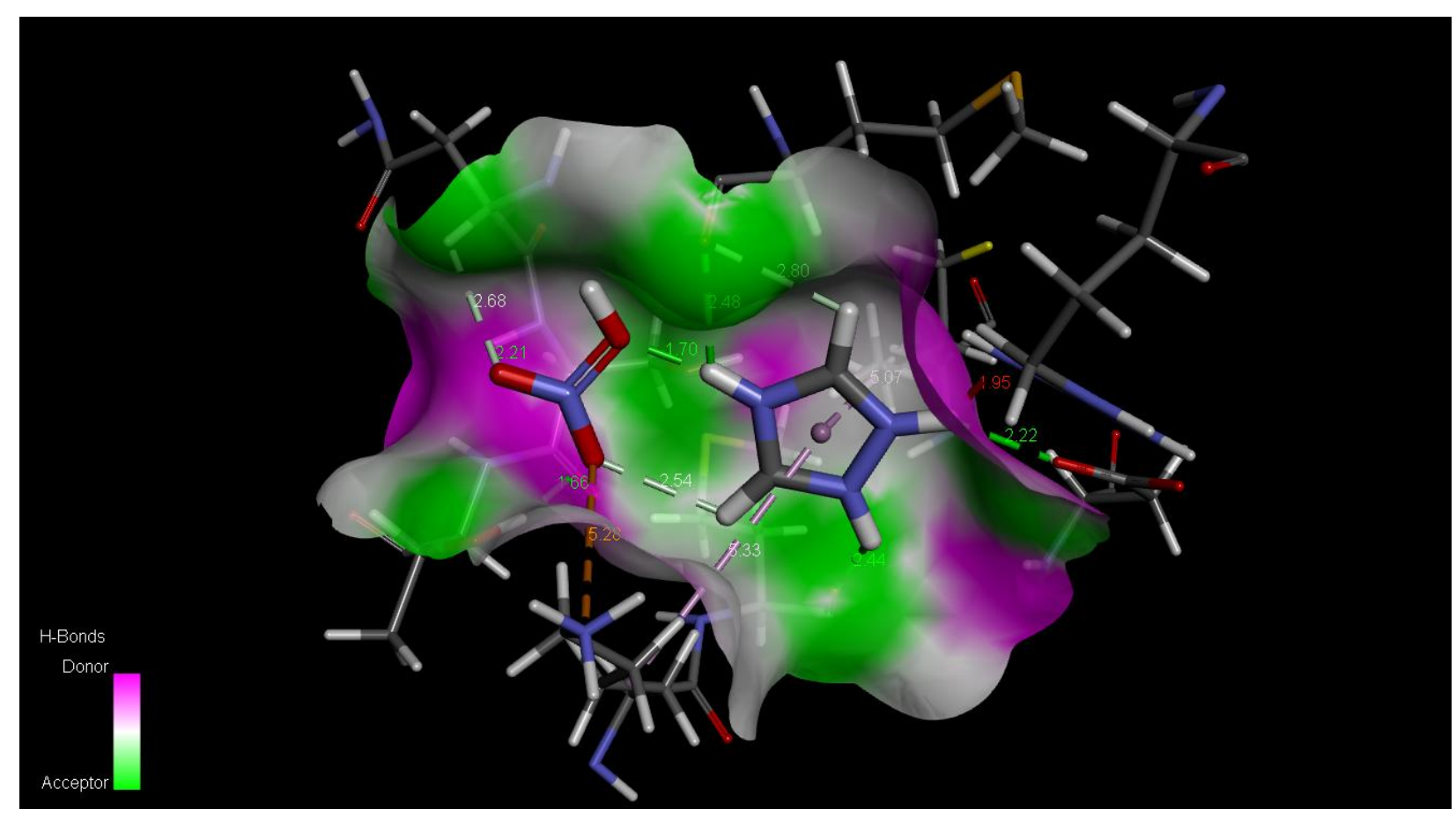

Fig. 23

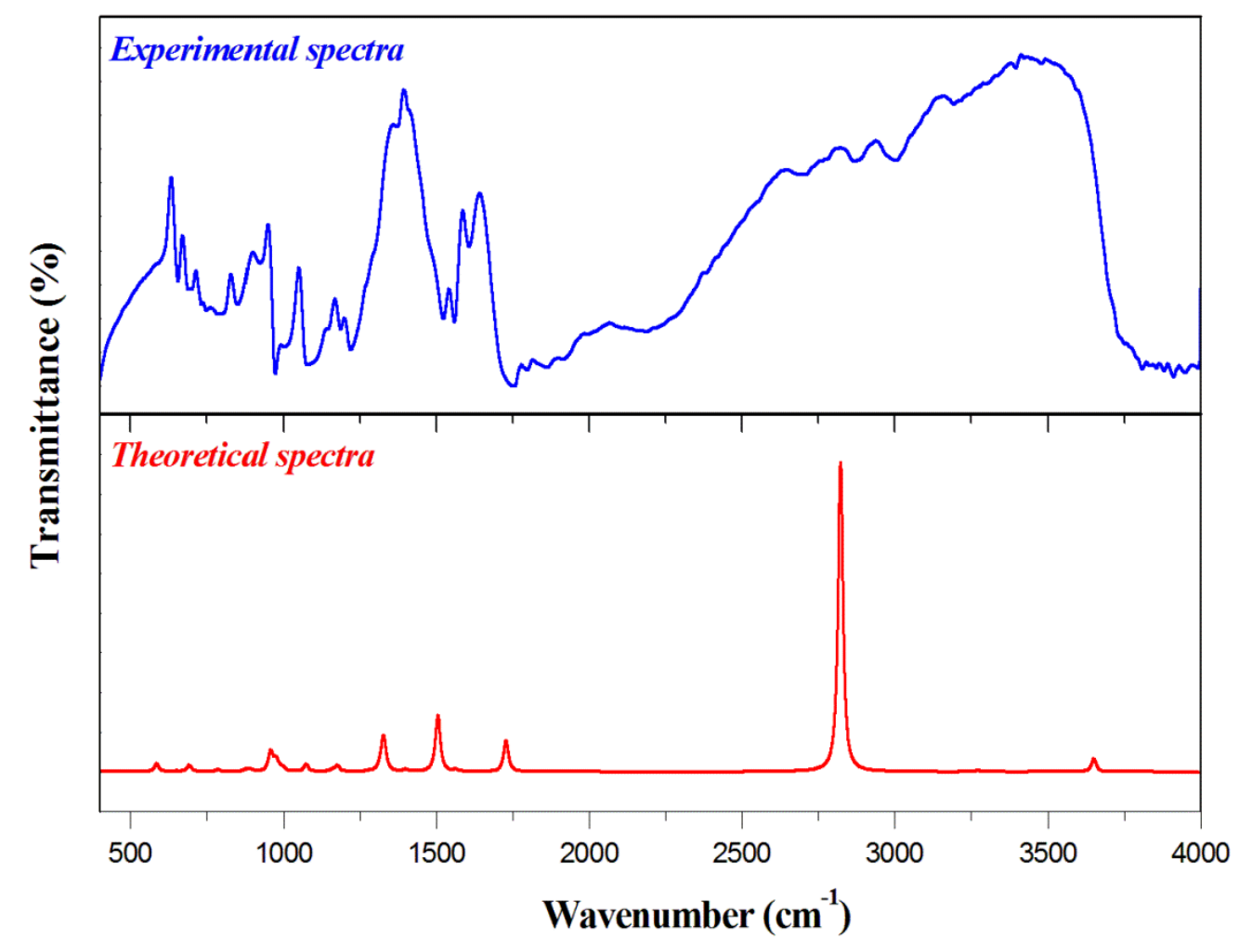

Fig. 24 


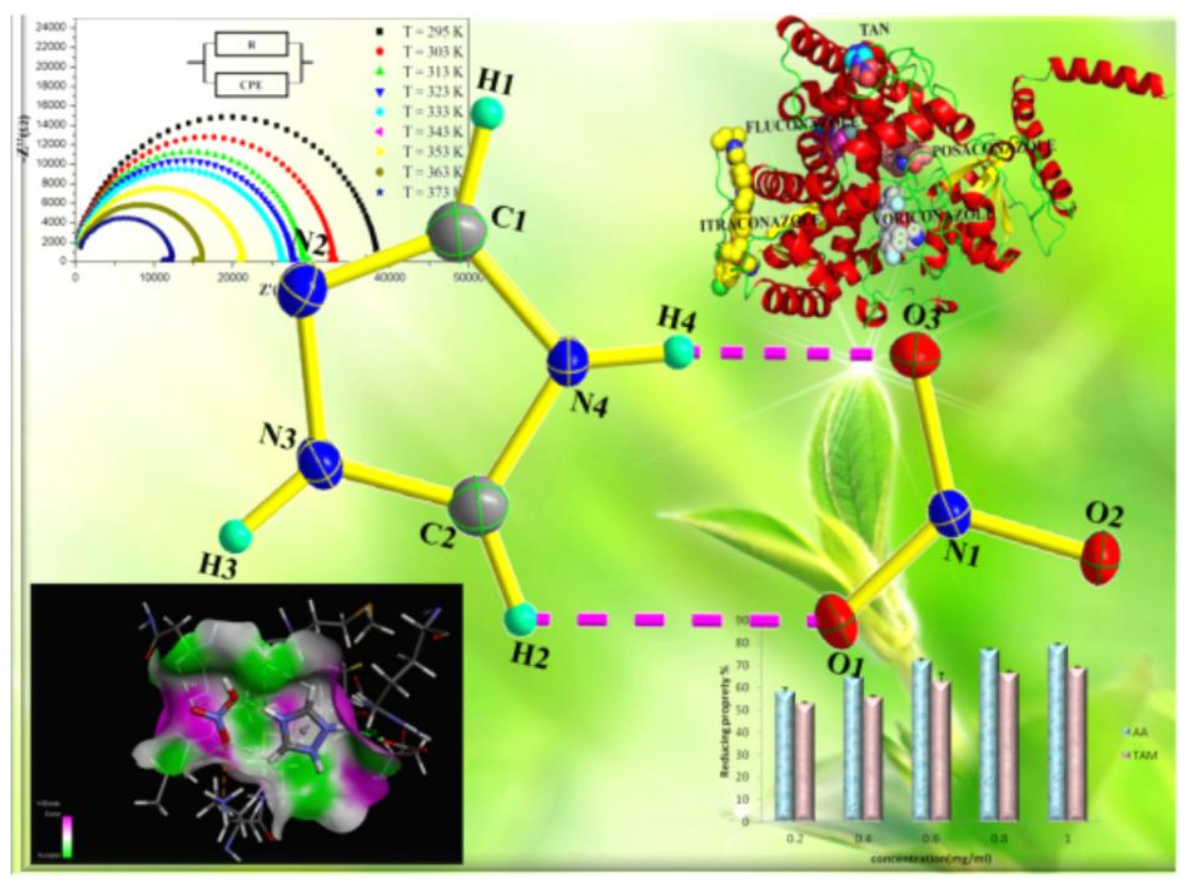

- The atomic arrangement of the synthesized compound shows three-dimensional network.

- The crystal packing stabilized by a set of hydrogen bonds also analyzed by Hirshfeld surface.

- The dielectric measurements show the appearance of relaxation phenomena.

- Investigation of molecular docking characteristics of TAN with saccharomyces cerevisiae CYP51.

- Antioxidant study, in vitro, shows significant scavenging capacity of free radicals (DPPH• and ABTS•). 
Table 1

\begin{tabular}{ll}
\hline CCDC & 1479753 \\
Temperature & $150 \mathrm{~K}$ \\
Empirical formula & $\mathrm{C}_{2} \mathrm{H}_{4} \mathrm{~N}_{4} \mathrm{O}_{3}$ \\
Formula weight $\left(\mathrm{g} \mathrm{mol}^{-1}\right)$ & 132.09 \\
Crystal system & Monoclinic \\
Space group & $\mathrm{P} 2{ }_{1} / \mathrm{c}$ \\
$\mathrm{a}$ & $8.8517(15) \AA$ \\
$\mathrm{b}$ & $8.3791(15) \AA$ \\
$\mathrm{c}$ & $7.1060(11) \AA$ \\
$\beta$ & $103.776(7)^{\circ}$ \\
$\mathrm{Z}$ & 4 \\
$\mathrm{~V}$ & $511.89(15) \AA^{3}$ \\
$\mathrm{~F}(000)$ & 272 \\
$\mu($ Mo K $\alpha)$ & $0.16 \mathrm{~mm}^{-1}$ \\
Index ranges & $-11 \leq \mathrm{h} \leq 11,-10 \leq \mathrm{k} \leq 9,-9 \leq 1 \leq 9$ \\
Reflections collected & 4547 \\
Independent reflections & 1147 \\
Reflections with I $>2 \sigma(\mathrm{I})$ & $9 \rho_{\text {min }}-0.32 \mathrm{e} \AA^{-3}$ \\
$\mathrm{R}_{\text {int }}$ & \\
Absorption correction: multi-scan & $\mathrm{T}_{\min }=0.910, \mathrm{~T}_{\mathrm{max}}=0.989$ \\
Refined parameters & 82 \\
$\mathrm{R}\left[\mathrm{F}^{2}>2 \sigma\left(\mathrm{F}^{2}\right)\right]$ & 0.062 \\
wR $\left(\mathrm{F}^{2}\right)$ & 0.152 \\
Goodness of fit & 1.19 \\
$\Delta \rho_{\text {max }} 0.38$ e $\AA^{-3}$ & 0.063 \\
\hline
\end{tabular}


Table 2

\begin{tabular}{|c|c|c|c|c|}
\hline \multirow[b]{3}{*}{ Parameters' } & \multirow[b]{3}{*}{ X-ray } & \multicolumn{3}{|c|}{ Calculated } \\
\hline & & $\mathrm{HF}$ & B3LYP & M06-2X \\
\hline & & $6-311++G(d, p)$ & $6-311++G(d, p)$ & $6-311++G(d, p)$ \\
\hline \multicolumn{5}{|c|}{ Bond lengths $(\AA)$} \\
\hline $\mathrm{N} 1-\mathrm{O} 3$ & $1.268(3)$ & 1.313 & 1.3706 & 1.3432 \\
\hline N1-O1 & $1.235(3)$ & 1.1908 & 1.2232 & 1.2156 \\
\hline $\mathrm{N} 1-\mathrm{O} 2$ & $1.253(3)$ & 1.1692 & 1.2025 & 1.1928 \\
\hline N3-N2 & $1.361(3)$ & 1.3412 & 1.3565 & 1.3467 \\
\hline $\mathrm{N} 3-\mathrm{C} 2$ & $1.312(3)$ & 1.3225 & 1.3424 & 1.3375 \\
\hline N3-H3 & 0.880 & 0.9931 & 1.0089 & 1.0087 \\
\hline $\mathrm{N} 4-\mathrm{C} 2$ & $1.329(3)$ & 1.3025 & 1.3234 & 1.3191 \\
\hline $\mathrm{N} 4-\mathrm{C} 1$ & $1.356(3)$ & 1.3579 & 1.3657 & 1.3625 \\
\hline N4-H4 & 0.880 & 1.7817 & 1.6702 & 1.6218 \\
\hline $\mathrm{N} 2-\mathrm{C} 1$ & $1.306(3)$ & 1.2885 & 1.3171 & 1.311 \\
\hline $\mathrm{C} 2-\mathrm{H} 2$ & 0.950 & 1.07 & 1.0782 & 1.0783 \\
\hline $\mathrm{C} 1-\mathrm{H} 1$ & 0.950 & 1.0697 & 1.0783 & 1.0779 \\
\hline \multicolumn{5}{|c|}{ Bond angles $\left(^{\circ}\right)$} \\
\hline N1-O3-H4 & 104.1 & 108.0741 & 106.8542 & 106.5849 \\
\hline O3-N1-O1 & $120.42(19)$ & 117.1167 & 117.1125 & 117.0455 \\
\hline $\mathrm{O} 3-\mathrm{N} 1-\mathrm{O} 2$ & 119.24(19) & 115.7194 & 115.3024 & 115.8627 \\
\hline O1-N1-O2 & $120.3(2)$ & 127.1639 & 127.5852 & 127.0917 \\
\hline N2-N3-C2 & $111.7(2)$ & 110.2623 & 110.8911 & 111.0148 \\
\hline N2-N3-H3 & 124.2 & 120.6776 & 119.9834 & 120.0542 \\
\hline C2-N3-H3 & 124.2 & 129.0601 & 129.1255 & 128.9309 \\
\hline $\mathrm{C} 2-\mathrm{N} 4-\mathrm{C} 1$ & $106.5(2)$ & 103.2719 & 103.8342 & 103.8091 \\
\hline C2-N4-H4 & 126.7 & 121.1394 & 121.3439 & 121.5456 \\
\hline C1-N4-H4 & 126.7 & 135.5885 & 134.8219 & 134.645 \\
\hline N3-N2-C1 & $103.6(2)$ & 102.8696 & 102.3326 & 102.5086 \\
\hline $\mathrm{N} 3-\mathrm{C} 2-\mathrm{N} 4$ & $106.9(2)$ & 109.4715 & 108.7777 & 108.6592 \\
\hline N3-C2-H2 & 126.6 & 124.639 & 125.3838 & 125.4218 \\
\hline $\mathrm{N} 4-\mathrm{C} 2-\mathrm{H} 2$ & 126.6 & 125.8895 & 125.8385 & 125.919 \\
\hline $\mathrm{N} 4-\mathrm{C} 1-\mathrm{N} 2$ & $111.4(2)$ & 114.1248 & 114.1644 & 114.0082 \\
\hline
\end{tabular}




\begin{tabular}{|l|l|lll|} 
N4-C1-H1 & 124.3 & 123.3095 & 123.5003 & 123.547 \\
N2-C1-H1 & 124.3 & 122.5657 & 122.3353 & 122.4448 \\
\hline \multicolumn{4}{|l|}{ Torsional Angles ( ${ }^{\circ}$ ) } \\
\hline C2-N3-N2-C1 & $-0.4(3)$ & 0.0221 & -0.0017 & 0.0152 \\
N2-N3-C2-N4 & $0.2(3)$ & -0.0121 & -0.0018 & -0.0142 \\
C1-N4-C2-N3 & $0.2(3)$ & -0.003 & 0.0044 & 0.0065 \\
C2-N4-C1-N2 & $-0.4(3)$ & 0.0183 & -0.0058 & 0.0033 \\
N3-N2-C1-N4 & $0.5(3)$ & -0.0249 & 0.0047 & -0.0113 \\
\hline
\end{tabular}

Table 3

\begin{tabular}{ccccc}
\hline$D-\mathrm{H} \cdots A$ & $D-\mathrm{H}$ & $\mathrm{H} \cdots A$ & $D \cdots A$ & $D-\mathrm{H} \cdots A$ \\
\hline $\mathrm{N} 3-\mathrm{H} 3 \cdots \mathrm{O} 2^{\mathrm{i}}$ & 0.88 & 1.86 & $2.735(3)$ & 179.0 \\
$\mathrm{~N} 4-\mathrm{H} 4 \cdots \mathrm{O} 3$ & 0.88 & 1.90 & $2.772(3)$ & 174.0 \\
$\mathrm{~N} 4-\mathrm{H} 4 \cdots \mathrm{O} 1$ & 0.88 & 2.48 & $2.980(3)$ & 116.5 \\
$\mathrm{C} 1-\mathrm{H} 1 \cdots \mathrm{O} 3^{\mathrm{ii}}$ & 0.95 & 2.31 & $3.022(3)$ & 131.7 \\
$\mathrm{C} 2-\mathrm{H} 2 \cdots \mathrm{O} 1$ & 0.95 & 2.53 & $3.015(3)$ & 112.1 \\
\hline
\end{tabular}

Symmetry code: (i) $\mathrm{x}, \mathrm{y}+1, \mathrm{z}$; (ii) $-\mathrm{x}+1, \mathrm{y}+1 / 2,-\mathrm{z}+1 / 2$. 
Table 4

\begin{tabular}{ccccc}
\hline Enrichment & $\mathrm{H}$ & $\mathrm{N}$ & $\mathrm{O}$ & $\mathrm{C}$ \\
\hline $\mathrm{H}$ & 0.33 & 1.44 & 1.68 & 0.73 \\
$\mathrm{~N}$ & & 1.33 & 0.28 & 1.69 \\
$\mathrm{O}$ & & & 0.5 & 0.27 \\
$\mathrm{C}$ & & & & 13.33 \\
\hline \% Surface & 45.85 & 14.2 & 37.45 & 2.5 \\
\hline
\end{tabular}

Table 5

\begin{tabular}{|c|c|c|c|c|c|c|c|c|c|c|c|}
\hline & $\rho(\mathbf{r})$ & $\nabla_{\rho(\mathbf{r})}^{2}$ & $\begin{array}{c}\text { H } \\
(\mathrm{kcal} / \mathrm{mol})\end{array}$ & $\begin{array}{c}\text { G(kcal/m } \\
\text { ol) }\end{array}$ & $\mathrm{V}(\mathrm{kcal} / \mathrm{mol})$ & $\mathrm{G}+\mathrm{V}$ & $\begin{array}{c}\mathrm{E}_{\text {int }} \\
(\mathrm{kcal} / \mathrm{mol})\end{array}$ & $\lambda_{1}$ & $\lambda_{2}$ & $\lambda_{3}$ & $\varepsilon$ \\
\hline N1-O3 & 0.3535 & $\begin{array}{l}-0.5483 \\
\end{array}$ & -191.5544 & 105.542 & -297.0964 & -191.5544 & -148.5482 & -0.9467 & -0.9405 & 1.3339 & 0.0069 \\
\hline N1-O1 & 0.5003 & -1.5444 & -388.7022 & 146.4108 & -535.1130 & -388.7022 & -267.5565 & -1.5281 & -1.5244 & 1.5081 & 0.0024 \\
\hline N1-O2 & 0.5265 & -1.3856 & -431.745 & 214.3765 & -646.1213 & -413.7448 & -323.0606 & -1.6411 & -1.260 & 1.5154 & 0.3027 \\
\hline $\mathrm{O} 1 \ldots \mathrm{H} 2$ & 0.0106 & 0.04566 & 1.038 & 6.125 & -5.087 & 1.038 & 2.5435 & -0.01003 & $\begin{array}{l}-0.0077 \\
\end{array}$ & 0.06344 & 0.2938 \\
\hline $\mathrm{O} 3 \ldots \mathrm{H} 4$ & 0.0571 & 0.64603 & 1.2408 & 100.1063 & -98.86546 & 1.2408 & -49.4327 & -0.1500 & -0.13258 & 0.92863 & 0.1315 \\
\hline N4-H4 & 0.2954 & -2.1172 & -350.4750 & 18.3351 & -368.8099 & -350.4744 & -184.405 & -1.4290 & -1.3808 & 0.6923 & 0.03476 \\
\hline $\mathrm{RCP}$ (cyclic) & 0.0531 & 0.4145 & 2.2350 & 62.7844 & -60.5495 & 2.235 & 30.2747 & -0.04911 & 0.2163 & 0.2472 & -1.2270 \\
\hline NRCP & 0.0085 & 0.0426 & 0.9331 & 5.7474 & -4.8143 & 0.9331 & -2.4071 & -0.0066 & 0.0065 & 0.0428 & -2.0299 \\
\hline $\mathrm{C} 2-\mathrm{H} 2$ & 0.2884 & -1.0579 & -178.5511 & 11.9293 & -190.4804 & -178.5511 & -95.2402 & -0.8508 & -0.8507 & 0.6436 & 0.00004 \\
\hline C1-H1 & 0.2896 & -1.0336 & -178.9783 & 16.1819 & -195.1602 & -178.9783 & -97.5801 & -0.8376 & -0.8223 & 0.6262 & 0.0260 \\
\hline N3-H3 & 0.0345 & -1.8711 & -315.965 & 22.427 & -338.3916 & -315.9646 & -169.196 & -1.3709 & -1.3361 & 0.8359 & 0.02603 \\
\hline N3-N2 & 0.3615 & $\begin{array}{l}-0.8842 \\
\end{array}$ & -0.8842 & -222.1461 & 82.8857 & -305.0318 & -222.1461 & -0.9275 & -0.91635 & 0.9596 & 0.0126 \\
\hline N3-C2 & 0.3239 & $\begin{array}{l}-0.8992 \\
\end{array}$ & -0.8992 & -292.5594 & 150.9399 & -443.4993 & -292.5594 & -0.7516 & -0.6282 & 0.48067 & 0.1963 \\
\hline C2- N4 & 0.3520 & -1.3739 & -1.3739 & -311.2299 & 94.8450 & -406.0749 & -311.2299 & -0.9137 & -0.8677 & 0.40757 & 0.05303 \\
\hline C9-N7 & 0.3552 & -0.9525 & -0.9525 & -337.0370 & 187.0159 & -524.0530 & -337.0370 & -0.8694 & -0.6186 & 0.53557 & 0.4054 \\
\hline C9- N6 & 0.3191 & -1.1310 & -1.1310 & -269.2007 & 91.0670 & -360.2676 & -269.2007 & -0.7511 & $\begin{array}{l}-0.7381 \\
\end{array}$ & 0.3583 & 0.0176 \\
\hline
\end{tabular}

Table 6

\begin{tabular}{ccccc}
\hline Donor NBO (i) & Acceptor NBO (j) & $\mathrm{E}(2)^{\mathrm{a}}$ & $\mathrm{E}(\mathrm{j})-\mathrm{E}(\mathrm{i})^{\mathrm{b}}$ a.u. & $\mathrm{F}(\mathrm{i}, \mathrm{j})^{\mathrm{c}}$ a.u. \\
\hline$\pi(\mathrm{O} 2-\mathrm{N} 1)$ & $\pi^{*}(\mathrm{O} 2-\mathrm{N} 1)$ & 9.85 & 0.33 & 0.062 \\
LP (1) O3 & $\sigma^{*}(\mathrm{O} 1-\mathrm{N} 1)$ & 5.79 & 1.09 & 0.072 \\
LP (2) O3 & $\sigma^{*}(\mathrm{O} 1-\mathrm{N} 1)$ & 1.84 & 0.87 & 0.037 \\
LP (2) O3 & $\sigma^{*}(\mathrm{O} 2-\mathrm{N} 1)$ & 7.62 & 0.92 & 0.077 \\
LP (3) O3 & $\pi^{*}(\mathrm{O} 2-\mathrm{N} 1)$ & 55.45 & 0.16 & 0.094 \\
LP (1) O1 & $\sigma^{*}(\mathrm{O} 3-\mathrm{N} 1)$ & 2.05 & 1.02 & 0.042 \\
LP (1) O1 & $\sigma^{*}(\mathrm{O} 2-\mathrm{N} 1)$ & 4.13 & 1.29 & 0.066 \\
LP (2) O1 & $\sigma^{*}(\mathrm{O} 3-\mathrm{N} 1)$ & 21.51 & 0.51 & 0.094 \\
LP (2) O1 & $\sigma^{*}(\mathrm{O} 2-\mathrm{N} 1)$ & 16.42 & 0.78 & 0.102 \\
LP (3) O1 & $\pi^{*}(\mathrm{O} 2-\mathrm{N} 1)$ & 129.69 & 0.17 & 0.138
\end{tabular}




\begin{tabular}{|c|c|c|c|c|}
\hline $\mathrm{LP}(1) \mathrm{O} 2$ & $\sigma^{*}(\mathrm{O} 3-\mathrm{N} 1)$ & 1.94 & 1.00 & 0.041 \\
\hline $\mathrm{LP}(1) \mathrm{O} 2$ & $\sigma^{*}(\mathrm{O} 1-\mathrm{N} 1)$ & 4.69 & 1.22 & 0.068 \\
\hline $\mathrm{LP}(2) \mathrm{O} 2$ & $\sigma^{*}(\mathrm{O} 3-\mathrm{N} 1)$ & 25.35 & 0.49 & 0.100 \\
\hline $\mathrm{LP}(2) \mathrm{O} 2$ & $\sigma^{*}(\mathrm{O} 1-\mathrm{N} 1)$ & 18.61 & 0.71 & 0.104 \\
\hline $\mathrm{LP}(1) \mathrm{O} 3$ & $\sigma^{*}(\mathrm{~N} 4-\mathrm{H} 4)$ & 7.58 & 1.09 & 0.084 \\
\hline $\mathrm{LP}(2) \mathrm{O} 3$ & $\sigma^{*}(\mathrm{~N} 4-\mathrm{H} 4)$ & 97.33 & 0.86 & 0.260 \\
\hline$\sigma(\mathrm{N} 3-\mathrm{N} 2)$ & $\sigma^{*}(\mathrm{~N} 4-\mathrm{C} 1)$ & 1.21 & 1.32 & 0.036 \\
\hline$\sigma(\mathrm{N} 3-\mathrm{N} 2)$ & $\sigma^{*}(\mathrm{C} 2-\mathrm{H} 2)$ & 1.79 & 1.28 & 0.043 \\
\hline$\sigma(\mathrm{N} 3-\mathrm{N} 2)$ & $\sigma^{*}(\mathrm{C} 1-\mathrm{H} 1)$ & 3.14 & 1.29 & 0.057 \\
\hline$\sigma(\mathrm{N} 3-\mathrm{C} 2)$ & $\sigma^{*}(\mathrm{~N} 4-\mathrm{H} 4)$ & 1.90 & 1.39 & 0.048 \\
\hline$\pi(\mathrm{N} 3-\mathrm{C} 2)$ & LP (1) N4 & 15.49 & 0.13 & 0.070 \\
\hline$\pi(\mathrm{N} 3-\mathrm{C} 2)$ & $\pi^{*}(\mathrm{~N} 2-\mathrm{C} 1)$ & 11.71 & 0.37 & 0.062 \\
\hline$\sigma(\mathrm{N} 3-\mathrm{H} 3)$ & $\sigma^{*}(\mathrm{~N} 4-\mathrm{C} 2)$ & 1.16 & 1.23 & 0.034 \\
\hline$\sigma(\mathrm{N} 3-\mathrm{H} 3)$ & $\sigma^{*}(\mathrm{~N} 2-\mathrm{C} 1)$ & 1.82 & 1.26 & 0.043 \\
\hline$\sigma(\mathrm{N} 4-\mathrm{C} 2)$ & $\sigma^{*}(\mathrm{~N} 3-\mathrm{H} 3)$ & 2.77 & 1.23 & 0.052 \\
\hline$\sigma(\mathrm{N} 4-\mathrm{C} 2)$ & $\sigma^{*}(\mathrm{~N} 4-\mathrm{C} 1)$ & 1.20 & 1.30 & 0.035 \\
\hline$\sigma(\mathrm{N} 4-\mathrm{C} 2)$ & $\sigma^{*}(\mathrm{~N} 4-\mathrm{H} 4)$ & 1.35 & 1.36 & 0.040 \\
\hline$\sigma(\mathrm{N} 4-\mathrm{C} 2)$ & $\sigma^{*}(\mathrm{C} 2-\mathrm{H} 1)$ & 3.01 & 1.27 & 0.055 \\
\hline$\sigma(\mathrm{N} 4-\mathrm{C} 1)$ & $\sigma^{*}(\mathrm{~N} 3-\mathrm{C} 2)$ & 1.46 & 1.28 & 0.039 \\
\hline$\sigma(\mathrm{N} 4-\mathrm{C} 1)$ & $\sigma^{*}(\mathrm{~N} 4-\mathrm{C} 2)$ & 1.31 & 1.32 & 0.037 \\
\hline$\sigma(\mathrm{N} 4-\mathrm{C} 1)$ & $\sigma^{*}(\mathrm{~N} 4-\mathrm{H} 4)$ & 1.20 & 1.32 & 0.037 \\
\hline$\sigma(\mathrm{N} 4-\mathrm{C} 1)$ & $\sigma^{*}(\mathrm{C} 2-\mathrm{H} 2)$ & 3.94 & 1.23 & 0.062 \\
\hline$\sigma(\mathrm{N} 4-\mathrm{H} 4)$ & $\sigma^{*}(\mathrm{~N} 3-\mathrm{C} 2)$ & 1.97 & 1.13 & 0.042 \\
\hline$\sigma(\mathrm{N} 4-\mathrm{H} 4)$ & $\sigma^{*}(\mathrm{~N} 4-\mathrm{C} 2)$ & 1.45 & 1.17 & 0.037 \\
\hline$\sigma(\mathrm{N} 4-\mathrm{H} 4)$ & $\sigma^{*}(\mathrm{~N} 4-\mathrm{H} 4)$ & 1.63 & 1.18 & 0.041 \\
\hline$\sigma(\mathrm{N} 4-\mathrm{H} 4)$ & $\sigma^{*}(\mathrm{~N} 2-\mathrm{C} 1)$ & 1.72 & 1.20 & 0.041 \\
\hline$\sigma(\mathrm{N} 2-\mathrm{C} 1)$ & $\sigma^{*}(\mathrm{~N} 3-\mathrm{H} 3)$ & 3.47 & 1.25 & 0.059 \\
\hline$\sigma(\mathrm{N} 2-\mathrm{C} 1)$ & $\sigma^{*}(\mathrm{~N} 4-\mathrm{H} 4)$ & 1.64 & 1.37 & 0.044 \\
\hline$\pi(\mathrm{N} 2-\mathrm{C} 1)$ & LP (1) N4 & 33.28 & 0.08 & 0.077 \\
\hline$\pi(\mathrm{N} 2-\mathrm{C} 1)$ & $\pi^{*}(\mathrm{~N} 3-\mathrm{C} 2)$ & 11.97 & 0.27 & 0.056 \\
\hline$\sigma(\mathrm{C} 2-\mathrm{H} 2)$ & $\sigma^{*}(\mathrm{~N} 3-\mathrm{N} 2)$ & 3.10 & 0.94 & 0.048 \\
\hline$\sigma(\mathrm{C} 2-\mathrm{H} 2)$ & $\sigma^{*}(\mathrm{~N} 4-\mathrm{C} 1)$ & 2.66 & 1.03 & 0.047 \\
\hline$\sigma(\mathrm{C} 1-\mathrm{H} 1)$ & $\sigma^{*}(\mathrm{~N} 3-\mathrm{N} 2)$ & 2.96 & 0.91 & 0.046 \\
\hline$\sigma(\mathrm{C} 1-\mathrm{H} 1)$ & $\sigma^{*}(\mathrm{~N} 4-\mathrm{C} 2)$ & 2.72 & 1.05 & 0.048 \\
\hline LP (1) N4 & $\pi^{*}(\mathrm{~N} 3-\mathrm{C} 2)$ & 98.21 & 0.19 & 0.125 \\
\hline LP (1) N4 & $\pi^{*}(\mathrm{~N} 2-\mathrm{C} 1)$ & 48.89 & 0.24 & 0.105 \\
\hline $\mathrm{LP}(1) \mathrm{N} 2$ & $\sigma^{*}(\mathrm{~N} 3-\mathrm{C} 2)$ & 6.02 & 0.89 & 0.066 \\
\hline $\mathrm{LP}(1) \mathrm{N} 2$ & $\sigma^{*}(\mathrm{~N} 3-\mathrm{H} 3)$ & 1.06 & 0.81 & 0.027 \\
\hline LP (1) N2 & $\sigma^{*}(\mathrm{~N} 4-\mathrm{C} 1)$ & 5.37 & 0.88 & 0.062 \\
\hline LP (1) N2 & $\sigma^{*}(\mathrm{C} 1-\mathrm{H} 1)$ & 1.24 & 0.85 & 0.029 \\
\hline$\pi^{*}(\mathrm{~N} 3-\mathrm{C} 2)$ & $\pi^{*}(\mathrm{~N} 2-\mathrm{C} 1)$ & 20.06 & 0.05 & 0.047 \\
\hline$\sigma^{*}(\mathrm{~N} 4-\mathrm{H} 4)$ & $\sigma^{*}(\mathrm{~N} 2-\mathrm{C} 1)$ & 10.01 & 0.03 & 0.048 \\
\hline
\end{tabular}

${ }^{a} \mathrm{E}(2)$ means energy of hyper conjugative interaction (stabilization energy).

${ }^{\mathrm{b}}$ Energy difference between donor and acceptor $\mathrm{i}$ and $\mathrm{j}$ NBO orbitals.

${ }^{c} \mathrm{~F}(\mathrm{i}, \mathrm{j})$ is the Fock matrix element between $\mathrm{i}$ and $\mathrm{j}$ NBO orbitals. 
Table 7

\begin{tabular}{|c|c|c|c|c|c|c|}
\hline \multirow[b]{2}{*}{ D-H...A } & \multicolumn{3}{|c|}{ Natural atomic charges } & \multicolumn{3}{|c|}{ Mulliken atomic charges } \\
\hline & $\mathbf{D}$ & $\mathbf{H}$ & $\mathbf{A}$ & $\mathbf{D}$ & $\mathbf{H}$ & $\mathbf{A}$ \\
\hline $\mathrm{N} 3-\mathrm{H} 3 \ldots \mathrm{O} 2$ & -0.34630 & 0.41798 & -0.33835 & -0.115122 & 0.344559 & 0.016329 \\
\hline N4-H4 ...O3 & -0.57875 & 0.50450 & -0.53266 & -0.472341 & 0.558855 & -0.105591 \\
\hline $\mathrm{N} 4-\mathrm{H} 4 \ldots \mathrm{O} 1$ & 0.57875 & 0.50450 & -0.42330 & -0.472341 & 0.558855 & -0.064319 \\
\hline $\mathrm{C} 1-\mathrm{H} 1 \ldots \mathrm{O} 3$ & 0.19706 & 0.20710 & -0.53266 & -0.070049 & 0.193962 & -0.105591 \\
\hline $\mathrm{C} 2-\mathrm{H} 2 \ldots \mathrm{O} 1$ & 0.23705 & 0.23192 & -0.42330 & -0.040496 & 0.218771 & -0.064319 \\
\hline
\end{tabular}

Table 8

\begin{tabular}{cccccc}
\hline Parameters & \multicolumn{5}{c}{ TD-DFT } \\
\cline { 2 - 5 }$(\mathrm{eV})$ & Gas & DMSO & Water & Methanol & Ethanol \\
\hline $\mathrm{E}_{\text {HOMO }}$ & -7.0959 & -7.0823 & -7.0959 & -7.0676 & -7.0526 \\
$\mathrm{E}_{\text {LUMO }}$ & -1.6057 & -1.6196 & -1.6057 & -1.6349 & -1.6504 \\
$\Delta \mathrm{E}_{\text {(HOMO } ~ \text { LUMO) }}$ & -5.4902 & -5.4627 & -5.4902 & -5.4327 & -5.4022 \\
$\mathrm{E}_{\text {HOMO-1 }}$ & -8.2622 & -8.2475 & -9.1512 & -8.2314 & -8.2151 \\
$\mathrm{E}_{\text {LUMO+1 }}$ & -1.1839 & -1.1725 & -1.1840 & -1.1603 & -1.1483 \\
$\Delta \mathrm{E}_{\text {(HOMO-1 LUMO+1) }}$ & -7.0783 & -7.075 & -7.9672 & -7.0711 & -7.0668 \\
Electron affinity $(\mathrm{A})$ & 1.6057 & 1.6196 & 1.6057 & 1.6349 & 1.6504 \\
Global electrophilicity $(\Psi)$ & 3.4479 & 3.4655 & 3.4479 & 3.4851 & 3.5052 \\
Ionization potential $(\mathrm{IP})$ & 7.0959 & 7.0823 & 7.0959 & 7.0676 & 7.0526 \\
Electronegativity $(\chi)$ & 4.3508 & 4.351 & 4.3508 & 4.3513 & 4.3515 \\
Global chemical potential $(\mu)$ & -4.3508 & -4.351 & -4.3508 & -4.3513 & -4.3515 \\
Global hardness $(\eta)$ & 2.7451 & 2.73135 & 2.7451 & 2.71635 & 2.7011 \\
Global softness $(\mathrm{S})$ & 0.1821 & 0.183 & 0.182 & 0.184 & 0.185 \\
\hline
\end{tabular}

Table 9

\begin{tabular}{lrrrrr}
\hline Compound & Total Energy & VDW & H-Bond & Electronic & Molecular Weight \\
\hline TAN & -86.63 & -34.14 & -52.74 & 0.25 & 132.08 \\
Fluconazole & -94.60 & -78.89 & -15.70 & 0.00 & 306.27 \\
Voriconazole & -99.09 & -82.43 & -16.66 & 0.00 & 349.31 \\
Itraconazole & -109.97 & -96.19 & -13.78 & 0.00 & 705.64 \\
Posaconazole & -114.58 & -97.88 & -16.70 & 0.00 & 700.78 \\
\hline
\end{tabular}


Table 10

\begin{tabular}{|c|c|c|c|c|c|}
\hline \multirow{2}{*}{$\begin{array}{c}\text { Experimental } \\
\text { IR }\end{array}$} & \multicolumn{3}{|c|}{ B3LYP/6-311++G(d,p) Method } & \multirow[b]{2}{*}{$\mathrm{I}^{\mathrm{i}}$} & \multirow[b]{2}{*}{ Vibrational assignments (\% PED) } \\
\hline & Unscaled & ${ }^{\mathrm{a}}$ Scaled & ${ }^{\mathrm{b}}$ Scaled & & \\
\hline 3425 & 3650 & 3588 & 3425 & 108.61 & $v \mathrm{NH}(100)$ \\
\hline 3156 & 3273 & 3217 & 3068 & 10.75 & vCH (91) \\
\hline 3156 & 3266 & 3210 & 3061 & 0.72 & vCH (92) \\
\hline 2639 & 2823 & 2775 & 2642 & 2522.55 & vOH (97) \\
\hline 1584 & 1727 & 1698 & 1604 & 259.36 & $\nu \mathrm{ON}(54) \quad \beta \mathrm{NHO}(33)$ \\
\hline 1394 & 1563 & 1497 & 1449 & 15.61 & $v \mathrm{NC}(59) \quad \beta \mathrm{HNN}(12) \quad \beta \mathrm{HCN}(11)$ \\
\hline 1394 & 1504 & 1441 & 1393 & 451.62 & $\nu \mathrm{ON}(31) \quad \beta \mathrm{NHO}(54)$ \\
\hline \multirow[t]{2}{*}{1394} & 1481 & 1419 & 1372 & 4.00 & $\beta \mathrm{HNN}(39) \quad v N C(37)$ \\
\hline & 1399 & 1340 & 1294 & 18.23 & $v \mathrm{NC}(67) \quad \beta \mathrm{HCN}(14)$ \\
\hline 1205 & 1327 & 1271 & 1226 & 281.67 & vON $(80)$ \\
\hline 1205 & 1315 & 1260 & 1214 & 41.14 & $v \mathrm{NC}(56) \quad \beta \mathrm{HCN}(13)$ \\
\hline 1165 & 1279 & 1226 & 1180 & 4.86 & $\beta \mathrm{HNN}(13) \quad v \mathrm{NC}(34) \quad \beta \mathrm{HCN}(45)$ \\
\hline 1047 & 1174 & 1125 & 1081 & 51.82 & $v \mathrm{NC}(71) \quad \beta \mathrm{HCN}(12)$ \\
\hline 1047 & 1155 & 1107 & 1063 & 14.09 & $\beta \mathrm{HNN}(22) \beta \mathrm{HCN}(14) \quad v N C(41)$ \\
\hline 949 & 1073 & 1028 & 985 & 60.38 & $v \mathrm{NC}(27) \quad v \mathrm{NC}(24) \beta \mathrm{HCN}(35)$ \\
\hline 949 & 997 & 955 & 913 & 28.40 & $\beta C N C(80)$ \\
\hline 896 & 984 & 942 & 901 & 15.33 & $\beta \mathrm{CNN}(80)$ \\
\hline 896 & 974 & 933 & 892 & 83.06 & $\delta \mathrm{CNHO}(79) \quad \delta \mathrm{NOHN}(14)$ \\
\hline 896 & 956 & 916 & 875 & 160.83 & $v \mathrm{ON}(66) \beta \mathrm{ONO}(24)$ \\
\hline 831 & 893 & 855 & 815 & 16.88 & $\delta \mathrm{HCNN}(88)$ \\
\hline 831 & 877 & 841 & 800 & 18.49 & $\delta \mathrm{HCNC}(80) \quad \delta \mathrm{NCNN}(12)$ \\
\hline 719 & 787 & 754 & 715 & 18.88 & $\gamma \mathrm{OOON}(97)$ \\
\hline 634 & 693 & 664 & 626 & 50.30 & $\delta \mathrm{HCNN}(10) \quad \delta \mathrm{CNNC}(75) \quad \delta \mathrm{NCNN}(10)$ \\
\hline 634 & 693 & 664 & 626 & 4.61 & $v \mathrm{ON}(23) \quad \beta O N O(61)$ \\
\hline 634 & 678 & 649 & 612 & 1.16 & $\delta \mathrm{HCNC}(14) \delta \mathrm{NCNN}(71)$ \\
\hline 634 & 650 & 623 & 585 & 5.47 & $\beta O N O(79)$ \\
\hline & 586 & 561 & 524 & 67.81 & $\delta \mathrm{HNNC}(92)$ \\
\hline & 195 & 187 & 154 & 17.33 & $v \mathrm{NH}(67) \quad \beta \mathrm{HNC}(18)$ \\
\hline & 136 & 130 & 99 & 8.53 & $v \mathrm{NH}(13) \quad \beta \mathrm{HNC}(67) v \mathrm{OH}(10)$ \\
\hline & 99 & 95 & 64 & 0.02 & $\delta \mathrm{HNCN}(92)$ \\
\hline & 77 & 73 & 43 & 7.24 & vOH (85) \\
\hline & 52 & 50 & 19 & 1.76 & $\delta \mathrm{CHON}(86)$ \\
\hline & 43 & 41 & 11 & 1.98 & $\delta \mathrm{CNHO}(15) \quad \delta \mathrm{NOHN}(79)$ \\
\hline
\end{tabular}

$\mathrm{I}^{\mathrm{i}}$ : infrared intensity $\left(\mathrm{km} . \mathrm{mol}^{-1}\right) \cdot v, \beta, \delta$ and $\gamma$ denote stretching, in-plane bending, torsion and out-of-plane bending modes, respectively. PED: potential energy distribution data are taken fromVEDA4.

${ }^{\text {a}}$ Scaling factor: from 4000 to $1700 \mathrm{~cm}^{-1}$ are scaled with 0.983 and lower than $1700 \mathrm{~cm}^{-1}$ are scaled with 0.958 .

${ }^{\mathrm{b}}$ Frequencies scaled by SPESCA program [109]. 


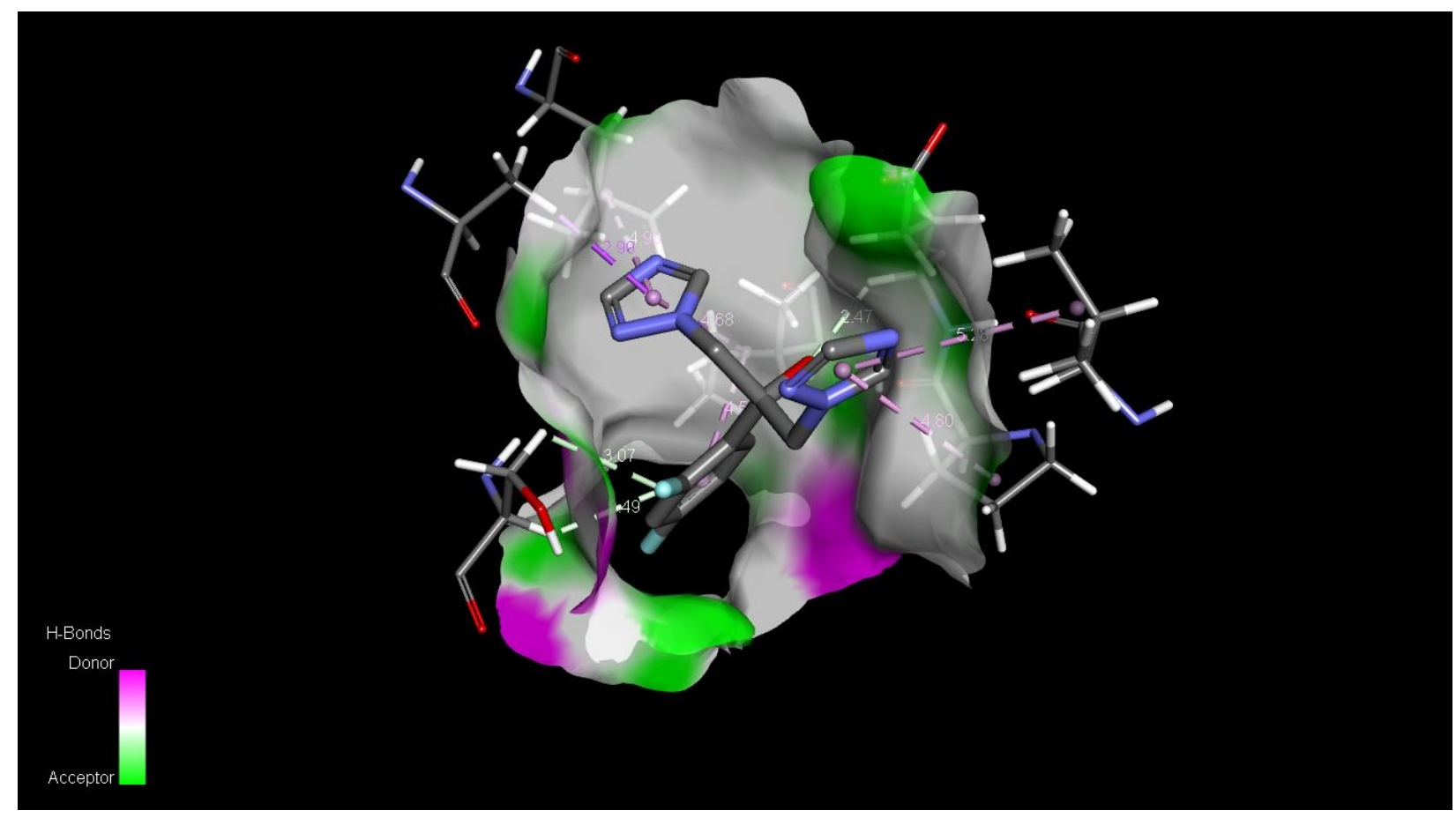

Fig. S 1

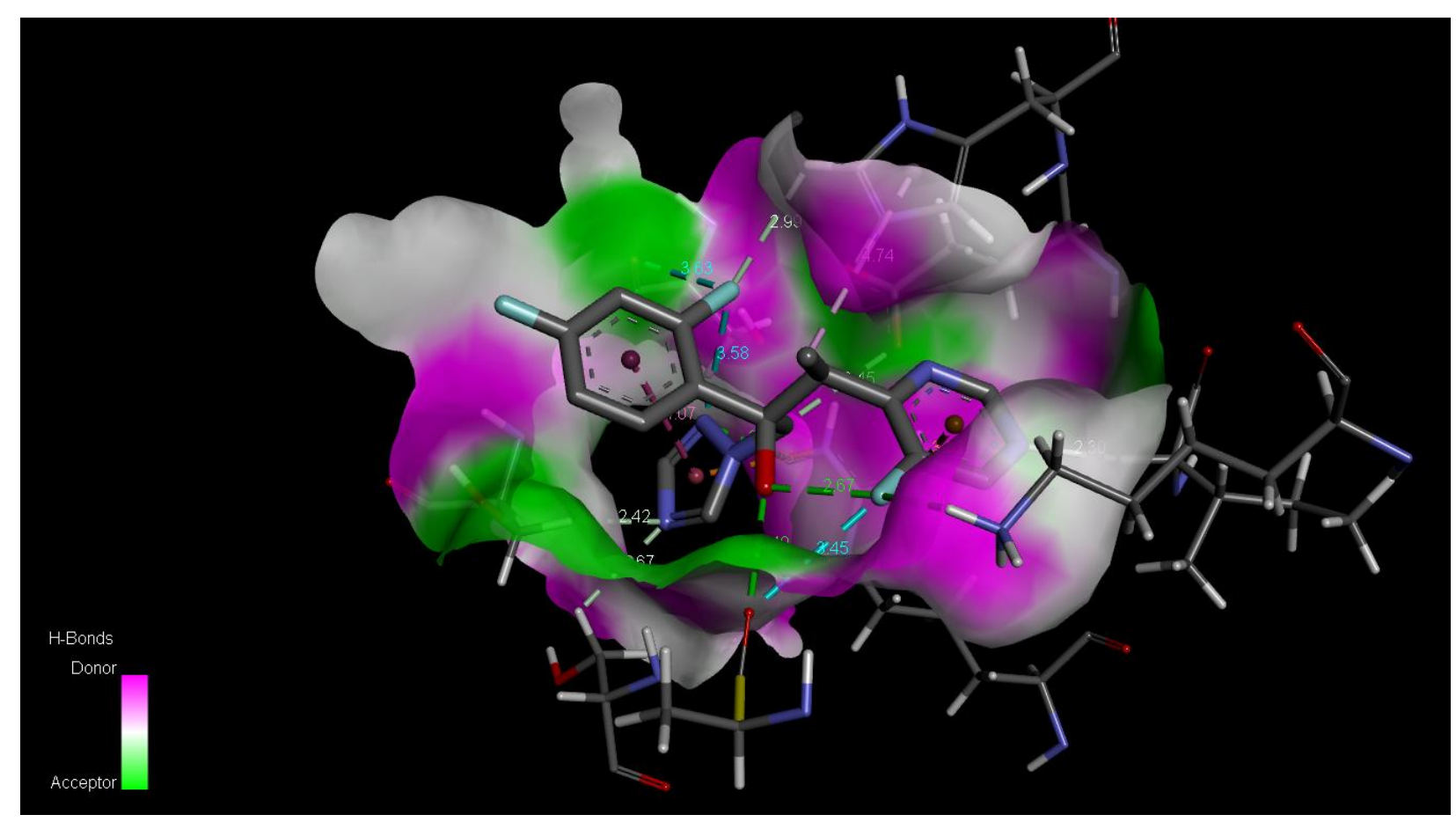

Fig. S 2 


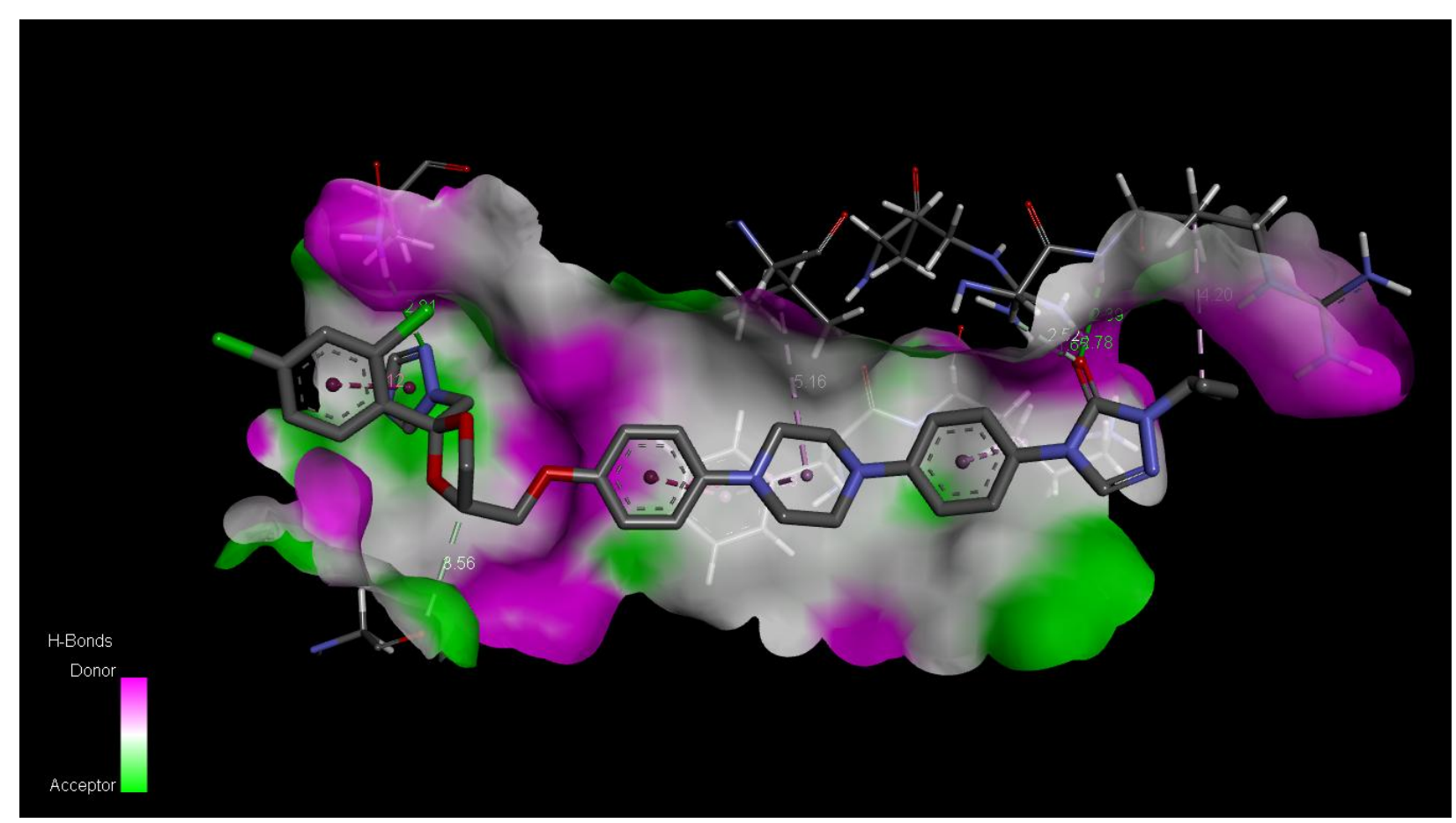

Fig. S 3

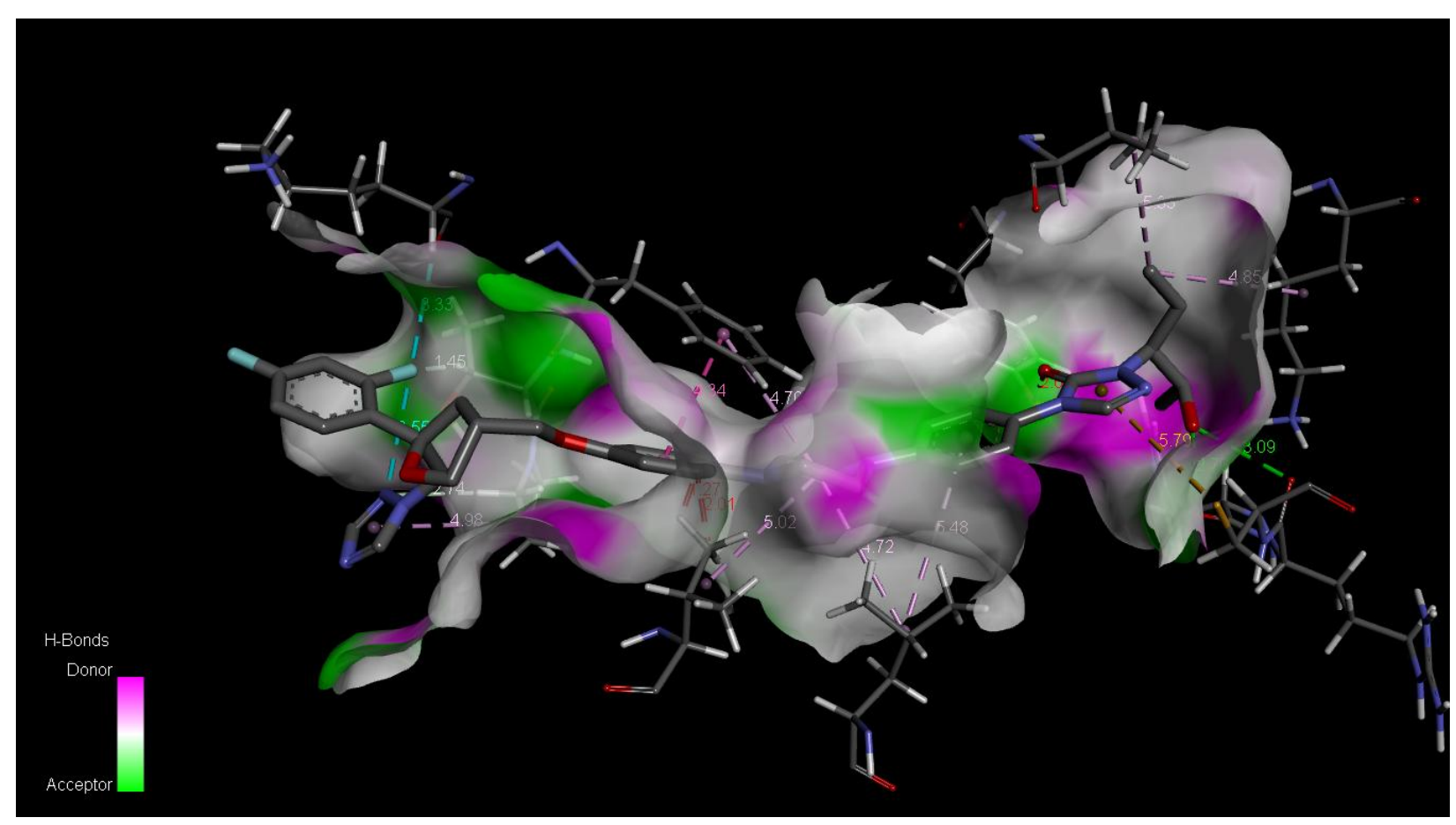

Fig. S 4 


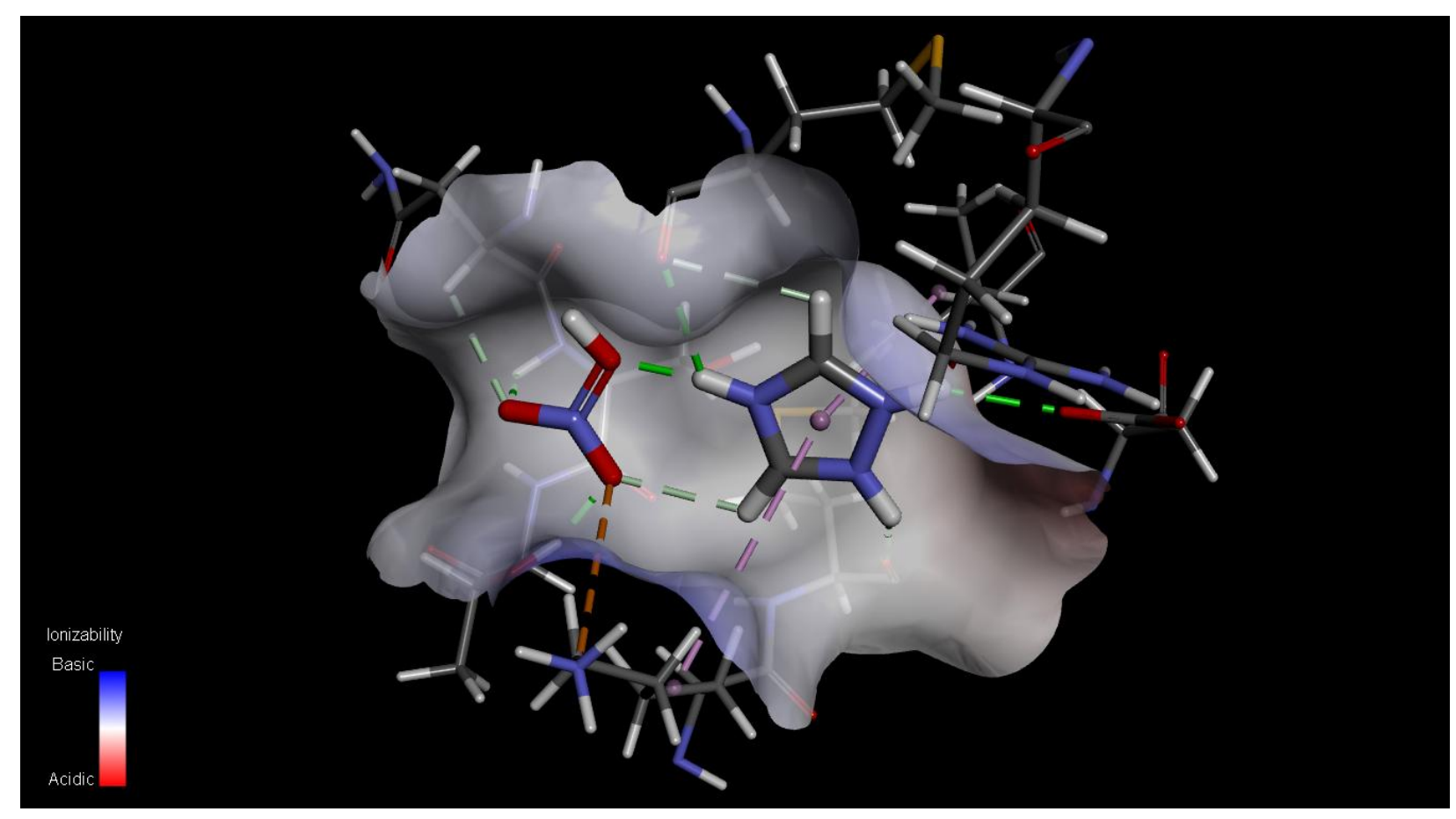

Fig. 5

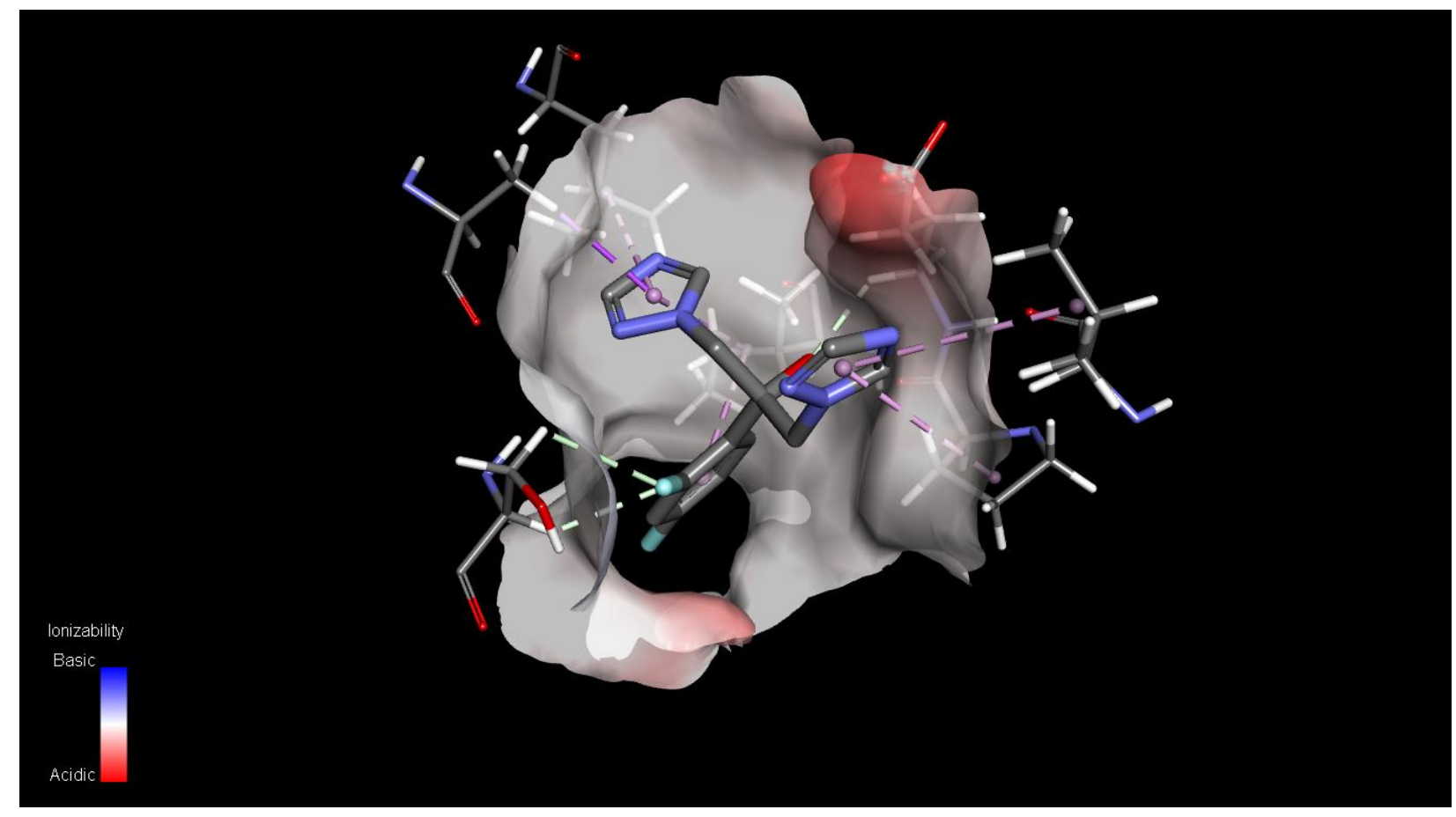

Fig. S 6 


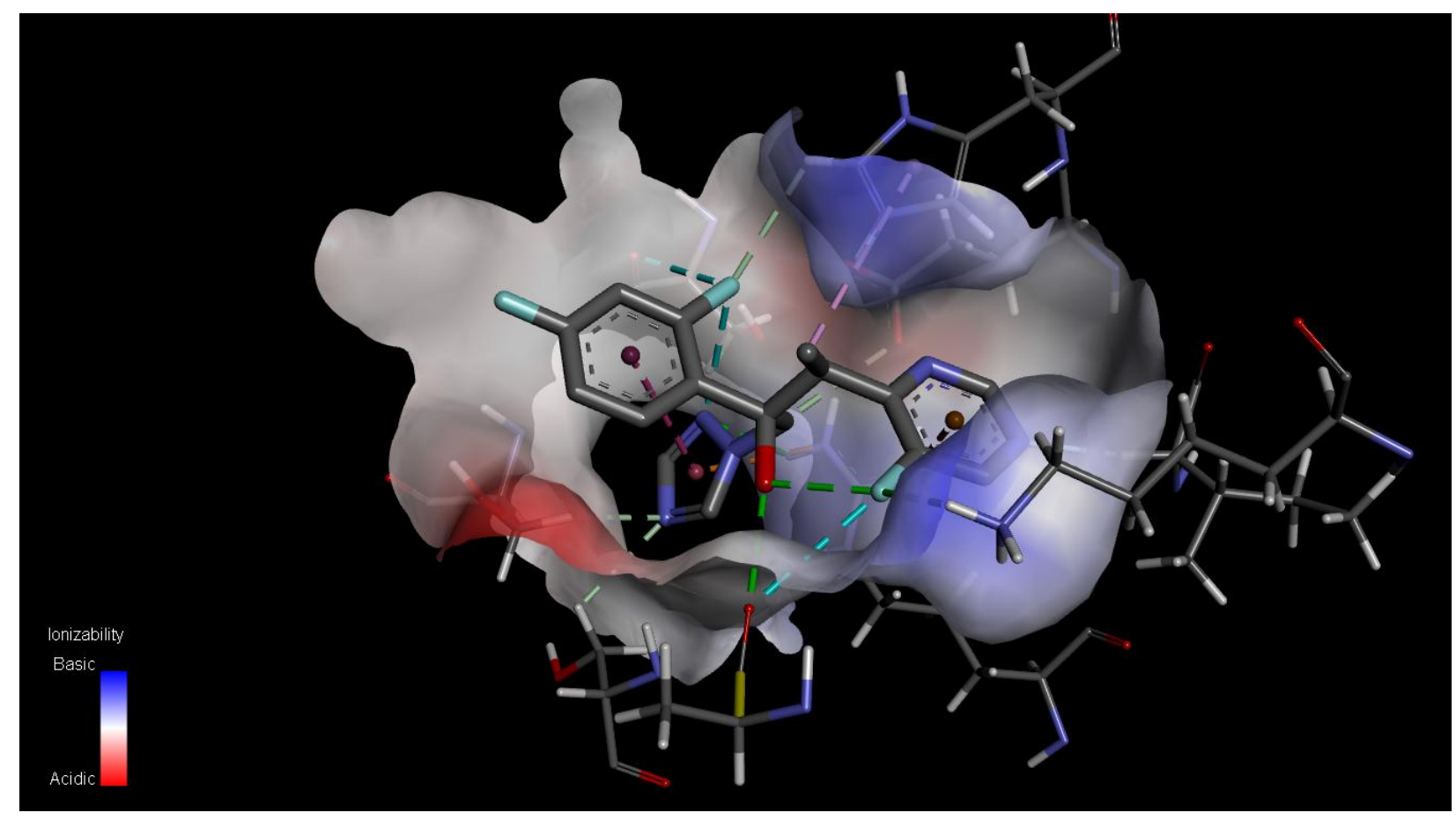

Fig. $\mathbf{S}$

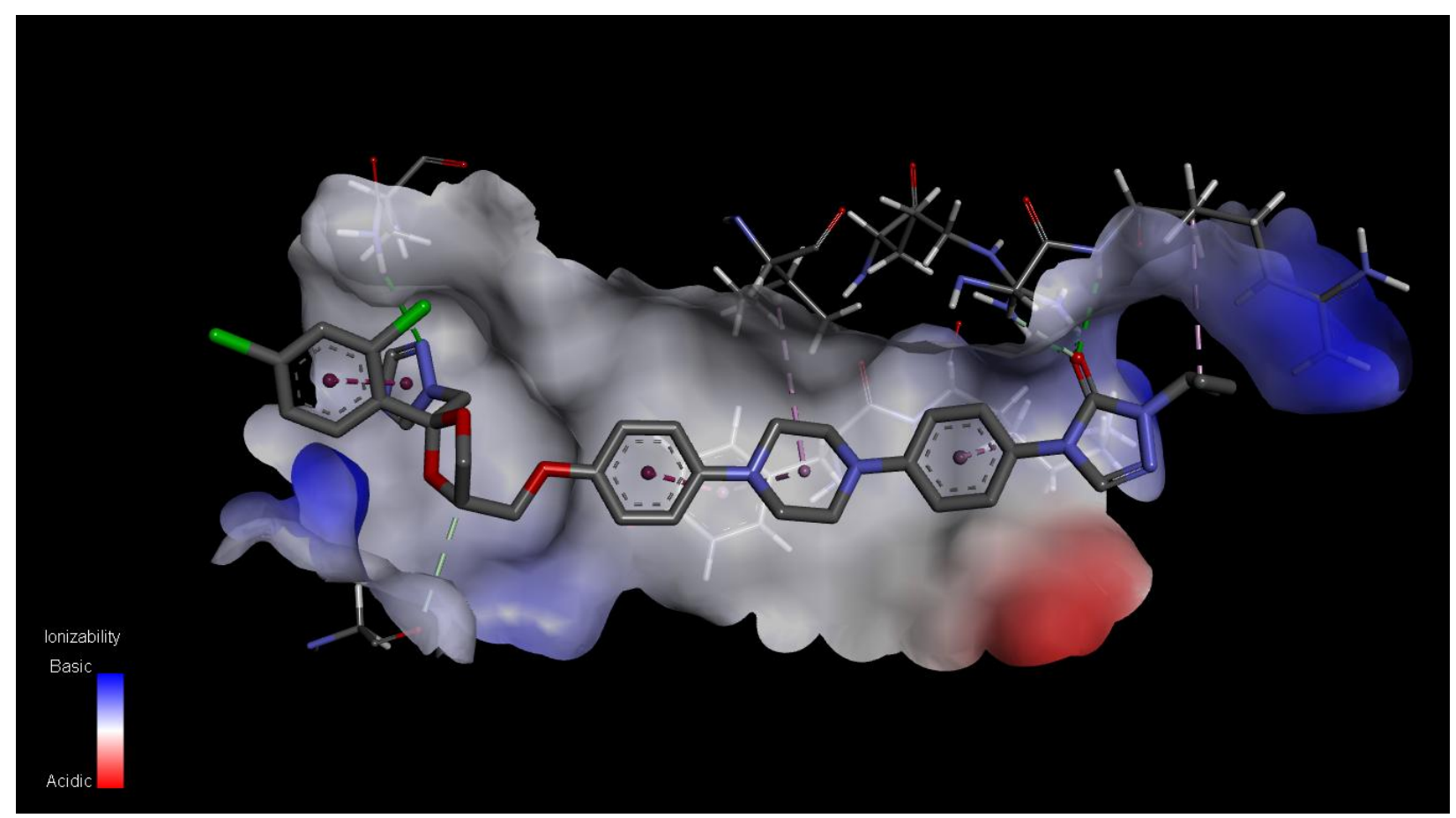

Fig. S 8 


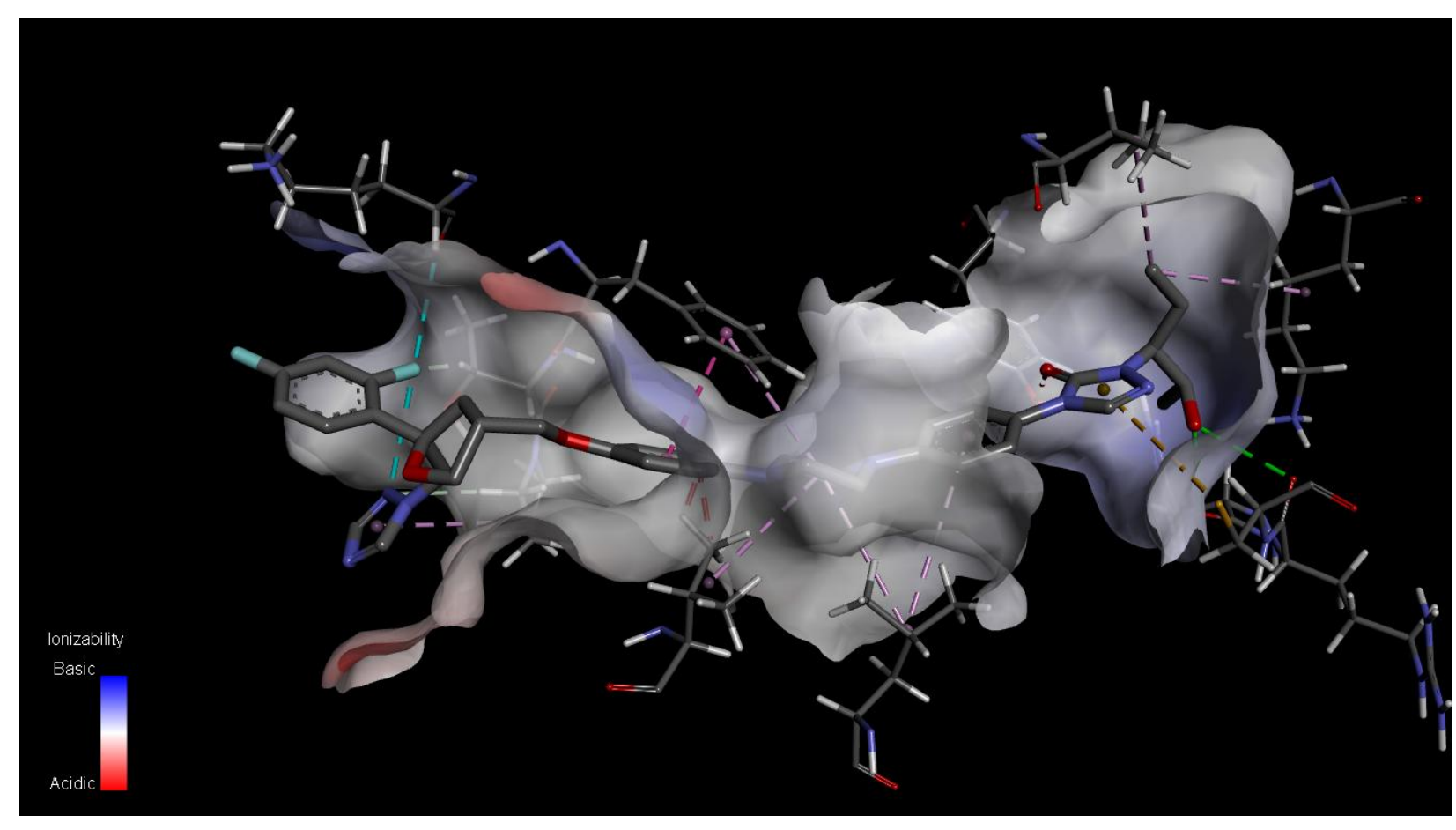

Fig. 59 
Click here to download Mol Files: checkCIF_PLATON (TAN).pdf 